\title{
GLOBAL AIDS RESDONSE
}

\section{2}

Country Progress Report January 2010 - December 2011

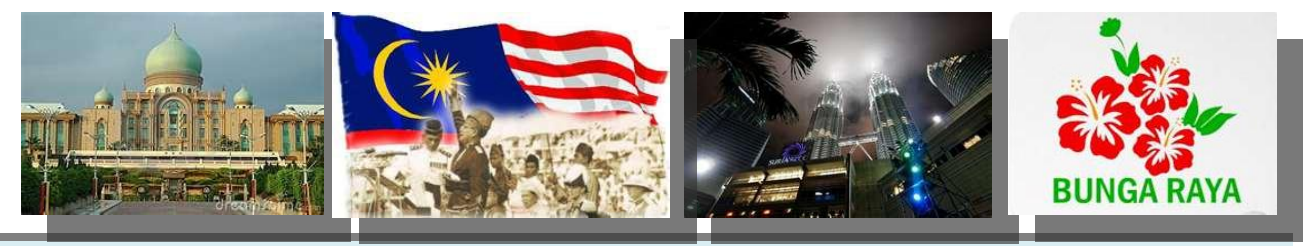

\section{MALAYSIA}

March 2012 


\section{MALAYSIA 2012 GLOBAL AIDS RESPONSE COUNTRY PROGRESS REPORT}

\section{Reporting Period: January 2010 to December 2011}

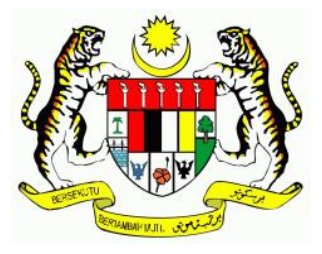

Report prepared by:

HIV/STI SECTION

Disease Control Division Ministry of Health Malaysia

Tel: +60388834387

Fax: +60 388834285

Correspondence: Dr. Sha'ari Ngadiman drshaari@moh.gov.my 
Acknowledgments

The editorial team is grateful to various government ministries and departments, MAC, civil societies, development partners and individuals who took part in developing this report. Among those involved were: Dr. Shahnizan Md. Zain (Medical Division); Amidon Awang Damit (Health Education); Dr. Rosli Ismail (District Health Officer), Dr. Sapiah Bahrin, Dr. Fatanah Ismail \& Dr. Nik Rubiah (Family Health Development Division); Dr. Norsiah Ali (Family Medicine Specialist); Dr. Suzana Hashim (TB Control); Dr. Rohaya A. Rahman, Dr. Hazura Mat Zubir, Dr. Khamisah Awang Lukman, Dr. Sarina Sidek, Dr. Mahani Nordin, Dr. Janizah Ghani, Dr. Masitah Mohamed (State AIDS Officers); Parimelazhagan, Tamayanty and many others from MAC and their partner organizations; WHO \& UN Agencies; Ambalagan Subramaniam (Prisons Department); Melati Ahmad \& Wan Norhizan (National Anti-Drug Agency; Marzita Ibrahim (Depart. of Islamic Dev.); Sam Phan (Royal Police of Malaysia); Min. Women, Fam. \& Community Development. Invaluable guidance and assistance was also provided by Dr. Maznah Dahlui from University Malaya in preparing the AIDS Spending Matrix.

\section{The Global AIDS Response Progress Report 2012}

This report was coordinated and produced by HIV/STI Section of Ministry of Health Malaysia.

\section{Editorial Team}

Lead author / writer:

Dr. Anita Suleiman

Senior Principal Assistance Director (Technical \& Behavioral Research) HIV/STI Section, Ministry of Health Malaysia

\section{Additional reporting and writing:}

Dr. Asiah Ayob

Senior Principal Assistance Director (M\&E)

HIV/STI Section, Min. of Health Malaysia

Dr. Corrine Capuano

Chair UNTG on HIV/AIDS

Mr. Low Soon Heng

Environmental Health Officer (M\&E)

HIV/STI Section, Min. of Health

Malaysia

Mr. Parimelazhagan Ellan

Programme Director, Malaysian AIDS Council

\section{Dr. Zakira Taib}

Senior Principal Assistance Director (Prevention) HIV/STI Section, Min. of Health Malaysia

\section{Editor:}

Dr. Sha'ari Ngadiman

\section{Dr. Fazidah Yuswan}

Senior Principal Assistance Director (Harm Reduction)

HIV/STI Section, Min. of Health Malaysia

Dr. Hairul Izwan A. Rahman Perak State AIDS Officer

Dr. Zahariyah Yaccob

Kedah State AIDS Officer

Ms. Marzita Ibrahim

Department of Islamic Development

Normaizira Hamdi

Research Officer

HIV/STI Section, Min. of Health

Malaysia 


\section{CONTENTS:}

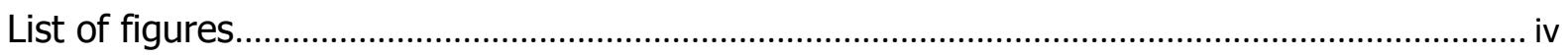

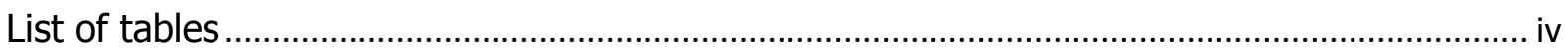

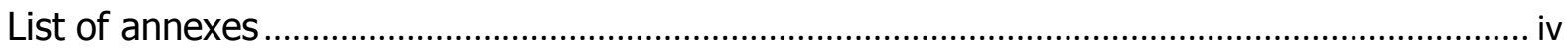

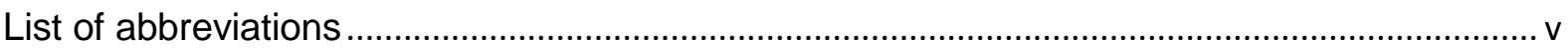

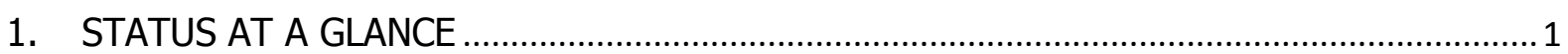

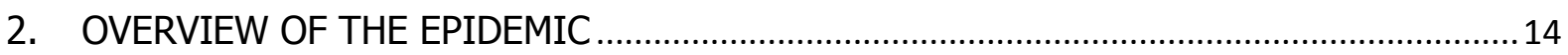

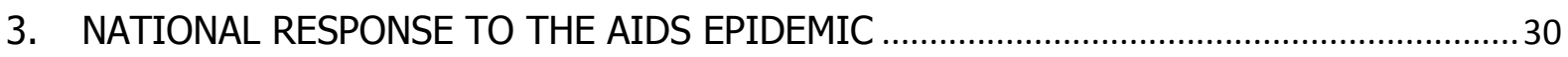

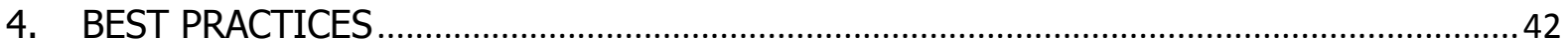

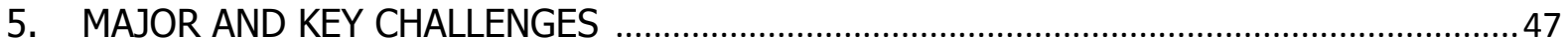

6. SUPPORT FROM THE COUNTRY'S DEVELOPMENT PARTNERS ….......................................49

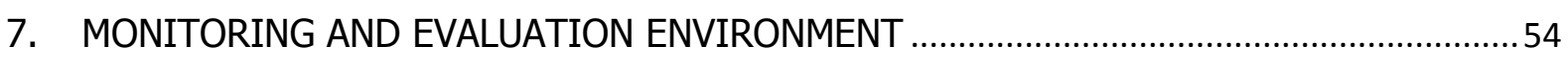




\section{List of figures}

Figure 1 Reported HIV and AIDS-related deaths, Malaysia 1986 - 2011

Figure 2 Reported HIV cases attributed to IDU and sexual transmission, Malaysia 1986-2011

Figure 3 Distribution of reported new HIV cases by age group, $1990-2011$

Figure 4 Gender-specific HIV Prevalence, Malaysia 1986- 2011

Figure 5 The changing trend of HIV transmission mode in the states of Malaysia, 2000 and 2011

Figure 6 HIV Screening in Malaysia, $2000-2011$

Figure 7 HIV prevalence among relatively low risk population based on screening programmes, Malaysia 2000-2011

Figure 8 HIV Prevalence (\%) among key at-risk populations (EPP estimates 2011)

Figure 9 New TB, HIV and TB-HIV Co-infection, Malaysia 1999-2011

Figure 10 Antenatal HIV screening, Malaysia $1998-2011$

\section{List of tables}

Table 1 Overview of the HIV epidemic in Malaysia 2011

Table 2 Overview of Global AIDS Response indicators

Table 3 Findings from IBBS and VDTS 2009

Table 4 Percentage of new HIV cases by risk factor

Table $5 \quad$ Estimates of Malaysian HIV epidemic (EPP 2011)

Table $6 \quad$ Source of approximate AIDS expenditure 2010-2011

Table 7 AIDS Spending Category - Approximate total expenditure from Domestic (Public and Private) and International Sources

\section{List of annexes}

Annex 1 Consultation/preparation process for the Country Progress Report on monitoring the follow-up to the Declaration of Commitment on HIV/AIDS

Annex 2 National Commitments and Policy Instrument (NCPI) 2012

Annex 3 National Funding Matrix 2010 - 2011

Annex 4 Distribution of HIV/AIDS/Death by year, Malaysia 1986 - 2011 


\section{List of abbreviations}

$\begin{array}{ll}\text { AIDS } & \text { Acquired Immune Deficiency Syndrome } \\ \text { ART } & \text { Anti-Retroviral Therapy } \\ \text { BSS } & \text { Behavioural Surveillance Survey } \\ \text { CBO } & \text { Community-based Organization } \\ \text { DIC } & \text { Drop-In Centre } \\ \text { DRC } & \text { Drug Rehabilitation Centre } \\ \text { FRHAM } & \text { Federation of Reproductive Health Associations of Malaysia } \\ \text { HAART } & \text { Highly Active Anti-Retroviral Therapy } \\ \text { HIV } & \text { Human Immunodeficiency Virus } \\ \text { IDU } & \text { Injecting Drug Use/User } \\ \text { IBBS } & \text { Integrated Bio-Behavioural Surveillance } \\ \text { ILO } & \text { International Labour Organization } \\ \text { MAC } & \text { Malaysian AIDS Council } \\ \text { MDGs } & \text { Millennium Development Goals } \\ \text { MMT } & \text { Methadone Maintenance Therapy } \\ \text { MOH } & \text { Ministry of Health } \\ \text { MTCT } & \text { Mother-to-child transmission } \\ \text { MWFCD } & \text { Ministry of Women, Family and Community Development } \\ \text { NADA } & \text { National Anti-Drug Agency } \\ \text { NCPI } & \text { National Composite Policy Index } \\ \text { NGO } & \text { Non-Government Organization } \\ \text { NPFDB } & \text { National Population and Family Development Board } \\ \text { NSEP } & \text { Needle and Syringe Exchange Programme } \\ \text { NSP } & \text { National Strategic Plan on HIV/AIDS } \\ \text { PLHIV } & \text { People Living With HIV } \\ \text { PMTCT } & \text { Prevention of Mother-to-Child Transmission } \\ \text { SRH } & \text { Sexual Reproductive Health } \\ \text { STD } & \text { Sexually Transmitted Disease } \\ \text { STI } & \text { Sexually Transmitted Infection } \\ \text { SW } & \text { Sex Worker } \\ \text { TB } & \text { Tuberculosis } \\ \text { TG } & \text { Transgender } \\ \text { UNAIDS } & \text { Joint United Nations Programme on HIV/AIDS } \\ \text { UNDP } & \text { United Nations Development Programme } \\ \text { UNICEF } & \text { United Nations Children's Fund } \\ \text { UNFPA } & \text { United Nations Population Fund } \\ \text { UNGASS } & \text { United Nations General Assembly Special Session } \\ \text { UNHCR } & \text { United Nations High Commissioner for Refugees } \\ \text { UNODC } & \text { United Nations Office on Drugs and Crime } \\ \text { UNTG } & \text { United Nations Theme Group on HIV } \\ \text { VDTS } & \text { Venue-Day-Time- Sampling } \\ \text { WHO } & \text { World Health Organization } \\ & \end{array}$




\section{STATUS AT A GLANCE}

\subsection{Stakeholder consultation and participation in report preparation}

The preparation of country report had begun as early as December 2011 . Under the leadership of Ministry of Health Malaysia, series of consultations were convened involving various stakeholders to capture as much of opinions and responses to HIV. Apart from Ministry of Health officials especially from HIV/STI Section, others involved were government ministries and departments, non-government organizations (NGO), civil society, bilateral and international agencies, clinicians and academia. Below is the exhaustive list of members involved in the preparation of this report.

a) Ministry of Health Malaysia: HIV/STI Section, TB Section, Family Health Development Division, Finance Division, Medical Development Division, State AIDS Officers and District Health Officers, Infectious Disease Consultant, Consultant Pediatrician (Infectious Disease), Family Medicine Specialist, Health Education Division, Pharmaceutical Division etc.

b) Ministry of Women, Family and Community Development (MWFCD)

c) National Anti-Drug Agency (NADA)

d) Ministry of Education (MOE)

e) Prison Department of Malaysia

f) Department of Islamic Development (JAKIM)

g) Royal Police of Malaysia (RPM)

h) Civil societies and NGO: Malaysian AIDS Council (MAC) and partner organizations, HIV community, Most-at-risk populations, Community Based Organizations

i) International and bilateral agencies : WHO, UNICEF, UNFPA

j) Universities: University Malaya, National Defense University

k) Country Coordinating Mechanism

The first in-country consultative meeting was convened in 15 February 2012 where orientation of report was briefed and indicators were agreed upon. During the meeting, stakeholders were also informed about newly added indicators for 2012 reporting. Good practices were identified and agreed to be included and highlighted in the report. The challenges and remedial actions were also determined in the same manner. 
Information collected and collated was a combination of national surveillance data, M\&E data, program reviews, analysis of current research data, reanalysis of previous research data, and interviews with key persons from government departments and NGO. A great deal of critical data was made possible and has been greatly facilitated by the newly formed M\&E unit within the Ministry of Health. Also, there has been an improvement in the reporting of AIDS Spending indicator with the use of National AIDS Spending Assessment (NASA). A briefing on NASA involving various stakeholders was convened on 7 March 2012. The National Commitment and Policy Instrument (NCPI) was completed using a consultative process consisting of workshop for each part A and $\mathrm{B}$. The workshop was convened on 29 February 2012 for part A and $1^{\text {st }}$ March 2012 for part B. Stakeholders consulted for part A were representatives of HIV/STI program at National, State and District level, representative of Multilateral Unit from Policy and International Relation Division, Ministry of Health. Stakeholders consulted for part B included representatives from community representing PLHIV, IDU, sex workers, transgender, MSM, young people, migrant worker and prisoners with MAC taking the lead.

The second consultative meeting involved Government stakeholders from the different ministries and agencies. These included representatives from the $\mathrm{MOH}, \mathrm{MWFCD}$, NADA, JAKIM and RPM. Part A of the NCPI and the narrative content were discussed with participants where final consensus was achieved. The Global AIDS Response Country Progress Report was fully coordinated and prepared by the HIV/STI Section of the Disease Control Division, Ministry of Health.

\subsection{Status of the epidemic}

Since the first case of HIV made its debut in this country 25 years ago till December 2011, number of people living with HIV (PLHIV) is estimated at $81,000^{1}$. By the end of 2011, Malaysia had a cumulative figure of 94,841 HIV, 17,686 AIDS and 14,986 deaths, thus giving reported PLHIV of $79,855^{2}$ (table 1 ). The epidemic in this country is still concentrated within most-at-risk populations (MARPS) especially among IDU, sex workers and transgender population. The annual number of reported new HIV cases by the Ministry of Health has been on a steady decline from a peak of 6,978 in 2002. In 2011, there were 3,479 new cases reported to the Ministry of Health, approximately halve of what was reported in 2002 with an average of 9 new cases each day. The notification rate of HIV also continues to experience a decrease from 28.4 in 2002 to 23.4 in 2005 and to 12.2 cases per 100,000 populations in 2011.

HIV in Malaysia is predominantly male as they constitute $90 \%$ of cumulative HIV cases of whom majority are IDU. However, the trend of female to male ratio is shifting from 
$1: 99$ in 1990 to $1: 10$ in 2000 and to $1: 4$ in 2011. In the earlier phase of the pandemic, IDU was the key driven factor. This trend has eventually changed over time from only 1 sexual transmission for every 9 IDU in 1990 to 2 sexual transmission for every 8 IDU in 2000 and 5 sexual transmission for every 5 IDU in 2010. With rigorous implementation of harm reduction programmes since 2005, we are able to reduce the number of HIV infection through sharing needles. Thus, in 2011 sexual transmission has superseded IDU as the main driven factor for the epidemic with ratio of 6 sexual transmissions for every 4 IDU reported.

About $26 \%$ of reported infections are amongst young people aged between 13 to 29 years old. Children aged below 13 years consistently contributed approximately $1 \%$ of cumulative total of HIV infections from 1986 to December 2011.

Table 1. Overview of the HIV epidemic in Malaysia 2011

\begin{tabular}{|ll|}
\hline Indicator & $\begin{array}{l}\text { Number/ } \\
\text { percentage }\end{array}$ \\
\hline Cumulative no. of reported HIV infections since first detection in 1986 & 94,841 \\
\hline Cumulative no. of reported AIDS since 1986 & 17,686 \\
\hline Cumulative no. of reported deaths related to HIV/AIDS since 1986 & 14,986 \\
\hline Estimated no. PLHIV [EPP 2011] & 81,000 \\
\hline Total number of PLHIV [surveillance data] & 79,855 \\
\hline New HIV infections detected in 2011 & 3,479 \\
\hline Notification rate of HIV (per 100,000) in 2011 & 12.18 \\
\hline Women reported with HIV in 2011 & 735 \\
\hline Cumulative no. of women reported with HIV as of December 2011 & 9,494 \\
\hline Children aged below 13 with HIV in 2011 & 65 \\
\hline Cumulative no. of children under 13 with HIV as of December 2011 & 974 \\
\hline Estimated no. PLHIV eligible for treatment [EPP 2011] & 37,306 \\
\hline No. PLHIV receiving ART (surveillance data) as of December 2011 & 14,002 \\
\hline Estimated adult (15 - 49 years) with HIV \& prevalence [EPP 2011] & 64,562 [0.41\%] \\
\hline
\end{tabular}




\subsection{Policy and programmatic response}

The national response to HIV started as far back in 1985 with inclusion of HIV, AIDS and death related to HIV/AIDS into the list of notifiable diseases under the Prevention and Control of Infectious Diseases Act ${ }^{3}$. To streamline National response, AIDS/STD Sector was then created within the Public Health Division in Ministry of Health Malaysia in 1993. In 1992, Malaysia AIDS Council (MAC) was formed under the auspices of the Ministry of Health, mainly to compliment the national responses to HIV.

During the earlier days, the design and development of the HIV/AIDS National Prevention and Control Program was sole responsibility of the Ministry of Health. Over period of time, this response has matured to include wider group of stakeholders including non-health sectors within government agencies, NGO, civil society, private agencies, bilateral and international agencies.

However, there are still opportunities to strengthen and sustain the commitment of all stakeholders especially in enhancing to achieve greater harmonisation, coordination and alignment; maintain and sustain optimum levels of funding; achieve greater programme coverage, effectiveness, and efficiency; and to continue the provision of affordable treatment to those who need it.

\section{(a)Strengthening the national commitment and supporting the NSP.}

Raising awareness and knowledge on HIV/AIDS has been a focus of the $\mathrm{MOH}$ since the formulation of Plan of Action in 1988. In collaboration with the Department of Religious Affairs, MAC, and UNDP, the MOH has been seeking the involvement of religious leaders, and their participation in joint efforts to educate and to initiate or support community programmes related to HIV/AIDS. Other targeted interventions are carried out by relevant NGOs and international organizations.

The first National Strategic Plan (NSP) on HIV/AIDS was developed in 2000. Under this strategic framework, the Cabinet Committee on HIV/AIDS (CCA) was established and chaired by Deputy Prime Minister. In December 2008 the Malaysian AIDS Council (MAC) was roped in as member to allow for the voice of civil society and the different communities represented by MAC to be effectively heard by members of the Cabinet. In 2009, the entire policy and decision making structure was revised and the CCA was restructured and known as the National Coordinating Committee on AIDS Intervention (NCCAI) chaired by the Minister of Health. Civil society is also represented on this

${ }^{3}$ Laws of Malaysia.Act 342. Prevention and Control of Infectious Diseases Act. 
committee. With latest revision, NSP 2011-2015 continues to provide a common ground and emphasis on an integrated and comprehensive approach addressing the needs of prevention, treatment, care and support. Another highest coordinating body where civil society is represented is the Country Coordinating Mechanism (CCM), chaired by the Deputy Minister of Health. It provides governance for all programmes and activities related to the Global Fund for AIDS, Tuberculosis and Malaria (GFATM) in Malaysia.

The responsibility for the overall coordination, monitoring, evaluation and reporting of Malaysia's HIV and AIDS responses is currently tasked to the HIV/STI Sector of the Disease Control Division, Ministry of Health. Currently, the HIV/STI Sector function as the National AIDS Programme (NAP) Secretariat supported by the AIDS Officers at every state. Similar mechanism is being implemented at every state and districts. The Secretariat interacts and engages the other institutions within the Federal Government (and the civil society) through HIV Focal Points who are present in each of the relevant Ministries.

\section{(b)Multi-sectoral engagement in the HIV response}

Another area of much improvement has been the multi-sectoral dimension of the response. Given the mandate by the Government under the NSP, much of the leadership in responding to the epidemic continues to be shouldered by the Ministry of Health. However, the level of multi-sectoral engagement has risen tremendously over the past five years. Non-health sectors i.e. the Ministry of Women, Family and Community Development (MWFCD), National Anti-Drug Agency (Home Affairs Ministry) Department of Orang Asli (Indigenous People) Affairs, the Department of Islamic Development (JAKIM), the Prison's Department, and the Information Ministry now form part of the key stakeholders in the country involved in the national HIV prevention and control programmes.

With the increase in proportion of female HIV cases in Malaysia over the past five years, MWFCD continues to play important role through its Taskforce on Women, Girls and HIV/AIDS. This taskforce is currently chaired by the Ministry of Women, Family and Community Development (MWFCD), mandated to guide the actions of the Government in its response to addressing the behavioural and socioeconomic factors behind sexual transmission of HIV. Previous two years has observed more than ten (10) awareness programmes being carried out nationwide by this Taskforce with objective to empower women and girls. 
Apart from awareness programmes, MWFCD has been instrumental in improving the overall response especially on matters pertaining to care and support services for PLHIV and those affected. An area which has seen significant change has been in the area of care and support services specifically the availability of shelters and drop-in centers. Community based organizations ( $\mathrm{CBO}$ ) are currently working in partnership with the MWFCD to provide essential support services for PLHIV.

\section{(c) ARV treatment, resource mobilization and funding support}

Malaysia is already and will continue providing affordable access to clinical care through the public health system.Two significant achievements have been accomplished, first, the availability and provision of first line ARV treatment at no cost for those who need it and second, the availability of ARV treatment for incarcerated populations specifically for prisoners with HIV as well as inmates in drug rehabilitation centers. Currently, the second line regime is also heavily funded by the government.

During the previous NSP (2006 - 2010), the Government has provided an allocation of RM 500 million (USD 143 million); approximately $90 \%$ of total funding for HIV and AIDS. The same support will continue for the NSP 2011-2015. A significantly large proportion of funds are already allocated for provision of ARV treatment for almost 15,000 people living with HIV. Under the Memorandum of Understanding signed between the government and MAC in 2003, a handsome allocation of government fund amounting to total RM 40 million (USD 13.2 million) was agreed in support of HIV responses by the NGO through MAC for a period of 10 years ending 2012. However, the total amount reimbursed was USD 21.4 million, $62 \%$ more than originally agreed on with introduction of harm reduction programme namely NSEP (since 2006). In addition to that, the government has funded an additional RM 2 million for HIV-related shelter homes since 2009 through MWFCD.

In 2010, the revision of ARV treatment initiation threshold from CD4 level of 200 cells $/ \mathrm{mm}^{3}$ to 350 cells $/ \mathrm{mm}^{3}$ by WHO has been adopted. This has significantly increased the number of PLHIV estimated to be in need of treatment and could further widen the gap between those who are on treatment and those who are not. Such revision will impose greater financial burden on public funds particularly in addition to ensuring that more people are able to access and adhere to treatment.

\section{(d)Managing drug users through harm reduction and new initiatives}

The harm reduction programme, comprising the Needle Syringe Exchange Programme (NSEP) and the Opiate Substitution Therapy (OST), remains the cornerstone of the 
Malaysian Government's HIV prevention strategy. This programme is currently being implemented in partnership with NGOs, CBOs and private health practitioners. Significant successes which have been attributed to increased sites and clients over the last few years have made this one of the programmes which has managed to get worldwide attention. A number of innovative strategies have been introduced lately i.e. the introduction of the MMT at NADA service centers and incarcerated settings specifically prisons. More than 80,000 injecting drug users have been beneficiaries of this programme so far ${ }^{4}$. NADA has introduced a new way of managing drug user from compulsory rehabilitation centers to voluntary open access services namely Cure and Care Clinic, Cure and Care Service Centre and Caring Community House. The prison department too has started MMT; beginning with only 1 prison in 2008 and has expanded to 18 by 2011 .

\section{(e) PMTCT programme}

The prevention of mother-to-child transmission (PMTCT) or prevention of vertical transmission programme in Malaysia was incepted nationwide in 1998. Focusing on ARV prophylaxis for the child, safer delivery and infant feeding practices, this programme relied heavily on detection of HIV infection during pregnancy. Available at all government health clinics and hospitals, PMTCT programme incorporates HIV screening utilizing an opt-out approach. Although it covers only women receiving antenatal care at these government facilities, it is estimated that over $90 \%$ of total antenatal mothers in 2011 nationwide utilize public antenatal facilities. Antenatal HIV cases from the private sector are also referred to the government medical system.

\section{(f) Mobilization and involvement of MARPs and civil society}

Involvement of key civil society stakeholders in national level policy and programme development continues to be dependent on issues of capacity and relevance. Civil society is being represented at the NCCAI and the CCM. In the former, civil society is represented by MAC while in the later several representatives (e.g. sex workers, PLHIV and transgender) have been elected onto the CCM by their respective communities. MAC which function as an umbrella organization to support and coordinate the efforts of partner organizations (PO) working on HIV and AIDS issues, facilitates the collaboration with civil society organisations (CSO) in the implementation of the National Strategy on HIV and AIDS. 


\section{(g)Engagement with religious leaders}

The involvement of religious leaders, especially Muslim religious leaders has increased significantly over the past few years. Numerous advocacy and investment in programming was done to mobilize and harness the support of Islamic religious leaders in HIV prevention and the provision of care and support. The past 3 years in particular have seen the remarkable development of programmes by the Department of Islamic Development (JAKIM) which involve a number of religious bodies engaging MARPs such as female sex workers and transgender through the availability of religious classes. Building on the successes of the "Islam and HIV/AIDS" project which was first initiated between 2001 to mid-2005, Muslim religious leaders have since involved in not only the implementation of HIV awareness programmes but also proactively established care and support facilities from financial and welfare assistance to shelters for Muslim PLHIV. The successes of "Islam and HIV/AIDS" programme has also gained recognition in other Muslim countries worldwide; as such the manual is being made available in English language for use in other countries especially in the Middle East.

\section{(h)Increased availability and improvement of quality strategic information}

Much progress has been made in understanding the Malaysian HIV epidemic and MARPs, particularly vulnerability to HIV and STI infection and the need for specific essential services. Two significant achievements have been accomplished within the last two years towards enhancing the quality and strategic information for the country. First, the formation of M\&E unit that manages programmes indicators as well as estimations and projections of HIV epidemic, second, the formation of HIV Technical and Behavioural Research unit that manages the Integrated Biological and Behavioural Surveillance Study (IBBS) and other HIV technical research in the HIV/STI Section of Ministry of Health. In addition, availability of surveys and research studies related to HIV by the universities, CSO and NGO such as Centre for Excellence on Research in AIDS (CERIA) and FRHAM has greatly complimented in providing quality and strategic information. Detailed disaggregated data has also become available as a result of a revision of the national HIV reporting system and the National AIDS Registry (NAR) by the Ministry of Health. The Internet-based NAR is designed to function as a more streamlined and effective national HIV programme monitoring mechanism.

\section{(i) Challenges}

Both government agencies and CSO are currently experiencing tremendous pressure to show the results of the 5 year strategic plan on HIV and AIDS. As a result, expectations have become significantly higher. However, resource priorities of public funding continue to limit the coverage of HIV and AIDS related services, particularly those dealing with sexual transmission of HIV and their accessibility and affordability to the 
vulnerable populations. Concern has been expressed as to whether many of the achievements made in the past few years are in fact financially sustainable due to the sole reliance on public funding. The vast majority of prevention programmes involving MARPs such as IDUs, men who have sex with men (MSM) and sex workers are conducted by CBOs and NGOs. Reaching out to these populations remains a significant challenge for both the Government and NGO programmes. As a result of inconsistent levels of funding, NGOs are often forced to prioritize and restrict coverage of existing programmes. As a result, interventions are often forced to confine themselves to certain geographical locations.

Issues of stigma, discrimination, denial and ignorance continue to have an impact on every programme of the NSP. The fear of being discriminated and self-stigma has hindered the PLHIV from accessing treatment and care. However, we believe that these issues are being handled in appropriate manner.

Additional challenges which continue to confront the national response include sustaining and scaling-up coverage of existing services, strengthening leadership and political will, maintaining current levels of financial commitment, developing efficient and transparent systems for allocation of financial resources and establishment of a national monitoring and evaluation framework.

\subsection{Overview of UNGASS indicators}

The following table narrates the overview of Malaysia's reporting on Global AIDS response progress indicators and summarizing the progress made over the past two years through comparison with the data reported in the 2009-2010 documents.

Table 2. Overview of Global AIDS Response indicators

\begin{tabular}{|c|c|c|c|c|}
\hline \multicolumn{2}{|c|}{ Indicators } & $\begin{array}{l}\text { Status } \\
2009-2010\end{array}$ & $\begin{array}{l}\text { Status } \\
2010-2011\end{array}$ & Comments \\
\hline \multicolumn{5}{|c|}{ General population } \\
\hline 1.1 & $\begin{array}{l}\text { Percentage of young women } \& \\
\text { men (15-24 years) who correctly } \\
\text { identify ways of preventing sexual } \\
\text { transmission of HIV and reject } \\
\text { major misconceptions about HIV } \\
\text { transmission }\end{array}$ & $\begin{array}{l}22.6 \% \\
\text { (National Service } \\
\text { survey 2008) }\end{array}$ & $28.5 \%{ }^{5}$ & $\begin{array}{l}\text { HIV-related KAP among } \\
\text { young people - a } \\
\text { nationwide survey } 2011 \\
\text { (unpublished). }\end{array}$ \\
\hline
\end{tabular}

${ }^{5}$ HIV-related knowledge among young people in Malaysia - anationwide survey (preliminary findings) 


\begin{tabular}{|c|c|c|c|c|}
\hline \multicolumn{2}{|c|}{ Indicators } & $\begin{array}{l}\text { Status } \\
2009-2010\end{array}$ & $\begin{array}{l}\text { Status } \\
2010-2011\end{array}$ & Comments \\
\hline 1.2 & $\begin{array}{l}\text { Percentage of young women \& } \\
\text { men ( } 15-24 \text { years) who have had } \\
\text { sexual intercourse before age of } 15\end{array}$ & $5.38 \%^{6}$ & $8.56 \%{ }^{7}$ & $\begin{array}{l}\text { HIV-related KAP among } \\
\text { students of secondary } \\
\text { schools - a nationwide } \\
\text { survey } 2011 \\
\text { (unpublished). }\end{array}$ \\
\hline \multicolumn{5}{|c|}{ Target 1. Reduce sexual transmission of HIV by 50 percent by 2015} \\
\hline \multicolumn{5}{|c|}{ General population } \\
\hline 1.3 & $\begin{array}{l}\text { Percentage of adults ( } 15-49 \text { years) } \\
\text { who have had sexual intercourse } \\
\text { with }>1 \text { partner in the past } 12 \\
\text { months }\end{array}$ & Not available & Not available & \\
\hline 1.4 & $\begin{array}{l}\text { Percentage of adults (15-49 years) } \\
\text { who had }>1 \text { sexual partner in the } \\
\text { past } 12 \text { months who report use of } \\
\text { condom during their last } \\
\text { intercourse }\end{array}$ & Not available & Not available & \\
\hline 1.5 & $\begin{array}{l}\text { Percentage women } \& \text { men }(15-49 \\
\text { years) who received an HIV test in } \\
\text { the past } 12 \text { months and know their } \\
\text { results }\end{array}$ & $98 \%$ & $100 \%$ & $\begin{array}{l}\text { Data from M\&E - HIV } \\
\text { screening in Malaysia that } \\
\text { include premarital, } \\
\text { antenatal, VCT, prisoners, } \\
\text { inmates of DRC, TB \& STI } \\
\text { patients, contacts of } \\
\text { HIV+. Blood donor not } \\
\text { included. }\end{array}$ \\
\hline 1.6 & $\begin{array}{l}\text { Percentage of young people (15- } \\
24 \text { years) who are living with HIV } \\
\text { (country with generalized } \\
\text { epidemic) }\end{array}$ & & & Not applicable \\
\hline \multicolumn{5}{|c|}{ Target 1. Reduce sexual transmission of HIV by 50 percent by 2015} \\
\hline \multicolumn{5}{|c|}{ Sex Workers } \\
\hline 1.7 & $\begin{array}{l}\text { Percentage of SW reached with } \\
\text { HIV prevention programmes }\end{array}$ & $\begin{array}{l}36.1 \%^{8} \\
\text { IBBS } 2009\end{array}$ & Not available & Will be conducted in 2012 \\
\hline 1.8 & $\begin{array}{l}\text { Percentage of SW reporting use of } \\
\text { a condom with their most recent } \\
\text { client }\end{array}$ & $\begin{array}{l}60.9 \% \\
\text { IBBS } 2009\end{array}$ & Not available & Will be conducted in 2012 \\
\hline 1.9 & $\begin{array}{l}\text { Percentage SW received an HIV } \\
\text { test in the past } 12 \text { mo. and know } \\
\text { their results }\end{array}$ & $\begin{array}{l}27.2 \% \text { received } \\
\text { test; } 90.2 \% \text { knew } \\
\text { result }^{8}\end{array}$ & Not available & Will be conducted in 2012 \\
\hline 1.10 & $\begin{array}{l}\text { Percentage SW who are living with } \\
\text { HIV }\end{array}$ & $\begin{array}{l}10.5 \% \\
\text { IBBS } 2009\end{array}$ & $0.3 \%$ & $\begin{array}{l}\text { Survey at selected health } \\
\text { facilities (private and } \\
\text { government) in } 4 \text { states }\end{array}$ \\
\hline
\end{tabular}

${ }^{6}$ Lee LK, Chen PCY, Lee KK and Kaur J. Premarital sexual intercourse among adolescents in Malaysia: a cross-sectional Malaysian school survey. Singapore Med J. 2008; 47(6):476

7 Preliminary report on nationwide survey among secondary school (16 years old) students in 6 states; assuming the premarital sexual

intercourse took place before aged 16 years old

${ }^{8}$ IBBS, Klang Valley Malaysia. 2009 (unpublished) 


\begin{tabular}{|c|c|c|c|c|}
\hline \multicolumn{2}{|c|}{ Indicators } & $\begin{array}{l}\text { Status } \\
2009-2010\end{array}$ & $\begin{array}{l}\text { Status } \\
2010-2011\end{array}$ & Comments \\
\hline \multicolumn{5}{|c|}{ Men who have sex with men (MSM) } \\
\hline 1.11 & $\begin{array}{l}\text { Percentage of MSM reached with } \\
\text { HIV prevention programmes }\end{array}$ & NA & $22.3 \%{ }^{9}$ & $\begin{array}{l}\text { PUSH project } 2010 \\
\text { (unpublished) } \\
\text { BSS among MSM in } \\
\text { Penang }\end{array}$ \\
\hline 1.12 & $\begin{array}{l}\text { Percentage of men reporting the } \\
\text { use of a condom the last time they } \\
\text { had anal sex with a male partner }\end{array}$ & $\begin{array}{l}62.9 \% \%^{10} \\
\text { VDTS } 2009\end{array}$ & $38 \%$ & $\begin{array}{l}\text { PUSH project } 2010 \\
\text { (unpublished) } \\
\text { BSS among MSM in } \\
\text { Penang }\end{array}$ \\
\hline 1.13 & $\begin{array}{l}\text { Percentage of MSM that received } \\
\text { an HIV test in the past } 12 \text { mo. and } \\
\text { know their results }\end{array}$ & $\begin{array}{l}41 \% \\
\text { VDTS } 2009\end{array}$ & $29.7 \%$ & $\begin{array}{l}\text { PUSH project } 2010 \\
\text { (unpublished) } \\
\text { BSS among MSM in } \\
\text { Penang }\end{array}$ \\
\hline 1.14 & $\begin{array}{l}\text { Percentage of MSM who are living } \\
\text { with HIV }\end{array}$ & $\begin{array}{l}3.9 \% \\
\text { VDTS } 2009\end{array}$ & $1.4 \%$ & $\begin{array}{l}\text { Survey at selected sites } \\
2011\end{array}$ \\
\hline \multicolumn{5}{|c|}{ Target 2. Reduce transmission of HIV among people who inject drugs by 50 percent by 2015} \\
\hline 2.1 & $\begin{array}{l}\text { Number of syringes distributed per } \\
\text { IDU per year by NSEP }\end{array}$ & Not applicable & 116 & $\begin{array}{l}\text { Survey among client of } \\
\text { NSEP at government and } \\
\text { NGO sites (2011) }\end{array}$ \\
\hline 2.2 & $\begin{array}{l}\text { Percentage of IDU who report the } \\
\text { use of a condom the last sex. } \\
\text { intercourse }\end{array}$ & $\begin{array}{l}27.8 \% \\
\text { (IBBS 2009) }\end{array}$ & Not available & Will be conducted in 2012 \\
\hline 2.3 & $\begin{array}{l}\text { Percentage of IDU reported using } \\
\text { sterile injecting equipment the last } \\
\text { time they injected }\end{array}$ & $\begin{array}{l}83.5 \% \\
\text { (IBBS 2009) }\end{array}$ & Not available & Will be conducted in 2012 \\
\hline 2.4 & $\begin{array}{l}\text { Percentage of IDU that have } \\
\text { received an HIV test in the past } 12 \\
\text { mo. and know their results }\end{array}$ & $\begin{array}{l}60.8 \% \\
\text { (IBBS 2009) }\end{array}$ & $100 \%$ & $\begin{array}{l}\text { Survey among client of } \\
\text { NSEP at government and } \\
\text { NGO sites (2011) }\end{array}$ \\
\hline 2.5 & Percentage of IDU living with HIV & $\begin{array}{l}22.1 \% \\
\text { (IBBS 2009) }\end{array}$ & $8.7 \%$ & $\begin{array}{l}\text { Data from harm reduction } \\
\text { services outlet (2011) }\end{array}$ \\
\hline \multicolumn{5}{|c|}{$\begin{array}{l}\text { Target 3. Elimination mother-to-child transmission of HIV by } 2015 \text { and substantially reduce AIDS- } \\
\text { related maternal deaths }\end{array}$} \\
\hline 3.1 & $\begin{array}{l}\text { Percentage of HIV positive } \\
\text { pregnant women who received } \\
\text { ARV to reduce the risk of MTCT }\end{array}$ & $100 \%$ & $89.4 \%$ & $\begin{array}{l}\text { MOH antenatal } \\
\text { surveillance data } 2011 \\
\text { and EPP } 2011\end{array}$ \\
\hline
\end{tabular}

${ }^{9}$ PUSH Project 2010. The prevalence of HIV and syphilis and its associated behavioural risk amongst men who have sex with men in state of Penang, Malaysia.CERia, University of Malaya.

${ }^{10}$ Kanter J., Koh C., Razali K. et al. Risk Behaviour and HIV prevalence among men who have sex with men in a multi-ethnic society: a venuebased study in Kuala Lumpur, Malaysia. Int. J. STD AIDS. 2011 Jan;22(1):30-7. 


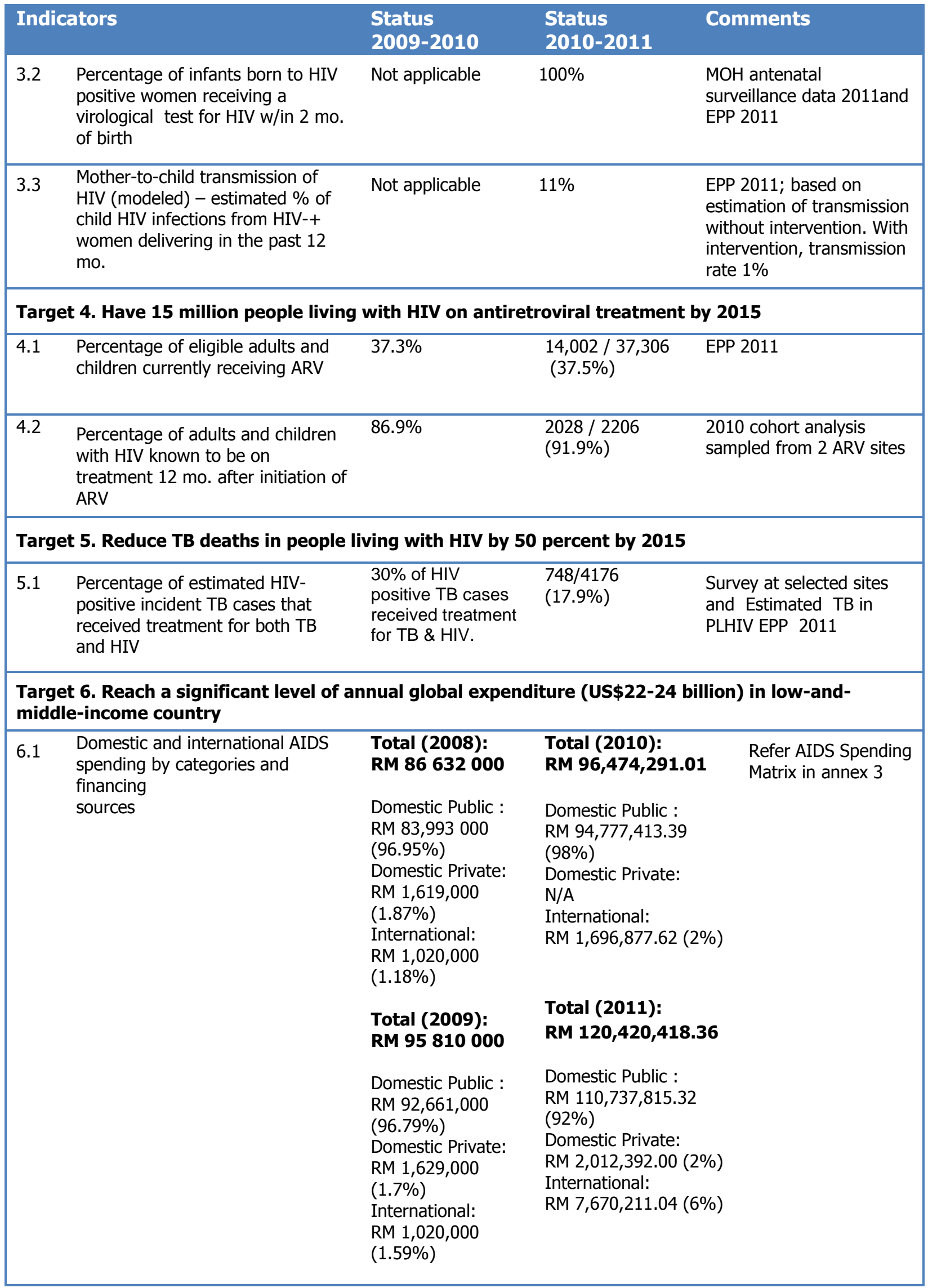




\begin{tabular}{|c|c|c|c|c|}
\hline \multicolumn{2}{|c|}{ Indicators } & $\begin{array}{l}\text { Status } \\
2009-2010\end{array}$ & $\begin{array}{l}\text { Status } \\
2010-2011\end{array}$ & Comments \\
\hline 7.1 & $\begin{array}{l}\text { National Commitments and Policy } \\
\text { Instrument (NCPI) (prevention, } \\
\text { treatment, care \& support, human } \\
\text { rights, civil society involvement, } \\
\text { gender, workplace programs, } \\
\text { stigma and discrimination and } \\
\text { Monitoring \& Evaluation - M\&E) }\end{array}$ & & $\begin{array}{l}\text { See attached NCPI } \\
\text { data (Annex 2) }\end{array}$ & $\begin{array}{l}\text { NCPI Workshops } \\
\text { (government; NGOs; } \\
\text { Multilateral and } \\
\text { bilaterals) }\end{array}$ \\
\hline 7.2 & $\begin{array}{l}\text { Proportion of ever-married or } \\
\text { partnered women aged } 15-49 \text { who } \\
\text { experienced physical or sexual } \\
\text { violence from a male intimate } \\
\text { partner in the past } 12 \text { mo. }\end{array}$ & Not applicable & 3,200 & $\begin{array}{l}\text { Data reported from: } \\
\text { Fight over domestic } \\
\text { violence in Malaysia } \\
\text { (website) }\end{array}$ \\
\hline 7.3 & $\begin{array}{l}\text { Current school attendance among } \\
\text { orphans and non-orphans (10-14 } \\
\text { years) }\end{array}$ & & & $\begin{array}{l}\text { Not applicable for this } \\
\text { country }\end{array}$ \\
\hline 7.4 & $\begin{array}{l}\text { Proportion of the poorest } \\
\text { households who received external } \\
\text { economic support in the last } 3 \\
\text { months }\end{array}$ & Not available & Not available & \\
\hline
\end{tabular}




\section{OVERVIEW OF THE EPIDEMIC}

\subsection{The epidemic overview}

Malaysia is a country with concentrated HIV epidemic based on WHO classification with infection rates remains high above $5 \%$ among most-at-risk populations (MARPS) especially among IDU, sex workers and transgender population ${ }^{11}$. Since the first case of HIV/AIDS made its debut in this country 25 years ago till December 2011, number of people living with HIV (PLHIV) is estimated at $81,000^{12}$. By the end of 2011 , Malaysia had a cumulative figure of 94,841 HIV, 17,686 AIDS and 14,986 deaths, thus giving reported PLHIV of $79,855^{13}$.

The annual number of reported new HIV cases by the Ministry of Health has been on a steady decline from a peak of 6,978 in 2002 (Figure 1). In 2011, there were 3,479 new cases reported to the Ministry of Health, approximately halve of what was reported in 2002 with average of 9 new cases each day (refer to Annex 4 for detail distribution of cases by year). The notification rate of HIV also continues to experience a decrease from 28.4 in 2002 to 23.4 in 2005 and to 12.2 cases per 100,000 populations in 2011.

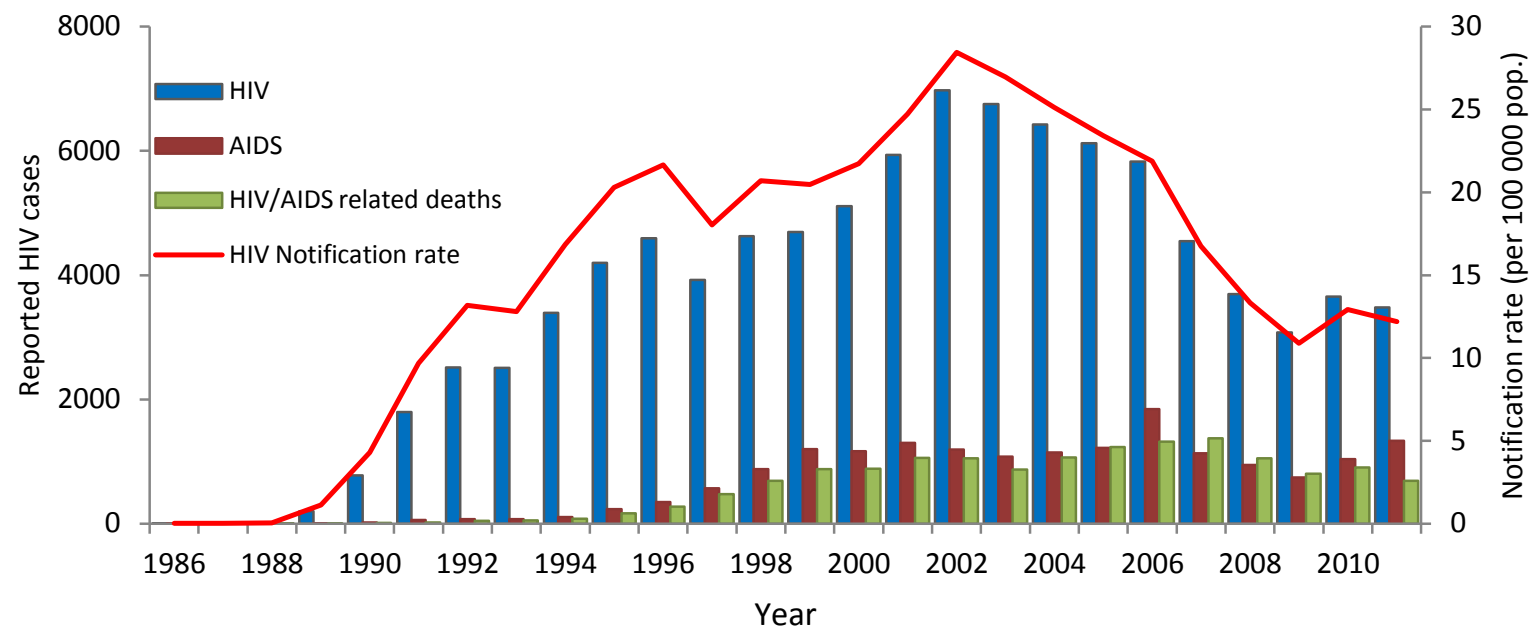

${ }^{11}$ Consensus Report on STI, HIV and AIDS Epidemiology. Malaysia, April 2001
${ }^{12}$ Estimation and Projection (2011), Ministry of Health Malaysia

${ }^{12}$ Antimation and Projection (2011), Ministry of Health Mart HIV/STI, Ministry of Health Malaysia 
There has been a decline in the number of AIDS-related deaths reported. The reduction has been directly attributed to the introduction of more affordable and accessible first and second line antiretroviral (ARV) treatment. As of 2011, there were 14,002 PLHIV on treatment which is $37.5 \%$ of the estimated number of PLHIV eligible for ARV treatment $(37,306)^{14}$. It has been estimated that by end of 2015 , Malaysia will have an estimated 81,317 people living with HIV.

HIV in Malaysia is predominantly male as they constitute $90 \%$ of cumulative HIV cases of whom majority are IDU. However, the trend of ratio female: male is changing from 1:99 in 1990 to $1: 10$ in 2000 to $1: 4$ in 2011. In the earlier phase of the pandemic, IDU was the driven factor. This trend has eventually changed over time from only 1 sexual transmission for every 9 IDU in 1990 to 2 sexual transmission for every 8 IDU in 2000 and 5 sexual transmission for every 5 IDU in 2010. With rigorous implementation of harm reduction programmes since 2005, we are able to reduce the number of HIV infection through sharing needles. Thus, in 2011 sexual transmission has superseded IDU as the main driven factor for the epidemic with ratio of 6 sexual transmissions for every 4 IDU reported (Figure 2).

Figure 2.Reported HIV cases attributed to IDU and sexual transmission, Malaysia 1986 - 2011

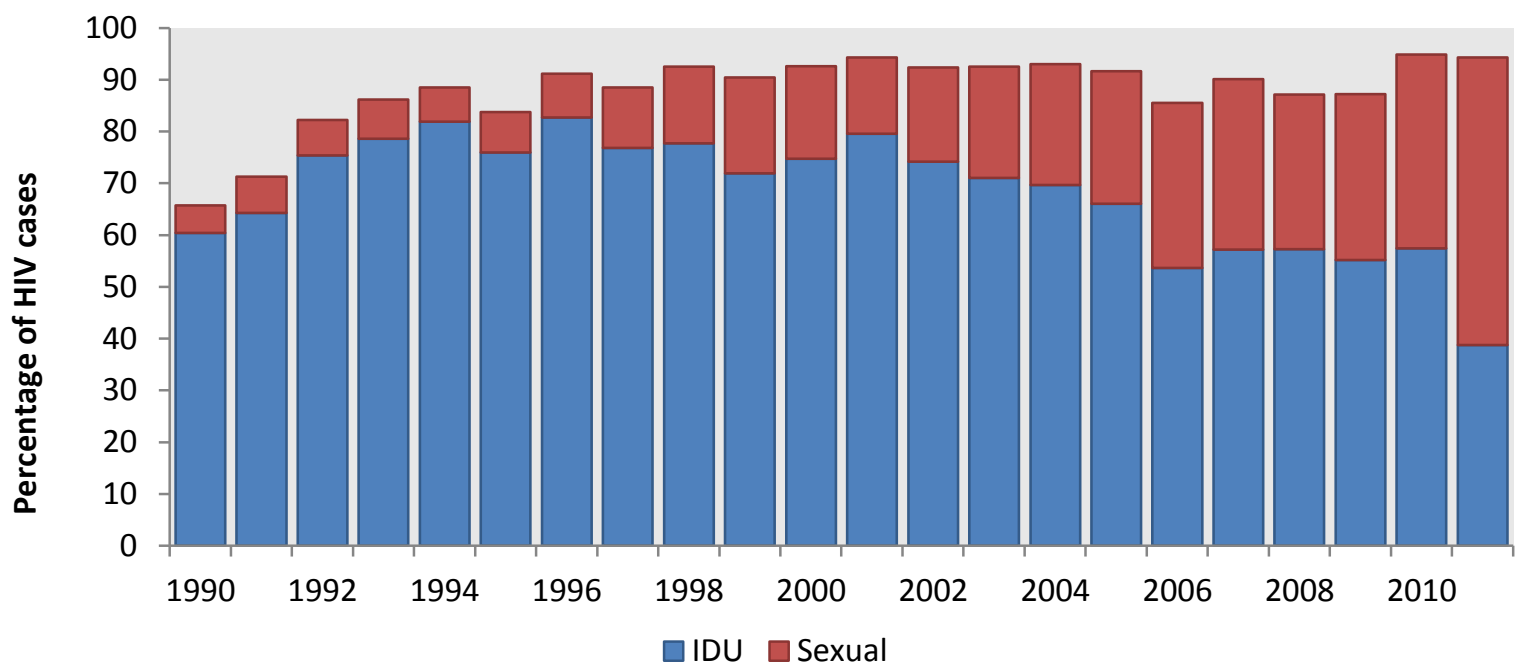

About $26 \%$ of reported infections are amongst young people aged between 13-29 years old and constantly around 1\% amongst less than 13 years old in 2011 (Figure 3). Overall, the country is observing a decreasing proportion of new reported HIV among young people aged 13-29 years while among older adult of 30-39 years, the trend is increasing. 
Figure 3. Distribution of reported new HIV cases by age group, $1990-2011$

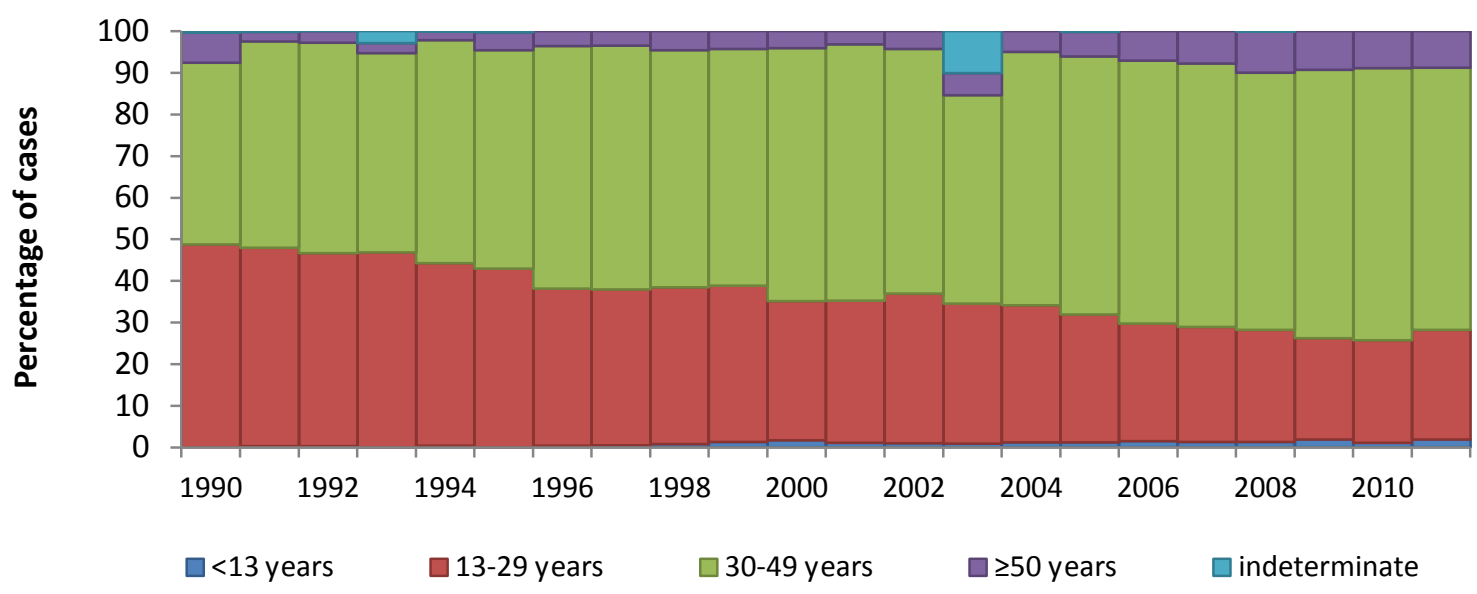

Male continue to represent the majority (90\%) of cumulative HIV cases in Malaysia. While the infection among males is showing a significant decline beginning 2003, the female is showing the opposite (Figure 4). Amongst men, 48\% acquired infection via injecting drug use and $47 \%$ through sexual mode ${ }^{15}$. Most HIV infections amongst women occurred mainly through heterosexual transmission (87\%). Women and girls are increasingly getting infected with HIV and constitute around $21 \%$ of newly infected persons nationwide in 2011 compared to being barely $5 \%$ ten years ago.

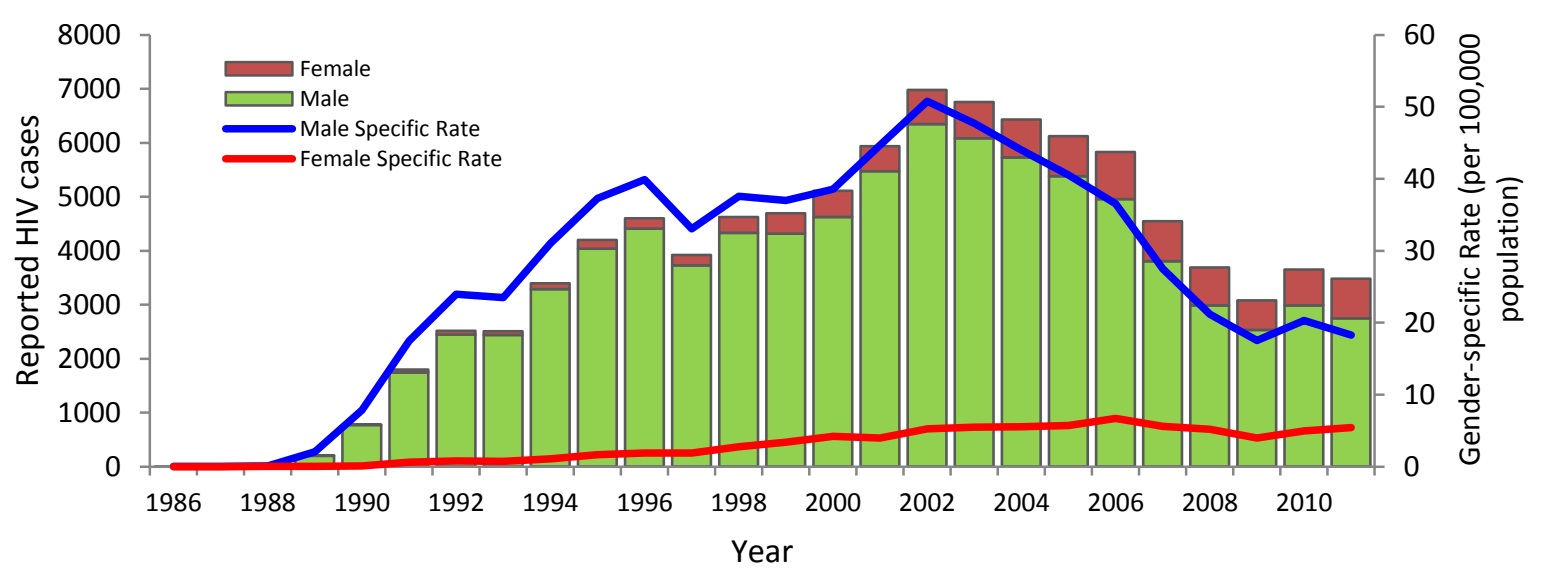

${ }^{15}$ National HIV Surveillance System. Ministry of Health Malaysia. 
With respect to geographical distribution, there is quite a distinct trend in transmission mode over a period of 10 years in the states of Malaysia. It appears that some states especially in eastern region (Pahang, Terengganu and Kelantan) of Peninsular Malaysia are still driven by IDU whereas some states in northern (Perlis, Kedah, Penang and Perak) and southern region (Negeri Sembilan, Melaka and Johor) have shifted to more of sexually driven. The central region (Selangor and Kuala Lumpur) had used to be IDU driven but has turned to sexually driven whereas east Malaysia (Sarawak, Sabah and Labuan) have always been predominantly sexually driven from the beginning of the epidemic (Figure 5).

Figure 5. The changing trend of HIV transmission mode in the states of Malaysia, 2000 and 2011

Newly reported HIV by states, Malaysia 2000

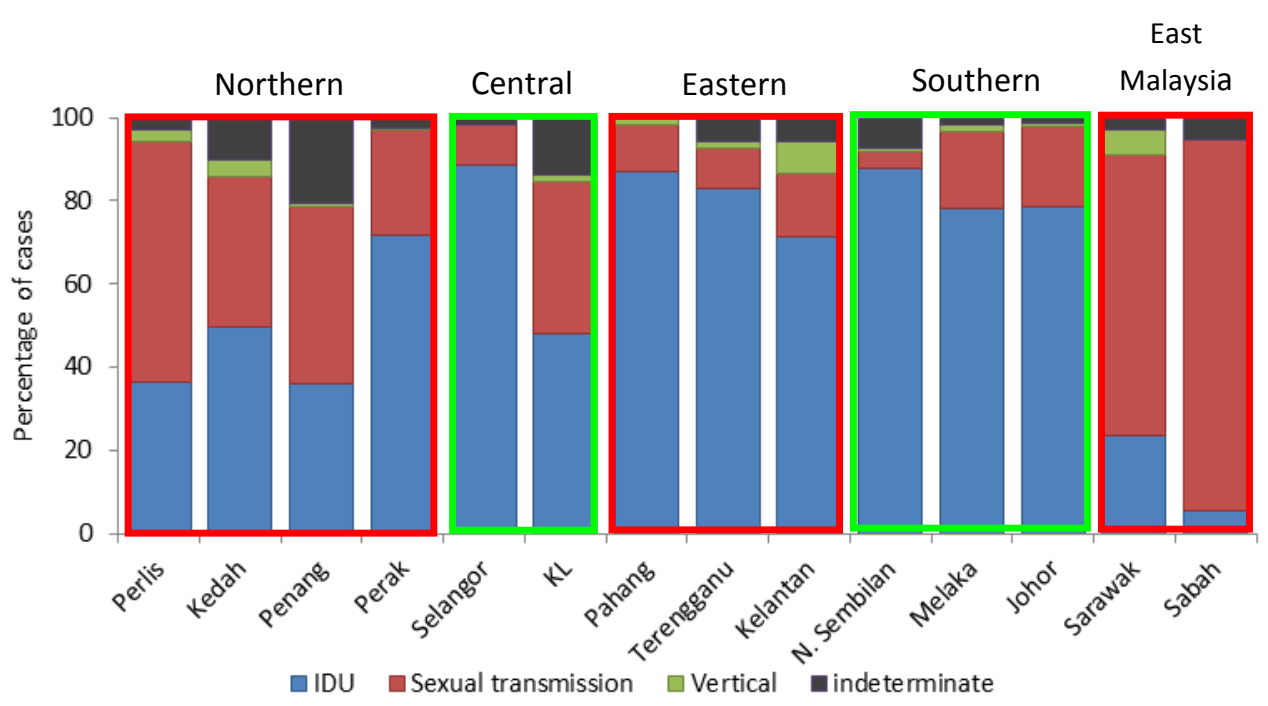

Newly reported HIV by states, Malayssia 2011

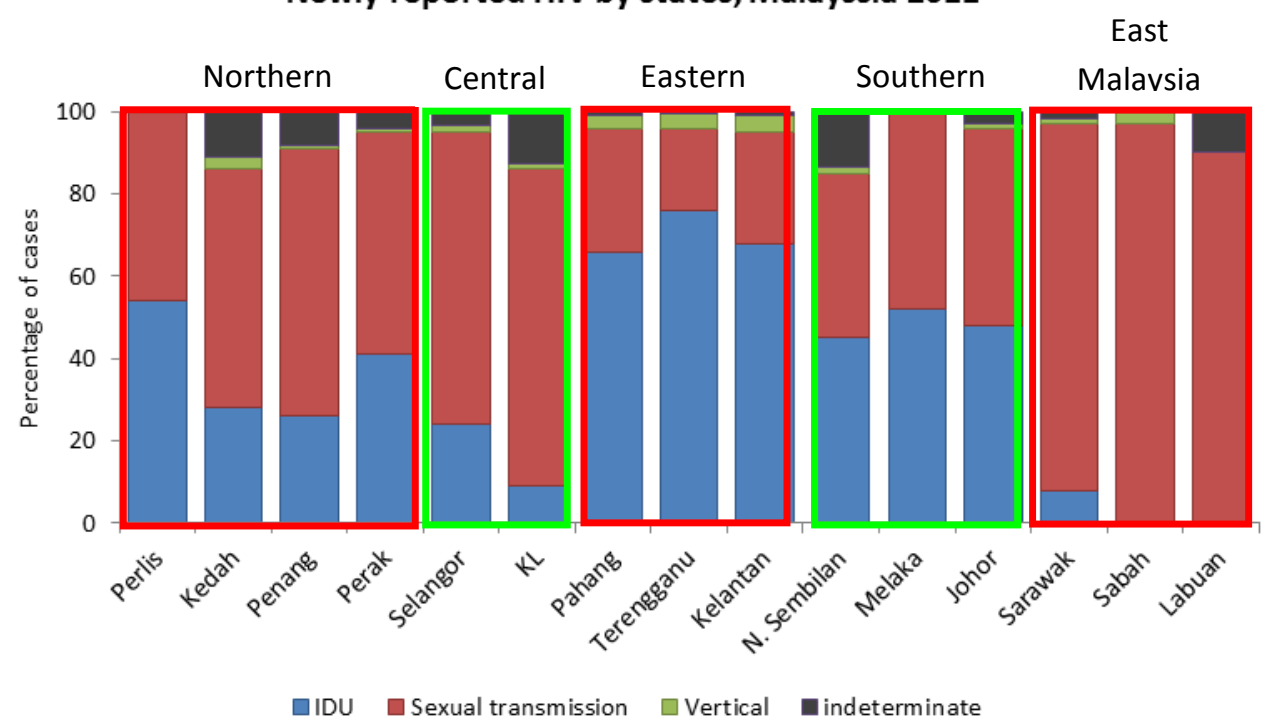




\subsection{HIV Screening}

Malaysia started introducing HIV screening since 1985. Currently, all government health facilities (2,836 health clinics inclusive of community clinics and 143 hospitals inclusive of non-MOH hospitals) are providing free HIV screening facilities. Malaysia has implemented various screening programmes since the early years of the HIV epidemic. As far as possible, the Ministry has tried to encourage the adoption of a voluntary, ethical and internationally accepted approach to HIV screening such as the Provider Initiated Testing and Counselling (PITC).

Among the screening programmes that has been implemented are mandatory HIV screening of all donated blood, blood products and organs, an opt-out antenatal screening and routine screening of inmates in drug rehabilitation centers and prisons, TB and STI cases, clients of harm reduction programme, contacts of cases and voluntary screening for premarital couples. Over the past five years, an average of 1.3 million HIV screening was conducted (Figure 6). It shows that despite maintaining surveillance programme and intensified screening activities, the detection rate of HIV is decreasing. This figure is compatible with the declining HIV reported cases through the surveillance system. It also validated the reduction in HIV cases in the country as estimated through estimation and projection exercise.

Figure 6. HIV Screening in Malaysia, 2000 - 2011

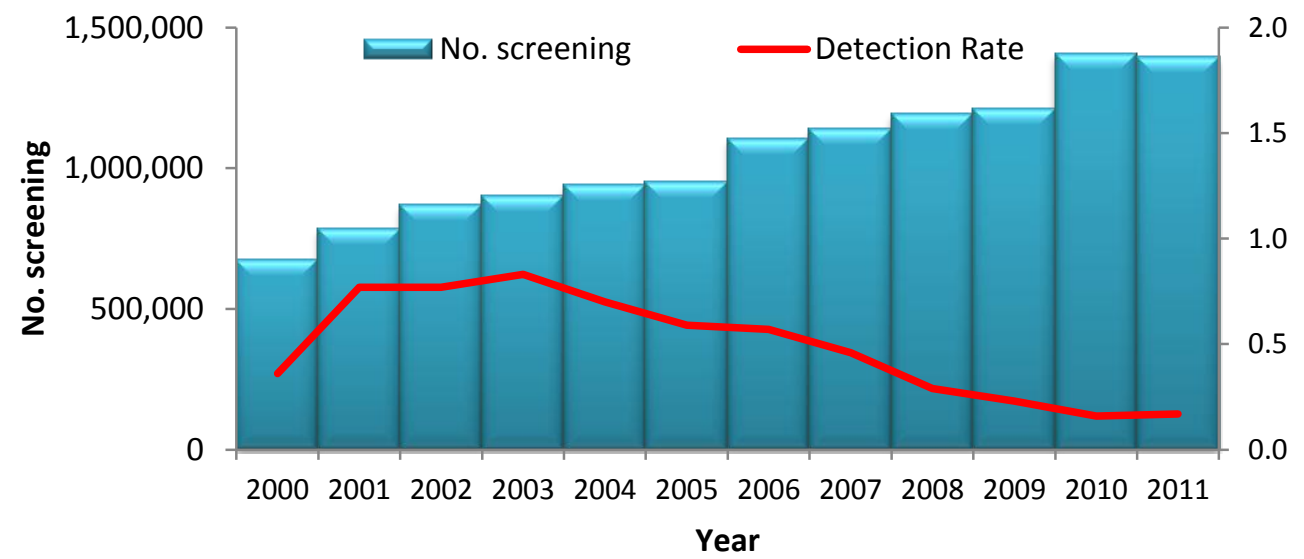

The Anonymous HIV Voluntary Screening programme was piloted in 2001 and later expanded nationwide in 2003. Screening is first carried out with a rapid test kit after which a reactive result is followed with a confirmation test. In 2011, as much as 19,804 people accessed this facility to obtain their HIV status out of which $57 \%$ were males and $65 \%$ were 
between the ages of 20 and 39. For those found to be with HIV, the main risk factor was injecting drug use (57\%), followed by sexual transmission (32\%). HIV prevalence was found to be around $0.4 \%$.

With the initiative of state religious department, premarital HIV screening for Muslim couples began in 2001 in one of the 14 states in Malaysia. By 2007, is it expanded nationwide and is made available in all government health centres. This screening is accessible to anybody who wishes to undergo premarital HIV screening, irrespective of religion background. In 2011, a total of 248,315 men and women were screened through this programme out of which $219(0.09 \%)$ were confirmed to be with HIV.

The Prevention of Mother to Child Transmission (PMTCT) programme was piloted in 1997, implemented nationwide in 1998 in all government health facilities. The program incorporates HIV screening utilising an opt-out approach. Approximately more than $75 \%$ of all pregnant women nationwide have access to antenatal care in public healthcare facilities. In 2011, a total of 443,453 pregnant women attending antenatal care had HIV screening. In addition, $\mathrm{MOH}$ had also started screening of HIV in labour room to cover the missedopportunity mothers for HIV screening and in 2011; about 10,105 pregnant women with unknown HIV status were screened. The prevalence of HIV among the missed-opportunity was $0.27 \%$, much higher than those who have been screened during antenatal period $(0.07 \%)$.

Based on surveillance data and screening activities, it has been shown that the cases in this country are still confined within the MARPS and that the prevalence among relatively low risk population as demonstrated through screening program is still low between 0.02 to $0.14 \%$ (Figure 7 ).

Figure 7. HIV prevalence among relatively low risk population based on screening programmes, Malaysia 2000-2011

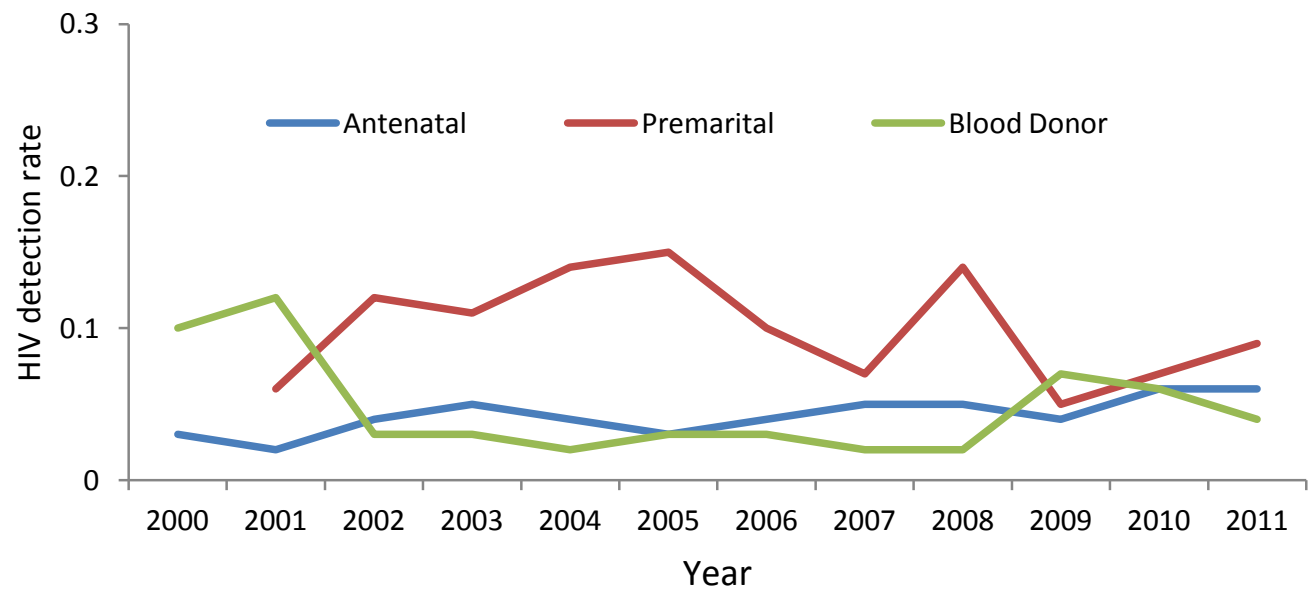




\subsection{Most At Risk Populations (MARPS)}

In 2002, it was decided that the existing HIV surveillance system that is based on notification of newly diagnosed HIV infection and screening in sub-populations, needed further strengthening, especially to predict the course of the epidemic. The Ministry of Health has incorporated the use of behavioural surveillance studies into the existing system. Hence, Behavioural Surveillance Surveys were adapted for this purpose beginning in 2004 which was later followed by the use of Integrated Bio-Behavioural Surveillance (IBBS) studies. The last IBBS survey was conducted in the Klang Valley focusing on three key affected populations (injecting drug users, female sex workers and transgender persons). The key findings of IBBS 2009 are summarized in table 3.

\section{a) Injecting Drug User (IDU)}

It is estimated that there are about 170,000 IDU in the country. The HIV screening activity among IDU in DRC started as early as 1989 and further strengthened in 1996. This screening activity had also expanded to include the harm reduction programme clients (NSEP and MMT) in 2005. At the beginning of the epidemic, IDU was the main driver with $70-80 \%$ of all new reported cases in 1990 s being attributed to injecting drug use. This has started to decline constantly in 2004, and had reached 39\% in 2011; signaling a rise in the proportion of sexually transmitted HIV. As of 2011, about 65,032 cases were infected from sharing needle and out of this about 9,141 (14\%) had passed away giving the total PLHIV among IDU about 55,891.

National HIV detection among new injecting drug users (IDU) is projected to reduce from $11 \%$ in 2011 to $10 \%$ in 2015 . Reducing rate indicates that ongoing prevention programs such as NSEP and MMT are effective preventive measures. From the surveillance data and screening activities in DRC and harm reduction services in 2011, we found HIV detection rate at $8.7 \%$ which is compatible with the estimated prevalence.

\section{b) Sex Workers}

A size estimation study of sex workers in Malaysia estimated the population of sex workers in Malaysia to be 60,000 comprised of 40,000 female sex workers (FSW) and 20,000 transgender $(\mathrm{TG})^{16}$. Sex worker accounts for approximately $0.6 \%$ of total reported cases or 611 of the 94,841 cases reported thus far. In comparison to the large proportion of injecting drug users reported to be infected with HIV, the number of HIV cases reported among sex workers is quite small. However, this is taken as a gross underreporting of this population as sex workers will not necessarily identify themselves

\footnotetext{
${ }^{16}$ Lim HE, Ang CL and Teh YK. Size estimation for local responses in Malaysia for HIV prevention in sex work, 2010 (unpublished)
} 
as such and may also not come forward for treatment. Current studies also only involve female and transgender sex workers. As it is, the situation with male sex workers is currently largely unknown as they are often hard to identify. As such, they are left out of existing outreach and intervention programmes.

FSW and TG are the highest infected risk populations with national rates estimated at $12 \%$ in 2011 and slightly reduced to $11 \%$ in $2015^{17}$. The IBBS conducted with sex workers in 2009 indicated that $10.5 \%$ of respondents were with HIV; about $61 \%$ reported the use of a condom with their most recent client while $38.6 \%$ correctly identified ways to prevent sexual transmission of HIV. This study also reported $6 \%$ had injected drugs in the past year and $20 \%$ of them had sexual partners who injected drugs. However, earlier behavioural surveillance survey (BSS) in 2004 reported $79 \%$ of respondents amongst female sex workers had used condom with their recent client and $20 \%$ had used drugs in one form or another ${ }^{18}$.

\section{c) Men Who Have Sex With Men (MSM)}

Under the existing classification in the HIV surveillance system, MSM are considered to be in the homosexual/bisexual category, and as of December 2011, there were 2,406 (2.5\%) out of 94,841 cumulative number of HIV reported cases were among this category. In 2009, a venue-day-time-sampling (VDTS) study was carried out among 517 respondents in Kuala Lumpur out of which 3.9\% were found to be with HIV. One in four reported having more than five male partners in the past six months. About $45 \%$ of those who had unprotected sex with a casual partner were almost 3 times more likely to be with HIV compared to those who did not engage in that activity. Approximately $16.1 \%$ had had sex with a female partner in the past six months. Due to social pressures, cultural context and the fear of facing stigma, MSM are more likely bisexual (i.e. having wives and girlfriends). There is an estimated 173,000 MSM in Malaysia.

With the current intervention, it is estimated that the HIV prevalence among MSM is stabilizing at $4.5 \%$ from 2011 to 2015 implying a steady rate of new HIV infections. Given many uncertainties around the MSM, HIV spread in MSM may reach higher prevalence in a short period.

${ }^{17}$ EPP 2011. Ministry of Health

${ }^{18}$ Summary Findings of Behavioral Surveillance Surveys (BSS) in Malaysia 2004.AIDS/STD Section, Ministry of Health Malaysia. 


\begin{tabular}{|c|c|}
\hline Key Population & Key Findings \\
\hline \multirow{6}{*}{$\begin{array}{l}\text { Injecting Drug } \\
\text { Users } \\
(n=630)\end{array}$} & HIV prevalence: $22.1 \%$ \\
\hline & Used sterile injecting equipment: $84 \% ; 27 \%$ through outreach programmes \\
\hline & Tested and knew results: $33 \%$ \\
\hline & Sexually active: $50 \%$; Condom use with most recent partner $28 \%$ \\
\hline & Paid for sex: $15 \%$ \\
\hline & Knowledge of modes of transmission: $50 \%$ \\
\hline \multirow{7}{*}{$\begin{array}{l}\text { Female sex } \\
\text { workers } \\
(n=551)\end{array}$} & HIV prevalence: $10.5 \%$ \\
\hline & Tested and knew results: $20 \%$ \\
\hline & Condom use with most recent client: $61 \%$ \\
\hline & Injecting drugs: $6 \%$ \\
\hline & Had sexual partners who inject drugs: $20 \%$ \\
\hline & Knowledge of modes of transmission: $39 \%$ \\
\hline & Reached through intervention programmes: $12 \%$ \\
\hline \multirow{6}{*}{$\begin{array}{l}\text { Men who have sex } \\
\text { with men (MSM) } \\
(n=529)\end{array}$} & HIV prevalence: $3.9 \%$ \\
\hline & Condom use: $55-72 \% \%$ \\
\hline & Injecting drugs: $6 \%$ \\
\hline & More than 6 male partners in the past 6 months: $26 \%$ \\
\hline & Sex with female partners: $16 \%$ \\
\hline & Knowledge of modes of HIV transmission: $80 \%$ \\
\hline \multirow{7}{*}{$\begin{array}{l}\text { Transgender (TG) } \\
(n=540)\end{array}$} & HIV prevalence: $9.7 \%$ \\
\hline & Tested and knew results: $19 \%$ \\
\hline & Sold sex: $84 \%$; Condom use with most recent client: $95 \%$ \\
\hline & Injecting drugs: $3 \%$ \\
\hline & Had sexual partners who inject drugs: $12 \%$ \\
\hline & Knowledge of modes of transmission: $37 \%$ \\
\hline & Reached through intervention programmes: $65 \%$ \\
\hline
\end{tabular}

\section{d) Transgender (TG)}

It is estimated that there are about 20,000 TG in this country ${ }^{19}$. TG are often stigmatized and discriminated by society. It was previously unknown as to how many cases of HIV were seen or estimated within this population. However, after the IBBS survey conducted with the TG community in 2009, a better picture has emerged of this population. From this survey, it was found that the population was experiencing a HIV prevalence of $9.7 \%$. Four out of 5 transgender persons were selling sex at some point of time last year. About $94 \%$ of them used condom during their last sexual encounter with a client. About $37 \%$ of respondents knew how to prevent sexual transmission of HIV. However, it was reported that $11.7 \%$ had sexual partners who injected drugs while $3.1 \%$ had injected drugs in the past year.

\footnotetext{
${ }^{19} \mathrm{Lim} H E$, Ang CL and Teh YK. Size estimation for local responses in Malaysia for HIV prevention in sex work, 2010 (unpublished)
} 
As shown in figure 8 below, the HIV epidemic in Malaysia is driven by IDU and sexual transmission among MARPs. There is also clear evidence based on operational research that overlapping of injecting drug use and high risk sexual behaviour is occurring resulting in HIV infection between the different populations. Based on the evidence, the government has taken steps towards increasing the coverage of IDUs under harm reduction programmes. Relevant government healthcare facilities have also scale-up the harm reduction programmes, eventually bringing down the costs of existing IDU related intervention programmes and activities.

Figure 8: HIV Prevalence (\%) among key at-risk populations (EPP estimates 2011)

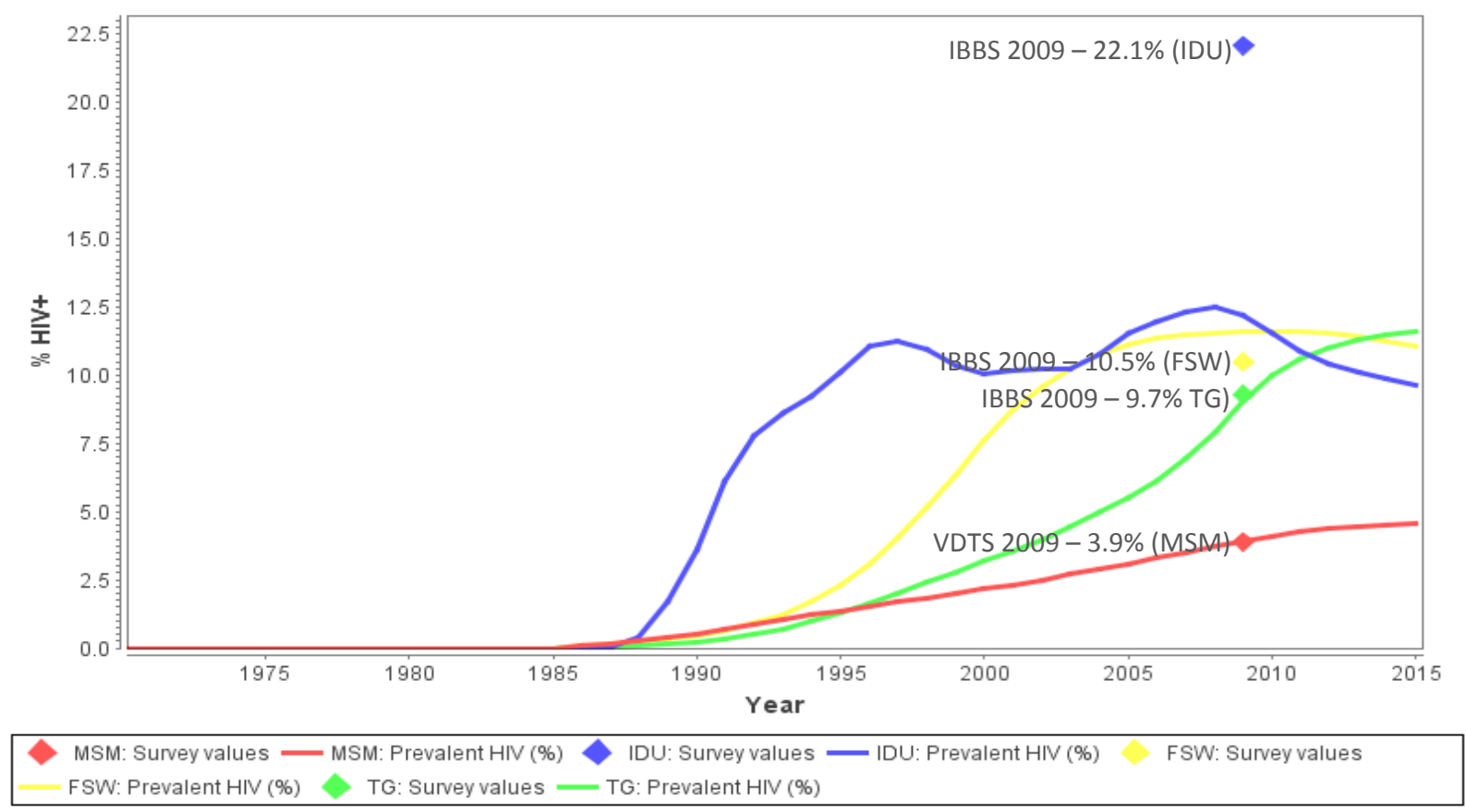

\section{e) Young population at risk}

Vulnerable populations are populations most likely to be exposed to HIV or populations at higher risk of exposure ${ }^{20}$. To date, no national study or survey has been conducted to estimate the number of children affected by HIV in the country and to examine their vulnerabilities to HIV infection.

\footnotetext{
${ }^{20}$ http://data.unaids.org/pub//InformationNote/2006/EditorsNotes_en.pdf
} 
Of the total 94,841 cumulative HIV cases since 1986, some 2,324 (2.4\%) were individuals aged 19 years and below. In 2011, children and young people aged 19 years and below made up 3.5\% (120) of 3,479 new reported HIV cases for that year out of which 65 (54\%) aged below 13 years who acquired infection through vertical transmission.

The vulnerabilities and situations encountered by both urban and rural children that expose them to HIV infection are many: sexual and physical violence, incest, sex work, human trafficking, underage and unprotected sex. Children with HIV have been reported to have faced stigma and are exposed to and experience acts of discrimination which could lead to ostracisation, exploitation, becoming homeless and loss of education.

\section{f) Migrant workers}

Malaysia has approximately 3 million foreign workers of whom 1.8 million are registered worker $^{21}$. HIV and selected other test (Hepatitis B, VDRL/TPHA and Malaria) as part of medical screening is a policy for incoming prospective foreign workers and for the annual renewal of work permits. The purpose is to detect unfit or pregnant migrant workers whom will be disqualified and deported back to their countries of origin. The HIV detection rate has been increasing from $0.03 \%$ in 2004 to $0.06 \%$ in 2009 and $0.08 \%$ in $2011^{22}$.

\section{g) Refugees}

As of 2011 there are $96,691^{23}$ refugees in this country which is $35 \%$ increase from the last two years $(71,400 \text { in } 2009)^{24}$. Despite being identified as a marginalised and vulnerable population under the National Strategic Plan on HIV/AIDS 2006-2010, data on incidence rates amongst refugees are not yet captured through the existing HIV surveillance system ${ }^{25}$. As monitored by the United Nations High Commissioner for Refugees (UNHCR) in Malaysia, the population of refugees living with HIV and AIDS as of December 2011 is 404 persons out of which 258 (64\%) are on ART and subsidized by the $\mathrm{MOH}^{26}$.

\footnotetext{
${ }^{21}$ Economic Transformation Program. A roadmap for Malaysia. Pg 553-587.

${ }^{22}$ Statistic on foreign workers medical screening 2011. Ministry of Health Malaysia.

${ }^{23}$ UNHCR (2011). Personal contact

${ }^{24}$ www.unhcr.org.my

${ }^{25}$ Ministry of Health (2005). National Strategic Plan on HIV/AIDS 2006-2010, (October 2005) pg 14

${ }^{26}$ UNHCR (2011). Personal communication
} 


\subsection{Recent trends in the epidemic}

\section{a) HIV/TB Co-infection}

Tuberculosis (TB) remains a public health challenge in Malaysia with around 16,000 20,000 new cases reported annually (Figure 9). Patients with HIV are highly vulnerable to $\mathrm{TB}$, because of their weakened immune systems. As part of its disease control and prevention measures, the Government currently conducts routine TB-HIV screening for all new inmates in incarcerated closed settings such as prisons and drug rehabilitation centres, which was started in 2001. From 1990 to 2011, the number of HIV/TB coinfection reported nationwide has increased from six (6) to $1,630 \mathrm{cases}^{27}$. Without treatment, as with other opportunistic infections, HIV and TB co-infection would shorten the life of the person infected. In effort to reduce morbidity and mortality of TB/HIV coinfection, the government has started Isoniazid prophylaxis in 2011.

The number of TB cases detected each year is relatively quite high in comparison to the reported incidence of HIV. An average of 18,500 cases was reported over the past five years. In 2011, about 20,666 new TB cases were registered in Malaysia. In 2011, 3.2\% of all TB cases screened were also having a co-infection of HIV, a proportion which has been gradually decreasing each year. However, it has been estimated that in 2011, about 52,205 people infected with TB, TB incidence without HIV about 2.4 per 1000 population and TB/HIV co-infection about $8 \%{ }^{28}$.

Figure 9. New TB, HIV and prevalence of TB-HIV Co-infection, Malaysia 1999-2011

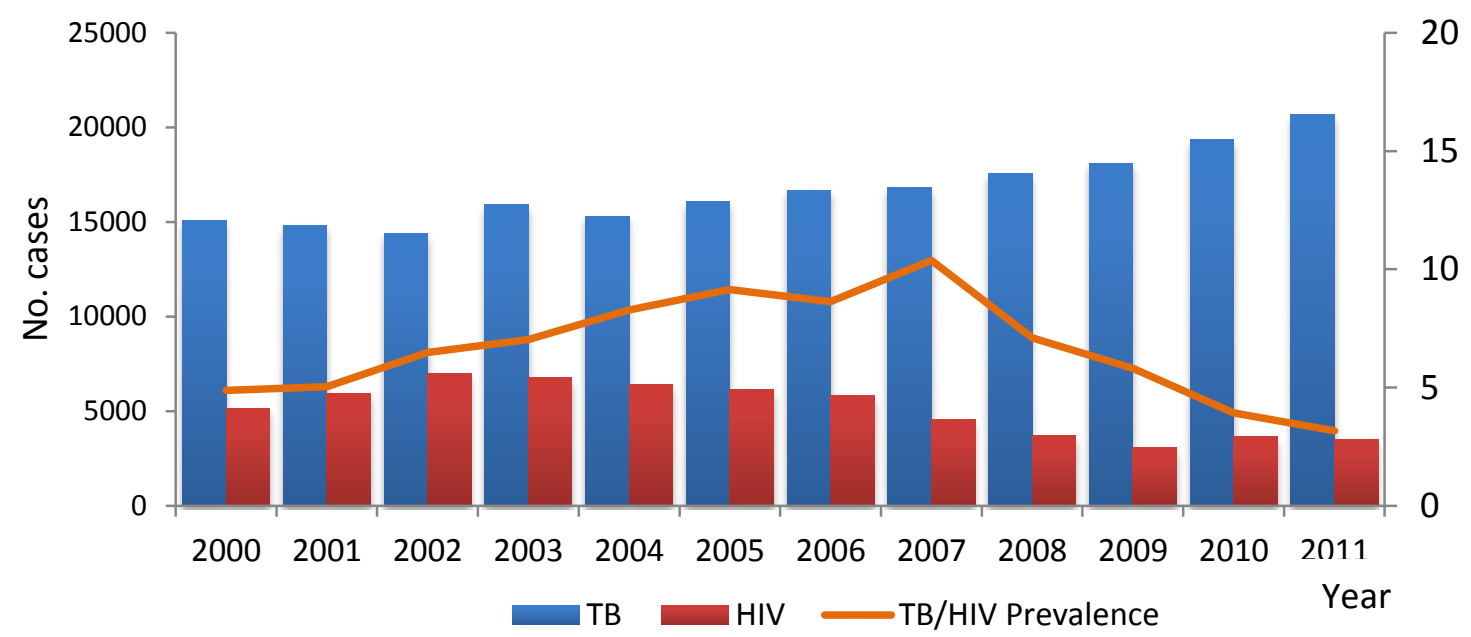

${ }^{27}$ Ministry of Health Malaysia. TB Surveillance report 2011

${ }^{28}$ EPP 2011. Ministry of Health 


\section{b) Increase proportion of HIV acquired through sexual transmission}

There is no doubt that, for the moment, injecting drug use remains the main mode of HIV transmission in Malaysia. The majority of reported HIV cases nationwide are attributed to the sharing of contaminated needles among IDU. Nevertheless, there are clear signal that sexual transmission is becoming a major factor that drive the country's epidemic in the future. Compared to ten years ago when infection through the IDU route was $70-80 \%$ of all new reported HIV cases, this proportion has declined to $38.7 \%$ in 2011 (table 4).

Table 4: Percentage of new HIV cases by risk factor

\begin{tabular}{|l|c|c|c|}
\hline \multicolumn{1}{|c|}{ Risk factor } & $\mathbf{1 9 9 0}$ & $\mathbf{2 0 0 0}$ & $\mathbf{2 0 1 1}$ \\
\hline Injecting drug use & $\mathbf{4 7 0 ( \mathbf { 6 0 . 4 \% ) }}$ & $\mathbf{3 , 8 1 5}(\mathbf{7 4 . 7 \% )}$ & $\mathbf{1 , 3 4 8 ( 3 8 . 7 \% )}$ \\
\hline Sexual transmission & $\mathbf{4 1}(\mathbf{5 . 2} \%)$ & $\mathbf{9 6 4}(\mathbf{1 8 . 8 \% )}$ & $\mathbf{1 , 9 3 1 ( 5 5 . 5 \% )}$ \\
Heterosexual & $38(4.8 \%)$ & $902(17.6 \%)$ & $1,573(45.2 \%)$ \\
Homosexual & $3(0.4 \%)$ & $62(1.2 \%)$ & $358(10.3 \%)$ \\
\hline
\end{tabular}

Source: Ministry of Health (2011)

Increasingly more new reported cases have been attributed to infection through the sexual route, namely unprotected sexual intercourse by both heterosexuals and homosexuals. Combined, sexual transmission of HIV is currently responsible for more than half of new HIV cases.

As of December 2011, HIV transmission attributed to heterosexual intercourse constitutes $18.9 \%$ of cumulative cases. However, there is significant increase in proportion of newly infected cases acquired through heterosexual contact from $4.9 \%$ in 1990 to $17.7 \%$ in 2000 to $45.2 \%$ in 2011 . Heterosexual transmission now accounts for almost half of newly reported HIV cases in Malaysia. As part of the prevention of mother-to-child-transmission (PMTCT) programme in 2011, more than 400,000 pregnant women were screened and 309 individuals were detected with HIV. About $88 \%$ of them acquired HIV through heterosexual contact.

The proportion of HIV cases reported as being homosexual/bisexual appears to be quite consistent with estimations of the MSM population which indicate a prevalence of less than $10 \%$. However, it is important to note that this population has increased in number 
and proportion from $0.4 \%$ in 1990 to $1.2 \%$ in 2000 and to $10.3 \%$ in 2011 . With more than $10 \%$ of all reported new cases in 2011 being from this route of transmission, there is concern about insufficient attention being drawn to HIV prevention amongst MSM and TG. Data from the VDTS also seem to indicate that self-identified MSM did not confine their sexual activity to amongst themselves but also had sex with women.

\section{c) HIV and Women}

As of December 2011, 9,494 women and girls in Malaysia have acquired HIV since 1986. About $45 \%$ of these cases were reported within the past six years. The HIV profile of the Malaysian HIV epidemic has slowly shifted from almost entirely male to having a higher proportion of female cases ${ }^{29}$. The gender-specific rate was clearly showing a downtrend of new infection among males beginning 2003, but infections among females are slowly taking its toll. This alarming trend is strongly linked to women and heterosexual transmission.

The surveillance data observed a constant reduction of new HIV cases annually starting 2003. But the ratio of male to female is increasing from 99:1 in 1990 to $10: 1$ in 2000 to $4: 1$ in 2011. According to estimates, there should be 4 males for every 1 female living with $\mathrm{HIV}^{30}$. By the end of 2011, the Ministry of Health recorded 735 new HIV cases and 203 AIDS cases among adolescent and adult women in Malaysia.

The $\mathrm{MOH}$ profile of female HIV cases in 2011 indicated that more than two thirds were between $20-39$ years of age, $86 \%$ had acquired HIV through heterosexual transmission and $40 \%$ were housewives.

\section{d) Multiple risk behaviours}

Although injecting drug users constitute a risk group in themselves, there is also an overlap between drug addiction and those involve with sex works. Often, drug users who sold sex did so mainly to pay for drugs. Individuals who fall into both categories are therefore particularly vulnerable to HIV and facing dual stigma. Though transmission remains mostly through sharing of contaminated injecting equipment among drug users, it is no longer possible to address specific populations individually without considering overlapping of risk behaviours involving injecting drug use and sex work amongst the most-at-risk populations. IDUs who are sex workers put themselves at risk and also facilitate the transmission of HIV between population groups.

${ }^{29}$ Ministry of Health Malaysia and UNICEF (2008). Women and girls confronting HIV and AIDS in Malaysia

${ }^{30}$ Estimation and Projection 2011. Ministry of Health Malaysia (unpublished) 
Sexual risk behaviour related to drug use should not just be considered within the bounds of sex work. While the impact of drugs on sexual behaviour may vary by type of drug used, length of use, sexual practice and other factors, there are a number of effects related to drug use that could contribute to risky sexual behaviour.

Overlapping of the two main risk behaviours, namely injecting drug use and sex work is also being observed within the local context. A nationwide study among sex workers conducted by UNFPA and FRHAM in 2008/2009 revealed that $16 \%$ of sex workers were using drugs while $13 \%$ were ex-drug users; close to $29 \%$ of them were injecting drug users and about a third shared needles with their friends and husband ${ }^{31}$. Behavioural surveillance surveys in $2004^{32}$ and IBBS $2009^{33}$ both revealed involvement of sex workers with injecting drug use and vice versa and are sexually active. Needles and syringes are commonly shared between sex workers and clients who pay for sexual services with drugs while condom use was found to be generally low and infrequent.

\subsection{Estimation and projection of HIV epidemic}

Series of discussion on estimates and projections of HIV in Malaysia was conducted from $5^{\text {th }}$ to $9^{\text {th }}$ March 2012. The discussion involved the representatives from the Ministry of Health, relevant government agencies and non-government agencies including the Malaysian AIDS Council (MAC). The purpose is to produce a consolidated report on estimates and projections of HIV in Malaysia for the 2011-2015 periods. Similar to the previous years, seroprevalence data, population size estimates and recent data from surveys and surveillance data were entered into the Estimation and Projection Package (EPP) Version 4.47 to generate several projections of the HIV epidemic especially among high risk groups.

Based on recent estimations and projections, the HIV prevalence among injecting drug users (IDU) is projected to reduce from $11 \%$ in 2011 to $10 \%$ in 2015 . While for MSM and clients of sex workers, the prevalence seems to be stabilizing with prevalence of $4.5 \%$ among MSM and $0.15 \%$ among clients respectively from 2011 to 2015 . This implies a steady rate of new HIV infections among them. Due to many uncertainties around the MSM and clients population sizes, HIV spread among MSM may be more than estimated. The same can be expected among clients of sex workers.

\footnotetext{
${ }^{31}$ HIV and Sex Work. Investing in Sexual and Reproductive Health and Rights. UNFPA \& FRHAM. 2010

${ }^{32}$ Summary Findings of Behavioral surveillance surveys in Malaysia 2004. Ministry of Health Malaysia and WHO.

${ }^{33}$ Integrated Bio-Behavioral Surveillance Report.Klang Valley Malaysia, 2009 (unpublished)
} 
It is estimated that by 2015 , Malaysia may have 81,317 people living with HIV and annual HIV-related deaths more than 6,608 persons (table 5). The key findings from the estimation and projection 2011 (EPP) workshops are as follows:

a) The HIV prevalence among injecting drug users (IDU) is projected to reduce from $11 \%$ in 2011 to $10 \%$ in 2015. Reducing rate indicates that ongoing prevention programs such as Needle Syringe Exchange Program (NSEP) and Methadone Replacement Therapy are effective preventive measures.

b) The estimated number of PLHIV nationwide is expected to increase because better coverage and access to ARV.

c) The number of AIDS related deaths is expected to decrease in the next 3-5 years, as accessibility to antiretroviral treatment and preventive activities increased.

d) The proportion of women newly infected with HIV is increasing. It estimated that there is 1 female living with HIV for every 4 males living with HIV.

e) The number of children less than 15 years old living with HIV is expected to reduce from 1411 in 2011 to 1197 in 2015 and the new infection reduce from 82 (2011) to 53 (2015). This is attributed to availability of early infant diagnosis in order to provide them with timely care and treatment and established PMTCT program.

f) The number of pregnant mothers needing PMTCT is estimated to decrease from 395 in 2011 to 327 in 2015.

Table 5. Estimates of Malaysian HIV epidemic (EPP 2011)

\begin{tabular}{|l|c|c|}
\hline & $\mathbf{2 0 1 1}$ & $\mathbf{2 0 1 5}$ \\
\hline Total People Living With HIV & 81,000 & 81,317 \\
Fale & $71,903(88.8 \%)$ & $72,405(89.0 \%)$ \\
Estimated adult prevalance & $9,096(11.2 \%)$ & $8,912(11.0 \%)$ \\
\hline Total new infections / year & $0.41 \%$ & $0.38 \%$ \\
Male & 6,415 & 6,567 \\
Female & 5,897 & 5,948 \\
\hline Total deaths related to HIV/AIDS / year & 518 & 619 \\
Male & 5,910 & 6,608 \\
Female & 5,287 & 5,945 \\
\hline
\end{tabular}




\section{NATIONAL RESPONSE TO THE AIDS EPIDEMIC}

Retrospectively, the national response to HIV started as far back in 1985. HIV, AIDS and death related to HIV/AIDS was listed as notifiable diseases under the Prevention and Control of Infectious Diseases Act ${ }^{34}$. Raising awareness and knowledge on HIV/AIDS has been the focus of $\mathrm{MOH}$ since the formulation of Plan of Action in 1988. The first National Strategic Plan (NSP) on HIV/AIDS was developed in 2000. In 2005, the NSP was reviewed and subsequently 5 years plan (NSP 2006 - 2010) for HIV responses was endorsed and implemented. With latest revision, NSP 2011-2015 continues to provide a common ground and emphasis on an integrated and comprehensive approach addressing the needs of prevention, treatment, care and support.

The responsibility for the overall coordination, monitoring, evaluation and reporting of Malaysia's HIV and AIDS responses is currently tasked to the HIV/STI Sector of the Disease Control Division, Ministry of Health. Currently, the HIV/STI Sector function as the National AIDS Programme (NAP) Secretariat supported by the AIDS Officers at every state. The Secretariat interacts and engages the other institutions within the Federal Government (and the civil society) through HIV Focal Points who are present in each of the relevant Ministries. During the earlier days, the design and development of the HIV/AIDS National Prevention and Control Program was sole responsibility of the Ministry of Health. Over period of time, this response has matured to include wider group of stakeholders including non-health sectors within government organizations, non-government organizations, civil society, private agencies, bilateral and international agencies. However, there are still opportunities to strengthen and sustain the commitment of all stakeholders especially in enhancing to achieve greater harmonisation, coordination and alignment; maintain and sustain optimum levels of funding; achieve greater programme coverage, effectiveness, and efficiency; and to continue the provision of affordable treatment to those who need it.

With latest revision in 2011 (NSP 2011-2015), this framework provided a common ground and emphasis on an integrated and comprehensive approach addressing the needs of prevention, treatment, care and support. Over the past five years, increased levels and additional sources of funding have made it possible to expand or upscale the support of HIV and AIDS interventions in the region, giving Malaysia avenues to accelerate the national response to the epidemic. Nevertheless, there remain gaps and opportunities for improvement in certain identified programmes.

The government and key stakeholders have agreed that the new National Strategy on HIV should be able to sustain and upscale the achievements and commitments, while at the

\footnotetext{
${ }^{34}$ Laws of Malaysia.Act 342. Prevention and Control of Infectious Diseases, Act 1988.
} 
same time be able to address concerns and identified gaps as well as respond more effectively to the needs of its stakeholders, especially those of civil society and most at risk communities.

The objectives of the NSP2011-2015 are as follows:

a) To further reduce by $50 \%$ the number of new HIV infections by scaling up, improving upon and initiating new and current targeted and evidence based comprehensive prevention interventions

b) To increase coverage and quality of care, treatment and support for People Living with HIV and those affected

c) To alleviate the socioeconomic and human impact of AIDS on the individual, family, community and society.

d) To create and maintain a conducive and enabling environment for government and civil society to play meaningful and active roles in decreasing stigma and discrimination.

e) To further increase general awareness and knowledge of HIV, and reduce risk behaviour for at risk and vulnerable populations.

This section on the national response to the AIDS epidemic in Malaysia will be discussed within the framework and context of the National Strategic Plan on HIV/AIDS. This framework outlines five main strategies:

Strategy 1 Improving the quality and coverage of prevention programmes among most at risk and vulnerable populations

Strategy 2 Improving the quality and coverage of testing and treatment

Strategy 3 Increasing the access and availability of care, support and social impact mitigation programmes for People Living with HIV and those affected.

Strategy 4 Maintaining and improving an enabling environment for HIV prevention, treatment, care and support.

Strategy 5 Increasing the availability and quality of strategic information and its use by policy makers and programme planners through monitoring, evaluation and research.

The execution and fulfillment of the following strategies will require renewed and strengthened commitment and multisectoral partnership of government, civil society and private sector stakeholders to work together in the spirit of consultation and collaboration under the 1Malaysia initiative. 


\subsection{Financing the response to HIV and AIDS in Malaysia}

\section{a) Domestic Public Funding}

The resources required to achieve the NSP coverage and impact goals have been calculated from estimates of the number of people receiving each service and the cost per person. Service estimates are based on the population in need of the service or programme and the coverage level to be achieved. Coverage is assumed to increase from the baseline levels to the planned targets by 2015. The unit costs for these services are based on existing interventions currently being implemented by agencies and organisations.

A bulk of the allocation for NSP implementation was spent on the provision of HIV treatment and HIV prevention programmes. In 2010, total expenditure was approximately RM 96.5 million (USD 31.9 million), about $98 \%$ was financed by Government funding and $2 \%$ by the international sources. In 2011, the AIDS expenditure had increased $18 \%$ to RM 120.4 Million (USD 39.9 million), out of which $92 \%$ was Government funded (table 6). As for sources of financing, as indicated in the table below, it is obvious that the domestic public funding from the Government shouldered most of the AIDS related expenditure, whereas international and private sector contributed to about $8 \%$.

Table 6: Source of approximate AIDS expenditure 2010-2011

\begin{tabular}{|l|c|c|c|c|}
\hline Source of Funding & $\begin{array}{c}\mathbf{2 0 1 0} \\
\text { (RM) }\end{array}$ & \% & $\begin{array}{c}\mathbf{2 0 1 1} \\
\text { (RM) }\end{array}$ & $\%$ \\
\hline Domestic Public & $94,777,413.39$ & 98.2 & $110,737,815.32$ & 92.0 \\
\hline Domestic Private & NA & 0 & $2,012,392.00$ & 1.6 \\
\hline International & $1,696,877.62$ & 1.8 & $7,670,211.04$ & 6.4 \\
\hline \multicolumn{1}{|c|}{ Total } & $\mathbf{9 6 , 4 7 4 , 2 9 1 . 0 1}$ & $\mathbf{1 0 0 . 0}$ & $\mathbf{1 2 0 , 4 2 0 , 4 1 8 . 3 6}$ & $\mathbf{1 0 0 . 0}$ \\
\hline
\end{tabular}

\section{b) Domestic Private Funding}

Information concerning the private sector is currently limited and majority of corporate entities engage the MAC and Malaysian AIDS Foundation (MAF) to provide support for specific programmes (e.g. the Standard Chartered Pediatric AIDS Fund). There was an increase support from domestic private in 2011 as shown by funding to MAC and PTF in 2011 amounting to RM 2,012,392.00 (USD 666,355). 
c) International funds

For the period of 2010 - 2011, funding allocated for HIV and AIDS programming in Malaysia from international sources slightly reduced from approximately USD 3.6 million in $2008-2009$ to USD 2.5 in $2010-2011^{35}$.

\section{d) AIDS Spending Categories}

Unlike previously, majority of domestic funding both in 2010 and 2011 was spent in care and treatment $(52.6 \%$ and $54.3 \%$ respectively) followed by prevention programmes ( $25 \%$ and $24.8 \%$ respectively). ARV procurement constituted the bulk of expenditure under care and treatment category with average expenditure about $72 \%$ while for prevention programmes, harm reduction made up the highest expenditure with average of about $58 \%$.

Table 7: AIDS Spending Category - Approximate total expenditure from Domestic (Public and Private) and International Sources

\begin{tabular}{|l|r|r|r|c|}
\hline \multicolumn{1}{|c|}{ AIDS Spending Category } & \multicolumn{1}{c|}{$\mathbf{2 0 1 0}(\mathbf{R M})$} & \multicolumn{1}{c|}{$\%$} & $\mathbf{2 0 1 1}(\mathbf{R M})$ & \% \\
\hline Prevention & $25,515,620.50$ & 26.4 & $29,841,733.80$ & 24.8 \\
\hline Care and treatment & $50,769,038.01$ & 52.6 & $65,356,231.48$ & 54.3 \\
\hline Orphans and vulnerable children & $1,889,466.00$ & 2.0 & $2,388,460.00$ & 2.0 \\
\hline $\begin{array}{l}\text { Programme Management and } \\
\text { Administration Strengthening }\end{array}$ & $13,508,525.56$ & 14.0 & $14,386,954.72$ & 11.9 \\
\hline Incentives for Human Resources & $1,898,813.74$ & 2.0 & $1,483,721.00$ & 1.2 \\
\hline $\begin{array}{l}\text { Social Protection and Social Services } \\
\text { including Orphans and Vulnerable }\end{array}$ & $2,000,000.00$ & 2.1 & $2,362,000.00$ & 2.0 \\
\hline Enabling Environment & $887,827.20$ & 0.9 & $4,596,317.36$ & 3.8 \\
\hline Research & $5,000.00$ & 0.0 & $5,000.00$ & 0.0 \\
\hline \multicolumn{1}{r|}{ TOTAL } & $\mathbf{9 6 , 4 7 4 , 2 9 1 . 0 1}$ & $\mathbf{1 0 0 . 0}$ & $\mathbf{1 2 0 , 3 0 0 , 4 1 9 . 3 6}$ & $\mathbf{1 0 0 . 0}$ \\
\hline
\end{tabular}

\subsection{Improving the quality and coverage programmes among most at risk and vulnerable populations}

HIV prevention efforts as outlined in NSP 2011 - 2015 focus on addressing the three primary prongs of HIV transmission in Malaysia, namely the sharing of needles and syringes through injecting drug use, unprotected sexual intercourse, amongst most at risk and vulnerable populations and advocacy amongst the most-at-risk youth populations.

\footnotetext{
${ }^{35}$ Government of Malaysia (2009). Country Proposal for Round 9 of the Global Fund for AIDS, Tuberculosis and Malaria.
} 


\section{a) Prevention of HIV transmission through harm reduction}

Harm reduction initiatives involving Methadone Maintenance Therapy (MMT) and needle and syringe exchange program (NSEP) have been part of the Malaysian response for several years. Together, these programmes aimed at reaching out to $102,000(60 \%)$ persons out of estimated population of 170,000 IDUs by 2015. Provision of harm reduction services continues and up-scaled through 297 NSEP sites and 674 MMT outlets established in government health facilities, NGO sites, private health facilities, National Anti-Drug Agency (NADA) service outlets and prisons.

Initiated in February 2006 and now entering its sixth year of operation, the NSEP is mainly provided by the NGO (74\%) and government health clinics (26\%). The numbers of NSEP outreach points run by NGO are 221 while NSEP sites in government clinics are 76. As of 2011, this programme has reached out to 34,244 IDU with average distribution of needle and syringe about 116 per IDU in a year. However, in the past two (2) years, the proportion of clients being referred to VCT and MMT were low which was average of $10 \%$ for VCT and only $4 \%$ had changed to oral substitution therapy (MMT). This programme need to be further improved for better outcome which is reducing the harm further through shifting from injecting drug to OST.

The government has fully adopted OST programme after the successful pilot project in 2006. As of 2011, this programme currently provided by government hospitals and clinics (218), private healthcare practitioners $(406)^{36}$ and has been extended to the National Anti-Drug Agency (NADA) service centres (32), and prisons (18); altogether making up 674 MMT centres throughout the country. This programme has reached out to 44,428 drug users nationwide. Through harm reduction services, a total of 78,872 drug users were reached out. Data from programme surveillance in Drug Rehabilitation Centres and Harm Reduction services in 2011 revealed HIV prevalence among IDU was $8.7 \%{ }^{37}$.

\section{b) Prevention of HIV transmission through sexual contact}

In addressing sexual transmission of HIV, coverage of interventions has improved through:

- promoting positive prevention;

- promoting behavioural change communication among MARPs and vulnerable populations;

- provision of sexual reproductive health (SRH) education and other essential SRH services;

- implementation of programmes for prevention of HIV to partners;

${ }^{36}$ The NDST Report 2011. Addiction Medicine Association of Malaysia 2011.

${ }^{37}$ Global AIDS Reporting 2012. 
- encouraging HIV testing through voluntary testing and counselling;

- promoting awareness of HIV and STIs through information, education and communication;

- peer-lead intervention.

Available data found that there is no improvement on condom use with last client among sex workers from $79 \%$ in $2004^{38}$ to $60.9 \%{ }^{39}$ in 2009 . Pattern of condom use among MSM was not encouraging $(38 \%)^{40}$. In view of the finding, the number of projects for sex workers has been escalated from seven in 2010 to 21 in 2011. This has resulted in $81 \%$ increase in the number of sex workers reached from 2,889 in 2010 to 5,243 in 2011. In 2011, about 1,698 MSM were reached by the HIV intervention programme through NGOs.

Survey in selected government health facilities and clinics run by NGO in 2011 revealed the HIV prevalence among sex workers and MSM at $0.3 \%$ and $1.4 \%$ respectively ${ }^{41}$. There are still room for improvement with regard to promoting behaviour change among sex worker and MSM.

\section{c) Prevention of mother to child transmission (PMTCT)}

The PMTCT programme involving antenatal mothers has been implemented since 1998. The government is committed to eliminate vertical transmission by 2015 through provision of quality, comprehensive national PMTCT services, in line with the WHO recommended four pronged strategies, to reach pregnant women, their partners and their infants, including most at risk populations. The existing PMTCT programme is currently available in government healthcare facilities that cover approximately $75 \%$ of total antenatal mothers nationwide. However, antenatal HIV cases from the private sector are also referred to the government medical system. Apart from maintaining existing services, the government also strive to increase the enrolment in PMTCT programme through involvement of private health facilities.

In 2011 , about 443,453 which is about $89 \%$ of estimated pregnant women $(500,000)$ had undergone PMTCT program at 1,060 government health facilities (figure 10). The HIV testing is being done during pregnancy, during labour and delivery, and during the post-partum period ( $<72$ hours), including those with previously known HIV ${ }^{42}$. With $100 \%$ coverage of pregnant women attending antenatal care in 2011, 309 were with HIV out of which 114 were known cases. The prevalence of HIV among pregnant

\footnotetext{
${ }^{38}$ Summary findings of Behavioral Surveillance Surveys (BSS)2004, Malaysia.

${ }^{39}$ Integrated Bio-Behavioral Surveillance Report.Klang Valley Malaysia, 2009 (unpublished)

${ }^{40}$ PUSH Project 2010. The prevalence of HIV and Syphilis and its associated behavioral risk amongst MSM in the state of Penag, Malaysia.

${ }^{41}$ Global AIDS Reporting 2012

${ }^{42}$ Global AIDS Report 2012.
} 
women in 2011 was $0.07 \%$ (Figure 10$)^{43}$, however the seroprevalence among newly detected HIV among pregnant women was $0.04 \%{ }^{44}$.

A total of 326 pregnant women were given triple ARV in 2011 (including 26 pregnant women detected late in 2010) to prevent mother-to-child transmission. All 228 infants born in 2011 from HIV infected pregnant women were given ARV prophylaxis for PMTCT resulting in 225 mother-to-child transmission infections being averted. In short, with PMTCT intervention, the transmission rate was reduced to as low as $1.3 \%$ compared to $32 \%$ estimated transmission rate had there been no intervention ${ }^{45}$. In effort to include partner or spouse, about 30\% reportedly have accessed to HIV screening through PMTCT programme ${ }^{46}$.

Coverage of PMTCT intervention in government healthcare centres improved from $49.7 \%$ in 1998 to $98.1 \%$ in 2009 to $100 \%$ in 2011 . $\mathrm{MOH}$ also started screening of HIV in labour room to cover the missed-opportunity mothers for HIV screening and in 2011 about 10,105 pregnant women with unknown HIV status were screened. The prevalence of HIV among the missed-opportunity was $0.18 \%$ (18 cases), much higher than those who have been screened during antenatal period $(0.07 \%)$. As a result of this programme, $99 \%$ of children born to HIV positive mothers are born uninfected. To achieve elimination of vertical transmission (eMTCT), this programme will be scaled up to involve private practioners.

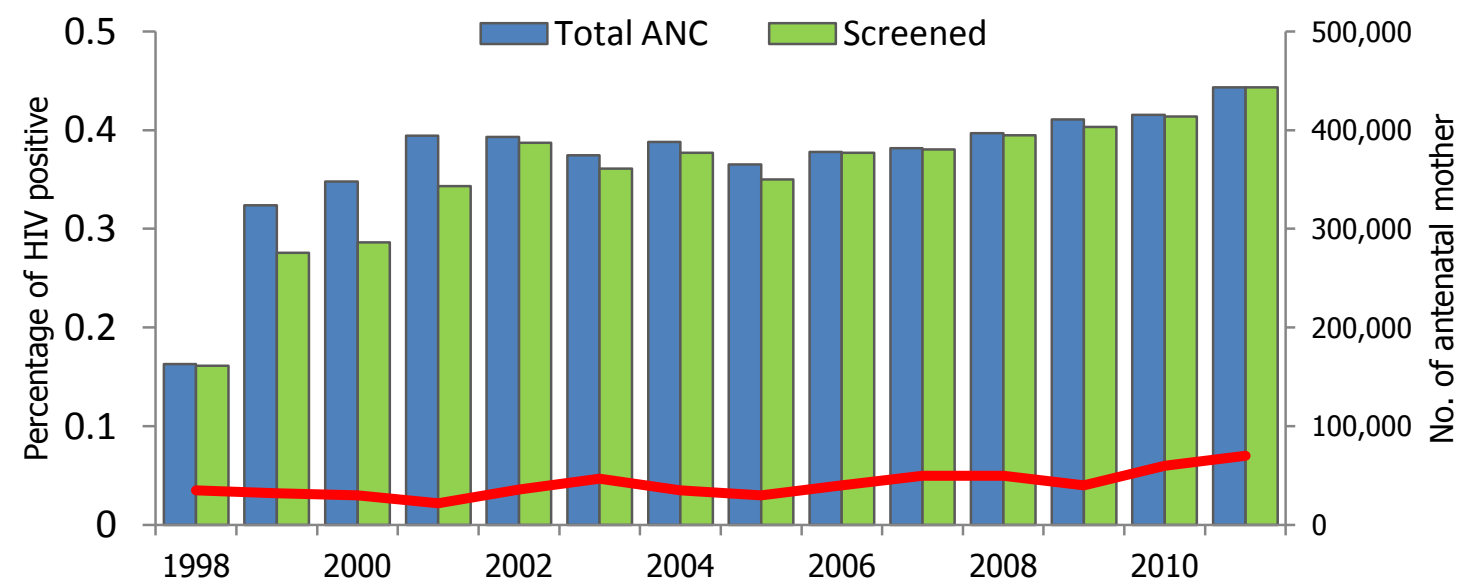

\footnotetext{
${ }^{43}$ Antenatal M\&E report, MOH 2011

44 Global AIDS Report 2012

${ }^{45}$ Global AIDS Report 2012

${ }^{46}$ Global AIDS Report 2012
} 


\section{d) Prevention of HIV among vulnerable populations}

Apart from main most-at-risk populations identified (IDU, sex workers and MSM) in this country, there are populations that are at higher risk of becoming infected or affected by HIV, who play a key role in how HIV spreads, and whose involvement is vital for an effective and sustainable response to HIV. Vulnerable populations involve groups that enjoy lesser legal, social or policy protection, which limit their ability to access or use HIV prevention services. Young women and men aged 15-24 years are regarded vulnerable than others to come to harm. Others vulnerable include women and children, migrants, or other groups that are vulnerable to abuse, discrimination and even hatred.

First described in the 2008 report and later in the joint Ministry of Health - UNICEF document titled Women and Girls Confronting HIV and AIDS in Malaysia, the increase in proportion of female HIV cases in Malaysia has become an issue of utmost concern and a priority for the Government. It recognised that sexual transmission of HIV is a major factor in the increasing proportion of women and girls. Thus, specific intervention focusing on women's vulnerability need to be addressed enabling them to protect themselves, particularly from the sexual transmission of HIV. To achieve this, a Taskforce on Women, Girls and HIV/AIDS was set up in 2009 and chaired by the Ministry of Women, Family and Community Development (MWFCD). The Taskforce is tasked to guide the actions of the Government in its response to addressing the behavioural and socioeconomic factors behind the sexual transmission of $\mathrm{HIV}^{47}$. It is also tasked to bring together actors beyond the health and medical sphere and include bodies such as the Social Welfare Department, National Population, Family Development Board (NPFDB), Department of Islamic Development, Ministry of Information and other bodies which address issues such as teenage pregnancies, sexual violence and gender inequality. In 2011, this task force has implemented at least five (5) awareness programmes aiming at empowering women and at least nine (9) awareness programmes targeting on young children and youths throughout the country. With regards to awareness on preventing sexual transmission of HIV and reject major misconceptions about HIV transmission, the level has increased from $22.6 \%$ in 2008 to $28.5 \%$ in $2011^{48}$.

Domestic violence and sexual abuse are important correlates of HIV risk in women ${ }^{49}$. An average of about 3200 domestic violence has been reported in Malaysia ${ }^{50}$. However, association between the violence and HIV need to be further explored.

\footnotetext{
${ }^{47}$ Ministry of Women, Family and Community Development (2009). Terms of Reference for the Taskforce on Women, Girls and HIV.

${ }^{48}$ HIV related knowledge among young women and men in Malaysia 2011 - a nationwide survey (unpublished)

${ }^{49}$ B. Lichtenstein. Domestic violence, sexual ownership and HIV risk in women in the American deep south.

(www.bigbendcares.org/images/pdfs/deepsouth.pdf)

50 Fight over domestic violence in Malaysia. www.venusbuzz.com/archieves/3589/fights-over-domestic-violence-in-malaysia/
} 


\subsection{Improving the quality and coverage of testing and treatment}

The Government continues to support testing services that include community-based, primary health care and hospital-based care. It provides psychosocial support including voluntary, counselling and testing (VCT), nutritional support and treatment for common opportunistic infections. Malaysia already provides and is committed to affordable access to clinical care through the public health system, including free or subsidized access to ART. People Living with HIV (PLHIV) in closed settings and those living outside the major cities are of particularly concern and are the focus of coverage under existing programmes. This is in addition to the services already possible for drug rehabilitation centre internees and prisoners who are living with HIV and are able to have access to HIV related treatment inclusive of CD4 follow-up and monitoring of ART.

In effort to build capacity both in provision of screening and treatment, the government has taken bold step in acknowledging HIV counselling as one of many post-basic courses offered for allied health since 2009. HIV screening is currently made available in all government health facilities at no cost through VCT or anonymous HIV screening, premarital screening, screening for TB/STI patients, contacts of PLHIV and inmates of Drug Rehabilitation Centres and prisons. In 2011 about 1,394,852 screening have been conducted and $0.17 \%$ were found to be with HIV.

The Government's achievements in the area of HIV treatment have been particularly impressive. Health services in the hospital and primary healthcare systems are of high standard, especially those relating to clinical management of HIV. Strong measures are in place to ensure blood supply safety whereupon testing of blood products is consistently conducted. This commitment would take on the form of improving the availability of treatment and lowering the actual cost of treatment. It also aimed to obtain the widest range of ARV drugs at the best possible cost to the Government.

Two significant achievements have been accomplished, firstly, the availability and provision of first line ARV treatment at no cost for those who need it and secondly, the availability of ARV treatment for incarcerated populations specifically for $\mathrm{HIV}+$ prisoners as well as inmates in drug rehabilitation centres. Currently, the second line regime is also heavily subsidised by the government. These up-scaling efforts have resulted in 14,002 PLHIV on ARV by end 2011 which is about $37.5 \%$ from estimated number that need $A R T^{51}$. Among those started on ART, $82 \%$ are still alive and known to be on treatment 24 months after initiation. There is indeed a need for better treatment education for PLHIV who are just initiating or currently on treatment. This is to assist in addressing the issue of adherence which is a consistent problem with PLHIV who do not understand the need to adhere to

\footnotetext{
${ }^{51}$ Global AIDS Response Report 2012
} 
treatment protocol. To overcome issue of ARV literacy, hospital peer support services are of great advantage.

\subsection{Increasing the access and availability of care, support and social impact mitigation programmes for People Living with HIV and those affected.}

It is important to note that the majority of the Government's achievements have been from the treatment perspective. Formidable gaps remain with regards to the delivery of care and support, which has been effectively delegated to the NGOs.

Since a couple years ago, there has been better collaboration from religious bodies and other relevant government agencies, especially related to welfare, on the issue of care and support for PLHIV. In 2009, the Department of Islamic Development indicated its commitment to building a shelter home for homeless Muslims living with HIV by 2010 . Department of Islamic Affairs Wilayah Persekutuan (JAWI) and more than half of State Islamic Religious Councils in Malaysia have also expressed its support for the establishment of hospices for religious outreach and to provide food ${ }^{52}$. Other faith-based organizations such as Malaysian Care, Catholic Welfare Services and Buddhist Tzu Chi have complimenting in care and support.

The MWFCD began funding 7 shelters for women and children infected and affected by HIV in 2008. This initial number of shelter homes was expanded to 16 in $2011^{53}$. The Department of Social Welfare has also begun extending financial assistance to PLHIV to facilitate the start of income generating activities (e.g. starting a taxi business) ${ }^{54}$.

To overcome issue on ARV adherence it is of great advantage to have hospital peer support services in government hospitals and health centres to assist in the delivery of care and support services. In the latter case, patients who attend the treatment at the hospital are then referred to NGO for follow-up support and services including treatment education and psychosocial support. Since year 2005, several NGOs which was funded by the government and other agencies has initiated hospital peer support programme involving PLHIV providing support and assistance to others who are with HIV and this number has grown to eight (8) in 2011 which cover 4,584 PLHIV. The work has complemented the ARV treatment provided by the hospital by providing information, peer support as well as assisting in psychosocial support in ensuring adherence to ARV. This kind of support may not necessarily be able to

\footnotetext{
${ }^{52}$ Global AIDS Response Report. Government stakeholder consultation 2012 
be accessed at the hospital due to the lack time and high patient load faced by the medical staff.

In 2011, corporate organizations namely Johnson \& Johnson, L'Oreal, World Vision and M.A.C Cosmetics have actively provided financial assistance towards care, support and awareness programmes among the vulnerable groups. This support are considered as a CSR initiatives of the organization and also as an approach to build a sustainable business whereby the needs of the community is closely aligned with their business.

\subsection{Maintaining and improving an enabling environment for HIV prevention, treatment, care and support.}

Prevention and treatment programmes are more effective when operating in an enabling environment which does not stigmatise and discriminate against those most at risk and those affected. Creating and maintaining a better understanding of HIV to reduce risk taking as well as stigma and discrimination are therefore essential. It is important to establish and maintain an enabling public policy and structural environment which will help to reduce HIV stigma and discrimination, respects human dignity, gender and sexuality and is supportive to HIV programmes and interventions.

Several approaches had been outlined in materializing this strategy:

a) Ensure HIV issues are mainstreamed into national social development plans and the necessary financial and technical resources are mobilised to support development and implementation of HIV and AIDS plans and programmes.

b) Strengthen capacity of key ministries and other government and civil society stakeholders at the national and local levels to develop and implement targeted evidence-based interventions.

c) Engage law enforcement, healthcare service providers, relevant public officials and civil society stakeholders, to assess and mitigate complications to the national HIV response.

d) Improve the representation, involvement and capacity of civil society, community based organizations and affected population networks in dialogue and decisionmaking, towards achieving Universal Access and strengthening the national response.

e) Strengthen the work of the private sector among local businesses to promote corporate social responsibility and to establish workplace-based HIV prevention programmes and to address stigma and discrimination in the private sector.

f) Intensify public understanding and awareness of HIV and AIDS through focused communications and integration into community-based HIV education messages. 


\subsection{Increasing the availability and quality of strategic information and its use by policy makers and programme planners through monitoring, evaluation and research.}

There is a continuous need to improve upon the availability of research, surveillance and bio-behavioural data, and analysis of monitoring and evaluation of HIV programmes to guide and determine policy and programme frameworks for prevention, treatment, care and support. In line with the Three Ones Principle, implementation of the National Strategic Plan is monitored and evaluated through the national HIV monitoring and evaluation framework, coordinated by the National AIDS Programme Secretariat that has been given the responsibility to monitor and evaluate the overall HIV/AIDS framework. Besides, the NAP Secretariat is also empowered to ensure that all relevant stakeholders report to the Secretariat on specific indicators as necessary and expected results and targets are monitored and evaluated periodically.

National HIV Surveillance which was started in 1986 is among important data that assist the country in evaluation of programmes and the epidemic. The responsibility of HIV surveillance is with the HIV/STI Sector of the Ministry of Health. A number of surveillance related activities that have been established include HIV sentinel surveillance, National AIDS Registry, Integrated Biological and Behavioural Surveillance (IBBS) and other strategic information. This information, together with data from other key stakeholders and civil societies assisted very much in estimation and projection of the country's epidemic. Other strategic information currently being developed with assistance from the universities, institutions and international agencies includes the ARV resistance surveillance, estimation of MARPs, PLHIVs, etc.

2010 to 2011 have seen positive progress especially within the Ministry of Health where an M\&E unit and Technical and Behavioural Research unit have been established to strengthen the availability and ensure quality strategic information. Since 2008, the Malaysian AIDS Council has been developing an online monitoring system and database that is providing increasingly valid and reliable data that feeds into increasingly critical program analysis. Other partners involved in the implementation of the National Strategic Plan continue to operate their own systems for programme monitoring and evaluation. 


\section{BEST PRACTICES}

\section{a) Scaling up Harm Reduction Programme}

Harm Reduction programme remains at the heart of the national response to drugs and HIV/AIDS. Implemented in partnership with community based organizations (CBOs) and private health practitioners, the programme is almost entirely funded by the Malaysian government, though some technical assistance has been systematically provided by WHO.

The inception of harm reduction programme, specifically opiate substitution therapy (OST) and needle and syringe programme (NSEP) are major contributors to the decreasing trend of HIV/AIDS in the country. As of December 2011, a cumulative number of about 44,500 IDUs were registered in the Opiate Substitution Therapy (OST) programme at 674 OST facilities throughout the country (48 hospitals, 168 government clinics, 32 facilities under National Anti-Drug Agency, 18 prisons, 406 general practitioners and each at Ar-Rahman Mosque and University Malaya Center of Addiction Science). Whereas for NSEP, there were 34,244 cumulative numbers of IDUs enrolled in the programme at 303 centers (23 sites, 203 outreach points and 76 government clinics).

The integration of harm reduction has been widely accepted as an important landmark in the government's change of attitude towards drug use in Malaysia. Indeed, the paradigm shift from a repressive approach to drugs relying on punishment and law enforcement action, to an approach that now fully integrates and accepts public health imperatives implemented in collaboration with health professionals and law enforcement officers has been documented and recognized as an important success for the country and the Region as a whole.

Another paradigm shift is currently taking place under the extraordinary leadership of key individuals and agencies. The Malaysian government has moved from a repressive approach to an approach integrating health imperatives a few years ago. Key agencies are again shifting programmatic objectives from compulsory abstinence to voluntary treatment options.

In the continuing effort to curb HIV / AIDS among IDUs, the country is committed to expand harm reduction program, targeting all health clinics will provide harm reduction services by the end of 2015 and at the same time provide technical expertise to National Anti-Drug Agency in the treatment and rehabilitation of drug users. 


\section{b) Moving from Prevention of Mother-to-Child Transmission (PMTCT) to Prevention of Parent-to-Child Transmission (PPTCT)- Pilot project in State of Kedah, Malaysia}

Of late it has been noted that the ratio of HIV infection acquired via sexual transmission has increased compared to that of sharing needles among the injecting drug users. This concern has mooted the initiative to expand HIV screening to the husbands of antenatal mothers receiving care at the public health facilities. The screening was done on a voluntary basis and a written consent was obtained prior to the screening. This platform benefits both the health care providers as well as the couples who undergo HIV testing. The heath care providers were able to identify the presence of risk factors associated with HIV infection; hence allowing them to plan and manage their clients accordingly. The couples on the other hand will be informed of their status and counseled - to maintain a healthy life style if they are infection free or advised to practice preventive measures to help contain the disease from spreading.

Of the total 33,194 antenatal attendees, 10,306 husbands (31\%) consented for the HIV screening. Of these, 2 discordant couples were detected and confirmed. Although the number is small, but detection of discordant couples emphasizes the need to promote parental awareness (and not merely focusing on the antenatal mother alone) when addressing the issue of vertical transmission.

\section{c) Institutionalised involvement of the Islamic religious welfare system}

Building on the successes of the "Islam and HIV/AIDS" project first initiated between 2001 to mid-2005 which was first reported in the 2008 report, Muslim religious leaders have since not only been actively involved in not only the implementation of HIV awareness programmes but also proactively established care and support facilities from financial and welfare assistance to shelters for Muslim PLHIV. This project, developed by the AIDS/STD Section of the Ministry of Health in partnership with the Malaysian AIDS Council and the United Nations Development Programme (UNDP), involved key stakeholders from the Islamic institutions as well as community leaders such as Imams at the grassroots level. The institutions engaged included the Department of Islamic Development (JAKIM) at the Federal level and State Religious Departments at the State level. Though the project itself ended in 2005, the resulting HIV module has since been institutionalised into the formal training of new Muslim leaders ${ }^{55}$.This module has since been translated into English language in 2011 in hope to educate and create awareness to all Muslim religious leaders around the globe. JAKIM in particular has been an active partner in creating awareness of HIV issues among the Muslim public in the country.

\footnotetext{
${ }^{55}$ Department of Islamic Development (2009). UNGASS Government Stakeholder Discussions, 23 December 2009.
} 
The past 5 years have seen encouraging development of programmes which involve a number of religious departments engaging most-at-risk populations such as female sex workers and transgender persons. The Islamic Religious Department for the Federal Territory (JAWI) in partnership with PT Foundation has made available religious classes for sex workers and others who are interested ${ }^{56}$. This outreach approach by the religious department has been much appreciated by the community as they are often bereft of their spiritual and religious needs as a result of discrimination and marginalisation in more conventional places such as mosques.

JAKIM has also now made it practice for the Friday sermon closest to World AIDS Day to be about HIV addressing related issues such as stigma and discrimination, and prevention. Friday sermons, which involve a large audience of men and are delivered by persons considered to be community or religious leaders, are used to communicate key HIV prevention and awareness messages.

Following the development of "Islam and HIV/AIDS" manual, in the past two years, many positive developments have since follow suit, among others are development of "Training of Trainers for Islam and HIV/AIDS", shelter home (Ilaj Home) for Muslim PLHIV, Muslim volunteers Team, "Training of Trainers for Muslim Volunteers" manual, "Muslim Volunteers" manual, "Islam and Transgendered person" manual, and many others.

Apart from development of manuals and training conducted in the past two years, JAKIM has been active in engaging transgender person (Mak Nyah) in their programme "Mukhayyam with Mak Nyah" in effort to create awareness about Islam and HIV and offer job placement. Positive outcome could be seen through the changes in physical appearance and increased in spiritual awareness among some of them.

\section{d) National AIDS Registry (NAR)}

By law, Prevention and Control of Infectious Diseases Act 1988 or Act 342), HIV/AIDS is one of the infectious diseases that need to be reported to the nearest Health Office. Since 2001 all notifiable infectious diseases need to be input into the E-notification System or e-Notis (online notification). However, the HIV/AIDS registry was not included in the system; instead it was carried out as a standalone registry in each respective state in Malaysia. The state then send aggregated data to the national level for monitoring and planning purposes.

It has been noted that a person who contracted the disease, the HIV viruses will remain in their body throughout their lives. Thus, cases of HIV/AIDS may be reported more than once in different states as cases especially IDU are highly mobile resulting in inaccuracy of

${ }^{56}$ PT Foundation (2009). UNGASS NGO Stakeholder Discussions, 22 December 2009 
aggregated data. Hence to overcome duplication of notifications, a national online registry (National AIDS Registry or NAR) of HIV/AIDS cases was proposed in the NSP $2006-2010$. The project was finally materialized in 2010.

An agreed rule was a person with HIV may be notified into the system for three times only i.e. on the time of diagnosis, when he develops AIDS and when he died. Hence by June 2010, all the HIV, AIDS and AIDS-related deaths must be verified, validated by Assistant Environmental Health Officer in the respective Health Districts, registered into the e-Notis and finally migrated into NAR. The cases were further validated by the national level to ensure its quality and reliability. With the new implemented NAR, it is with confidence that HIV/AIDS cases reported in Malaysia is true, reliable and gives a comprehensive trends and burden of the said disease in Malaysia.

\section{e) Elimination of Mother to Child HIV Transmission (eMTCT)}

In 2009, UNAIDS and WHO called for the elimination of mother to child transmission (eMTCT) of HIV. Earlier, in 2007, WHO had launched an initiative for the global elimination of congenital syphilis (CS). The goal of eliminating new HIV infections among children by 2015 is a key component of the UNAIDS Strategy 2011-2015 and was endorsed by all UN Member States in the June 2011 UN General Assembly Political Declaration on HIV/AIDS. Eliminating mother to child transmission of HIV and syphilis directly contributes towards the attainment of Millennium Development Goals 4 (reduce child mortality), 5 (improve maternal health), and 6 (reduce the spread of HIV).

Moving towards eliminating MTCT of HIV and/or syphilis, Malaysia has established high quality PMTCT and CS programmes. A comprehensive approach to the elimination of new HIV infections among children consists of four prongs:

i. Preventing HIV among women of reproductive age;

ii. Providing appropriate counseling and support and contraceptives, to women living with HIV;

iii. For pregnant women living with HIV, ensuring HIV testing and counseling and access to the antiretroviral drugs needed to prevent HIV infection from being passed on to their babies during pregnancy, delivery and breastfeeding;

iv. Providing HIV care, treatment and support for women, children living with HIV and their families.

Malaysia is has strong commitment from its political leaders when it comes to HIV, STI and health issues. The country has more than 350 hospitals and over 7,200 health clinics 
including private ${ }^{57}$. PMTCT was piloted in 1997 and adopted as a national programme in 1998. Guidelines were revised in 2009 with rapid tests, HAART, PCR tests for babies and tracing of spouses and partners now part of the package of interventions. Infant feeding guidelines were also revised. VDRL coverage is at nearly 100 per cent, and HIV screening of pregnant women is at $98-100 \%$ in public health facilities and more than $50 \%$ of private health facilities provide HIV antenatal screening ${ }^{58}$. In 2011 , more than $90 \%{ }^{59}$ of all antenatal mothers were screened for HIV and the prevalence rate was $0.07 \%{ }^{60}$.

The Government is committed to providing ARV therapy to all those who need it, by making it affordable and accessible to all. We have taken courageous steps to make cheaper antiretroviral drugs available in the country. Indeed, since May 2006, Malaysia has been successfully manufacturing its own combination of 3-in-1 ARV drugs. Currently, ARV drugs are given free to those who need such treatment in our government hospitals and health clinics. In 2011 , less than $1 \%$ of children born to women living with HIV acquire HIV, which demonstrates that the goal of eliminating mother-to-child transmission is feasible ${ }^{61}$. In line with 'Getting to Zero' and as reported by UNAIDS 2011, "Malaysia has already moved significantly towards the 2015 goal with coverage rates exceeding 90\%".

\footnotetext{
${ }^{57}$ Health Facts 2010. Ministry of Health Malaysia

${ }^{58}$ BN Sha'ari, Director General of Health's Technical Report 2010. Ministry of Health Malaysia

${ }^{59}$ EPP 2011

${ }^{60}$ M\&E Surveillance Data, Ministry of Health Malaysia

${ }^{61}$ M\&E Surveillance Data, Ministry of Health Malaysia
} 


\section{MAJOR AND KEY CHALLENGES}

\section{(a) Reducing the HIV sexual transmission}

As discussed earlier, there are clear indications that sexual transmission is becoming a major factor in the future of the country's epidemic. Compared to earlier epidemic where infection through the IDU route was about two thirds of all new reported HIV cases, more than half of all new infections now were attributed to sexual route, namely unprotected sexual intercourse by heterosexuals, MSM and transgender. The proportion is increasing each year. This dynamic continues to represent a major challenge in future responses to the epidemic and have been the focus of the upcoming National Strategy on HIV and AIDS.

The rise in proportion of sexual transmission would require a further strengthening of commitment from the Government to undertake and improve upon programmes which specifically address the issue of sexual reproductive health, especially among young people. Policy-makers need to be better informed about the importance of adolescent health and sexual reproductive health, particularly within the context of HIV. They should also understand the serious consequences if this important issue is not addressed adequately.

What is of utmost concern is unacceptable level of HIV-related knowledge among young people; and where knowledge is high, it was not being practiced. Sexual Reproductive Health education must not only ensure that awareness and knowledge is imparted but also accompanied by life skills. There needs to be clear, coherent policies and direction concerning sexual reproductive health that includes promotion of gender and rights. As issues relating to sexuality and young people are often contentious and linked to public morality, more must be done to further consult and engage religious leaders and other community leaders.

\section{(b) Sustainability of human, financial and infrastructure resources}

Majority of prevention programs were heavily funded by the government. It has been a major concern of NSP 2011-2015 to maintain and sustain high levels of funding especially with increase in ARV treatment coverage. The revision of treatment protocol that resulted in earlier ARV initiation at CD4 350 instead of 250 has inevitably led to increase in estimated number of persons eligible for treatment. Thus, the financial cost to sustain the programme will double fold annually. The $\mathrm{MOH}$ is committed to support NGO programmes as long as effective activities are carried out. However, it was felt that the provision of all funding for 
the national AIDS programme being solely dependent on the Government is not sustainable. As such, it is recommended that NGOs be able to raise funds from other sources.

\section{(c) Stigma and discrimination}

Stigma and discrimination continues to be a challenge. It is not only affect the lives of PLHIV and those around them, but also present themselves as obstacles to the progress and implementation of HIV prevention, treatment, care and support programmes. Perceived or actual occurrence of stigma and discrimination among health care workers and communities remains an issue, however there has been much improvement compared to two decades ago. Certain hospitals have staffs who are more friendly, supportive and less judgmental. Thus, PLHIV who require treatment tend to favour these hospitals and healthcare facilities while other service locations are not utilized though they may be closer to the patients' home. Much need to be done by the NGO and faith-based organizations specifically to lessen self-stigma among MARPS as this hinder utilization of public health services. Support groups placed in health clinics or hospitals and also strong networking between health provider and NGO/CBO could facilitate in minimizing and eliminate stigma and discrimination among MARPS as well as among health care providers. 


\section{SUPPORT FROM THE COUNTRY'S DEVELOPMENT PARTNERS}

Over the years, Malaysia has received many types of support, including financial and technical assistance, from a number of development partners as part of the response to the HIV epidemic in the country. In the past, both bilateral and multilateral agencies have been major partners in prevention efforts, the strengthening of care, support and treatment mechanisms as well as working towards the creation and sustaining of an enabling environment.

The United Nations in Malaysia currently constitute the largest development partner and which provides support to national country partners bilaterally as well as jointly through the United Nations Theme Group on HIV (UNTG).Activities under the 2011 Workplan were implemented utilising funding from the Resident Coordinator mechanism, UNDP, UNU-IIGH and UNAIDS. UNAIDS provided the bulk of the funding for UNTG under its $2010-2011$ biennium workplan for the Asia Pacific region.

The UNTG in Malaysia ensures that coordination mechanisms are working effectively provides overall policy and programmatic guidance as well as reviews and provides recommendations to the UN Country Team's strategic directions on HIV and AIDS.The UNTG currently comprises representatives from the World Health Organization (WHO), the United Nations Development Programme (UNDP), the United Nations Population Fund (UNFPA), the United Nations Children's Fund (UNICEF), the United Nations High Commissioner for Refugees (UNHCR), and the United Nations University - Institute for International Global Health (UNU - IIGH). The WHO Representative is the Chair of the UNTG on HIV and AIDS in Malaysia for the 2010 - 2012.

Five core support strategies under the 2009-2010 Strategic Framework for United Nations Theme Group on HIV were identified to ensure a coherent and effective UN action in support of an expanded national response to HIV. The framework, which was extended to include 2011, also provides coordinated support of the Government of Malaysia and civil society partners in the implementation of the National Strategic Plan on HIV/AIDS 2006 2010 and its successor, the National Strategy on HIV and AIDS 2011 - 2015. All 2011 activities were developed based on these supporting strategies. These strategies are:

i. Strengthening leadership and advocacy for effective action on the epidemic

ii. Promoting and ensuring civil society engagement and partnership development

iii. Strengthening the availability of strategic information required to guide efforts of partners

iv. Promoting and building capacity in tracking, monitoring and evaluation of responses to the epidemic. 
v. Providing support in the mobilisation of financial, technical and political resources

Activities under the 2011 Workplan were implemented utilising funding from the Resident Coordinator mechanism which amounted to USD 3 000. Significant funding was obtained from the UNAIDS Regional Support Team (Asia and Pacific) to support the activities of the UNTG in 2011. This support, over the 2010-2011 period, amounted to USD 164 747. UNDP provided an allocation of USD 22500 for the finalisation of the National Strategy on HIV and AIDS 2011 - 2015. UNU-IIGH also provided USD 5000 for support of activities under the workplan. The UNTG's activities, implemented under the 2011 workplan and the Strategic Framework, resulted in some progress and achievements which included:

\section{a) Strengthening leadership and advocacy for effective action on the epidemic}

As part of the UNTG's support to the government in the continued finalisation of the National Strategy on HIV and AIDS 2011 - 2015 (NSP) as well as its implementation, technical support was provided throughout the first half of 2011 to assist the Government and civil society stakeholders. This technical support included the coordination of briefing workshops, coordination meetings with government and civil society organisations as well as participation in the evaluation and assessment of NGO projects.

The end of the 2006 - 2010 NSP prompted collaboration with government and nongovernment partners on the development of the National Strategy on HIV and AIDS for 2011 - 2015 in 2010. UNDP, as part of the UNTG committed funding to support this initiative in 2010 which involved development of the strategic framework and accompanying costed action plan. It includes a monitoring and evaluation mechanism to measure progress in implementation of the strategy. The bulk of the work took place in 2010 and involved finalisation work which took place in 2011.

In March 2011, a round table discussion on migrant workers and access to HIV related healthcare was held which involved participation by government and civil society representatives from Malaysia and Indonesia. The objectives of the meeting were to discuss access of migrant workers to HIV and TB related healthcare services; and to obtain an update on progress towards realising the commitments under the ASEAN Declaration on the Protection and Promotion of the Rights of Migrant Workers and the ASEAN Declaration on HIV and AIDS.

The International Seminar on Socio-economic and Mental Health Burden of HIV/AIDS in Developing Countries was organized in November 2011 with the participation and 
involvement of over 70 government and non-government stakeholders. It provided a platform to discuss current developments in the response to HIV in Malaysia. The UNTG provided technical assistance and conference scholarships for a number of government and NGO participants to attend.

Via coordination of the UNTG and utilising the support of the regional UNAIDS and UNDP mechanisms, a large number of government and civil society participants from Malaysia were able to attend and participate in regional meetings, workshops and conferences organized as part of capacity building, advocacy as well as consultations. These meetings included:

- Asia Pacific Regional Dialogue of the Global Commission on HIV and the Law, Bangkok, Thailand (16 - 17 February 2011)

- Asia Pacific Regional Consultation on Universal Access to Prevention, Treatment, Care and Support, Bangkok, Thailand (30 - 31 March 2011)

- Regional Training on Strategic Information on HIV among Men Having Sex with Men (MSM) and Transgender (TG) People, Manilla, Philippines (23 May - 1 June 2011).

- United Nations General Assembly High Level Meeting on AIDS, New York, USA (8 10 June 2011

- 10th International Congress on AIDS in Asia \& the Pacific, Busan, South Korea (26 30 August 2011)

- 2nd Malaysian National AIDS Conference, Penang, Malaysia (3 - 5 October 2011)

- 4th Indonesian National AIDS Conference, Yogyakarta, Indonesia (3 - 6 Oct. 2011)

The UN Cares programme continued in Malaysia. As part of enabling and empowering UN staff to respond to HIV within their professional and private lives, a number of briefing sessions with UN staff from all agencies and a photo exhibition were conducted.

\section{b) Promoting and ensuring civil society engagement and partnership development}

As part of strengthening civil society leadership, commitment and accountability towards realisation of Universal Access, the UNTG was able to provide funding as well as technical support towards the observance of International AIDS Memorial Day and World AIDS Day in 2011. This support was channelled to the activities of specific CSOs which included PT Foundation and the Malaysian AIDS Council. 


\section{c) Strengthening the availability of strategic information required to guide efforts of partners}

One of the challenges identified in the Strategic Framework was the changing trends of the HIV epidemic in Malaysia. A multi-ministerial taskforce on Women, Girls and HIV/AIDS was formed by the Government in an effort to ascertain the necessary responses needed to address this issue. The UNTG continues to participate in the implementation of the Taskforce's work. As part of strengthening the availability of strategic information and improving the response to emerging populations at risk, three grants under the UNAIDS Programme Acceleration Fund were concluded in 2011. They were:

Assessment of Risks and Vulnerabilities associated with Transactional Sex amongst Refugees in Kuala Lumpur (UNHCR with Malaysian AIDS Council)

HIV and AIDS Awareness Programme for Migrants within West Malaysia (UNDP with Tenaganita)

Using the PLHIV Stigma Index to Address Stigma and Discrimination and their Causes in Malaysia (UNFPA with MTAAG+ (Positive Malaysian Treatment Access and Advocacy Group)

\section{d) Promoting and building capacity in tracking, monitoring and evaluation of responses to the epidemic.}

Towards the end of 2011, the UNTG began discussions towards the preparation of the Global AIDS Progress Report to be submitted in 2012. As part of this process, a number of preparatory consultations are organised by the Ministry of Health to complete the different components of the report including the National Composite Policy Index questionnaire. The UNTG is closely working with the $\mathrm{MOH}$ and is providing technical assistance in developing the Progress Report, including data validation and narrative report writing. So far the $\mathrm{MOH}$ has taken a leadership role in this matter showing true ownership of the process. The report is to be submitted by the Government in March 2012.

\section{e) Providing support in the mobilisation of financial, technical and political resources}

In 2008, Malaysia became eligible to receive Global Fund grants for HIV and AIDS programmes under the revised Income Level and Cost-Sharing Eligibility Criteria as it is one of the nine countries in the Middle Income Level category identified to have concentrated HIV epidemics. Under the UNTG workplan, assistance would be provided to support Malaysia's involvement in the Global Fund processes, particularly since much of the initiative was driven by civil society organisations.

In 2011, after a successful grant application in Round 10, the UNTG provided technical support in the preparation of the Grant Agreement signing, implementation of the grant by the Principal Recipient and its Sub Recipient, and the running of the Country Coordinating 
Mechanism (CCM). The UNTG is also currently represented on the CCM by the Chair of the UNTG and participates in the decision making processes of this body. Dr Capuano has also been nominated by the CCM as one of the 9 members of the newly established oversight committee. The UNTG also provides continuous technical feedback to the Global Fund Secretariat on issues related to the grant implementation in Malaysia.

\section{Other UNTG support}

The UNTG provided in-country coordination for the visit of Dr. Nafis Sadik, UNSG's Special Envoy on HIV/AIDS for Asia and the Pacific, to Malaysia in 5 - 6 September 2011.

Participation in HIV/AIDS Technical Support Facility organized workshops on capacity building for community leaders and technical consultants.

Assisted in discussions between UNAIDS, UNODC and the National Anti-Drug Agency for the organising of the 2nd Expert Roundtable Meeting on Compulsory Centres for Drug Users in East and Southeast Asia. This meeting is planned to be organised for the first half of 2012 . 


\section{MONITORING AND EVALUATION ENVIRONMENT}

In line with the National Strategic Plan on HIV/AIDS 2006 - 2010 and the latest NSP 2011 2015, the country now has a national Monitoring and Evaluation (M\&E) unit within HIV/STI Sector of Ministry of Health beginning 2010 that look into HIV programme monitoring using variety of instruments and sources as below.

- web-based National AIDS Registry;

- comprehensive antenatal screening;

- Programmatic data from the Malaysian AIDS Council's Partner Organisations and the NSEP Programme via MAC M\&E system;

- Separate M\&E system established for the NSEP;

- Additional surveillance, monitoring and evaluation sources including screening of blood donors, Muslim pre-marital registrants and Drug Rehabilitation Centre patients, prisoners and antenatal mothers.

The analysis and use of M\&E data from the two Harm Reduction programmes (NSEP \& MMT) has enabled for justification and institutional support from the Cabinet Committee on AIDS for the scaling up of these interventions. M\&E data was also utilised to introduce premarital HIV screening to address the issue of heterosexual transmission. It also enabled the Government to justify its stance in promoting such testing. In addition to new development of M\&E unit, the HIV/STI Sector of Ministry of Health has also established a unit that is responsible for all HIV technical and behavioural research including IBBS that has been decided periodically every two years. The next round of IBBS is expected in 2012.

As the main coordinator of NGOs and CBOs responding to HIV, MAC is tasked to monitor the various government grants granted to itself and other organisations working on the different aspects of the national response. In relation to that, as part of M\&E, MAC is given the responsibility to report back on the individual projects utilising the various national progress indicators as part of M\&E. It is also given the responsibility of providing feedback to the Government on issues and concerns affecting its constituents. In 2009, the MAC has since developed an online monitoring system and database that has improve on the data quality for use in critical program analysis. 


\section{ANNEX 1:}

\section{Consultation/preparation process for the Country Progress Report on monitoring the follow-up to the Declaration of Commitment on HIV/AIDS}

1) Which institutions/entities were responsible for filling out the indicator forms?
a) NAC or equivalent
b) NAP
b) Others (please specify)

\begin{tabular}{|l|l|} 
Yes & No \\
\hline Yes & No \\
\hline Yes & No
\end{tabular}

2) With inputs from

Ministries

Education
Health
Labour
Foreign Affairs

Others: Women, Family and Community Development, Defence, Home Affairs, Information, Department of Islamic Development

\begin{tabular}{|c|c|}
\hline Yes & No \\
Yes & No \\
Yes & No \\
\hline Yes & No \\
\hline Yes & No \\
\hline
\end{tabular}

Civil society organisations

People living with HIV

Private sector

United Nations organisations

Bilaterals

International NGOs

3) Was the report discussed in a large forum?

\begin{tabular}{|c|c|}
\hline Yes & No \\
Yes & No \\
\hline Yes & No \\
\hline Yes & No \\
\hline Yes & No \\
\hline Yes & No \\
\hline
\end{tabular}

4) Are the survey results stored centrally?

5) Are data available for public consultation

Yes No

Yes No

Yes No

6) Who is the person responsible for submission of the report and for follow-up if there are questions on the Country Progress Report?

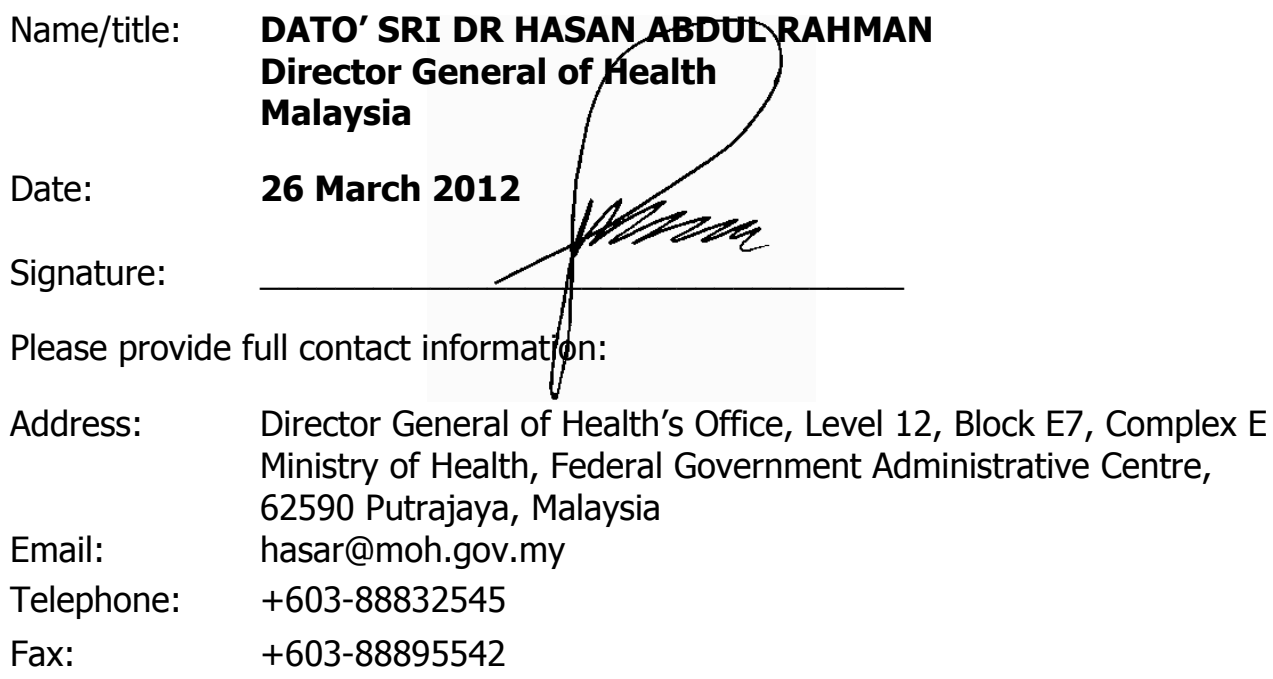




\section{ANNEX 2:}

\section{National Commitments and Policy Instrument (NCPI) 2012}

\section{Country: MALAYSIA}

Name of the National AIDS Committee Officer in charge of NCPI submission and who can be contacted for questions, if any:

Name: $\quad$ Dr. Sha'ari Ngadiman Deputy Director of Disease Control (Communicable Disease) \& Head of HIV/STI Section

Address: $\quad$ HIV/STI Section, Disease Control Division, Level 4, Block E10, Ministry of Health, Complex E, Federal Government Administrative Centre, 62590 Putrajaya, Malaysia

Tel: $\quad$ +60388834387

Fax: $\quad$ +60388834285

Email: $\quad$ drshaari@moh.gov.my

Date of submission: 26 March 2012 


\section{National Commitments and Policy Instrument (NCPI) Data Gathering and Validation Process}

\section{Describe the process used for NCPI data gathering and validation:}

A series of workshops and working sessions were convened with government and civil society stakeholders to obtain data for Parts A and B of the National Composite Policy Index (NCPI) questionnaire as well as for the narrative component of the report.

An orientation and preparatory briefing on the reporting process was organised by the Ministry of Health on 15 December 2011 for both Government and civil society stakeholders to ensure that all partners understood the process and was also able to participate as much as possible in providing input and information to the development of the report.

The first consultative meeting to discuss the NCPI and narrative component of the report was held on 15 February 2012 and was attended by civil society stakeholders who included representatives of various communities of most-at-risk populations, People Living With HIV, advocacy groups, community based organisations as well as a number of various multilateral organisations. The Malaysian AIDS Council (MAC), the lead coordinating HIV non-governmental organisation in the country with NGOs working on HIV and AIDS related issues as its partner organisation, tasked itself to ensuring the coordination of the civil society responses to Part B of the NCPI Questionnaire. As a result of the earlier briefing conducted, Part $B$ was able to be presented to the participants as a draft completed with inputs from the different partner organisations of MAC. It was further improved upon through the deliberations of this workshop.

The discussions which followed also included content for the different parts of the narrative section. The report is coordinated fully by the HIV/STI Section of Ministry of Health. The second consultative meeting involved Government stakeholders from the different Ministries and agencies. These included representatives from the Ministry of Health, Ministry of Women, Family and Community Development, National Anti-Drug Agency, Department of Islamic Development and Royal Malaysian Police, AIDS Officers and District Health Officers. Part A of the NCPI and the narrative content were discussed with HIV/STI Section of the Ministry of Health taking the lead in the deliberations. The questionnaire was completed through joint discussions with all those in attendance.

\section{Describe the process used for resolving disagreements, if any, with respect to the} responses to specific questions:

There were a number of disagreements and disputes on a number of issues. However, as the development of the answers to the questionnaire was done through group work, issues of contention were settled through a deliberative process whereupon both opposing views would be given a certain amount of time for debate and discourse after which a consensus decision was undertaken by the group.

Highlight concerns, if any, related to the final NCPI data submitted (such as data quality, potential misinterpretation of questions and the like):

Participants answering the questionnaire understood and were able to answer the questions to the best of their abilities 


\section{NCPI Respondents}

[Indicate information for all whose responses were compiled to fill out (parts of) the NCPI in the below table; add as many rows as needed]

NCPI-PART A [to be administered to government officials]

(Note - the discussion were conducted through work)

\begin{tabular}{|c|c|c|c|c|c|c|}
\hline \multirow[t]{2}{*}{ Organisation } & \multirow[t]{2}{*}{ Names/ Position } & \multicolumn{5}{|c|}{$\begin{array}{l}\text { Respondents to Part A } \\
\text { [indicate which parts each } \\
\text { respondent was queried on] }\end{array}$} \\
\hline & & A.I & A.II & A.III & A.IV & A.V \\
\hline Ministry of Health & $\begin{array}{l}\text { Dr.Sha'ari Ngadiman } \\
\text { Deputy Director Disease Control \& } \\
\text { Head of HIV/STI Section }\end{array}$ & $\checkmark$ & $\checkmark$ & $\checkmark$ & $\checkmark$ & $\checkmark$ \\
\hline Ministry of Health & $\begin{array}{l}\text { Dr. Anita Suleiman } \\
\text { Senior Principal Assistant Director } \\
\text { (Technical \& Behavioural Research \& } \\
\text { Collaborations) }\end{array}$ & $\checkmark$ & $\checkmark$ & $\checkmark$ & $\checkmark$ & $\checkmark$ \\
\hline Ministry of Health & $\begin{array}{l}\text { Dr.Fazidah Yuswan } \\
\text { Senior Principal Assistant Director } \\
\text { (Harm Reduction) }\end{array}$ & $\checkmark$ & $\checkmark$ & $\checkmark$ & $\checkmark$ & $\checkmark$ \\
\hline Ministry of Health & $\begin{array}{l}\text { Dr.Asiah Ayob } \\
\text { Senior Principal Assistant Director (M\&E) }\end{array}$ & $\checkmark$ & $\checkmark$ & $\checkmark$ & $\checkmark$ & $\checkmark$ \\
\hline Ministry of Health & $\begin{array}{l}\text { Dr. Zakira Taib } \\
\text { Senior Principal Assistant Director Senior } \\
\text { Principal Assistant Director (Prevention) }\end{array}$ & $\checkmark$ & $\checkmark$ & $\checkmark$ & $\checkmark$ & $\checkmark$ \\
\hline Ministry of Health & $\begin{array}{l}\text { Dr. Shanizan Mohd Zain } \\
\text { Senior Principal Assistant Director } \\
\text { (Medical Development Division) }\end{array}$ & $\checkmark$ & $\checkmark$ & $\checkmark$ & $\checkmark$ & $\checkmark$ \\
\hline Ministry of Health & $\begin{array}{l}\text { Dr. Sapiah Baharin } \\
\text { Senior Principal Assistant Director } \\
\text { (Family Health Development Division) }\end{array}$ & $\checkmark$ & $\checkmark$ & $\checkmark$ & $\checkmark$ & $\checkmark$ \\
\hline Ministry of Health & $\begin{array}{l}\text { Dr. Fatanah Ismail } \\
\text { Senior Principal Assistant Director } \\
\text { (Primary Care) }\end{array}$ & $\checkmark$ & $\checkmark$ & $\checkmark$ & $\checkmark$ & $\checkmark$ \\
\hline Ministry of Health & $\begin{array}{l}\text { Dr. Suzana Mohd Hashim } \\
\text { Senior Principal Assistant Director } \\
\text { (Tuberculosis Control) }\end{array}$ & $\checkmark$ & $\checkmark$ & $\checkmark$ & $\checkmark$ & $\checkmark$ \\
\hline Ministry of Health & $\begin{array}{l}\text { Dr. Nik Rubiah Nik Abd. Rashid } \\
\text { Senior Principal Assistant Director } \\
\text { (Family Health Development Division) }\end{array}$ & $\checkmark$ & $\checkmark$ & $\checkmark$ & $\checkmark$ & $\checkmark$ \\
\hline Ministry of Health & $\begin{array}{l}\text { Md. Amidon Awang Damit } \\
\text { Health Education Division }\end{array}$ & $\checkmark$ & $\checkmark$ & $\checkmark$ & $\checkmark$ & $\checkmark$ \\
\hline Selangor Health Dept. & $\begin{array}{l}\text { Dr.Masitah Mohamed } \\
\text { Selangor AIDS Officer }\end{array}$ & $\checkmark$ & $\checkmark$ & $\checkmark$ & $\checkmark$ & $\checkmark$ \\
\hline $\begin{array}{l}\text { WP Kuala Lumpur } \\
\text { Health Dept. }\end{array}$ & $\begin{array}{l}\text { Dr Che Abdullah Hassan } \\
\text { WP Kuala Lumpur AIDS Officer }\end{array}$ & $\checkmark$ & $\checkmark$ & $\checkmark$ & $\checkmark$ & $\checkmark$ \\
\hline Malacca Health Dept & $\begin{array}{l}\text { Dr Norhayati Md Amin } \\
\text { Malacca AIDS Officer }\end{array}$ & $\checkmark$ & $\checkmark$ & $\checkmark$ & $\checkmark$ & $\checkmark$ \\
\hline
\end{tabular}




\begin{tabular}{|c|c|c|c|c|c|c|}
\hline \multirow[t]{2}{*}{ Organisation } & \multirow[t]{2}{*}{ Names/ Position } & \multicolumn{5}{|c|}{$\begin{array}{l}\text { Respondents to Part A } \\
\text { [indicate which parts each } \\
\text { respondent was queried on] }\end{array}$} \\
\hline & & A.I & A.II & A.III & A.IV & A.V \\
\hline Perak Health Dept. & $\begin{array}{l}\text { Dr. Hairul Izwan bin Abdul Rahman } \\
\text { Perak AIDS Officer }\end{array}$ & $\checkmark$ & $\checkmark$ & $\checkmark$ & $\checkmark$ & $\checkmark$ \\
\hline Kedah Health Dept. & $\begin{array}{l}\text { Dr. Zahariyah Yacob } \\
\text { Kedah AIDS Officer }\end{array}$ & $\checkmark$ & $\checkmark$ & $\checkmark$ & $\checkmark$ & $\checkmark$ \\
\hline Penang Health Dept. & $\begin{array}{l}\text { Dr. Janizah Ghani } \\
\text { Penang AIDS Officer }\end{array}$ & $\checkmark$ & $\checkmark$ & $\checkmark$ & $\checkmark$ & $\checkmark$ \\
\hline Pahang Health Dept. & $\begin{array}{l}\text { Dr.Rohaya Abd. Rahman } \\
\text { Pahang AIDS Officer }\end{array}$ & $\checkmark$ & $\checkmark$ & $\checkmark$ & $\checkmark$ & $\checkmark$ \\
\hline Negeri Sembilan Health Dept. & $\begin{array}{l}\text { Dr. Sarina Sidek } \\
\text { Negeri Sembilan AIDS Officer }\end{array}$ & $\checkmark$ & $\checkmark$ & $\checkmark$ & $\checkmark$ & $\checkmark$ \\
\hline Terengganu Health Dept. & $\begin{array}{l}\text { Dr. Mahani Nordin } \\
\text { Terengganu AIDS Officer }\end{array}$ & $\checkmark$ & $\checkmark$ & $\checkmark$ & $\checkmark$ & $\checkmark$ \\
\hline Kelantan Health Dept. & $\begin{array}{l}\text { Dr. Hazura Mat Zubir } \\
\text { Kelantan AIDS Officer }\end{array}$ & $\checkmark$ & $\checkmark$ & $\checkmark$ & $\checkmark$ & $\checkmark$ \\
\hline Sabah Health Dept. & $\begin{array}{l}\text { Dr. Khamisah Awang Lukman } \\
\text { Sabah AIDS Officer }\end{array}$ & $\checkmark$ & $\checkmark$ & $\checkmark$ & $\checkmark$ & $\checkmark$ \\
\hline Sarawak Health Dept. & $\begin{array}{l}\text { Dr. Mohd. Asri Rifin } \\
\text { Sarawak AIDS Officer }\end{array}$ & $\checkmark$ & $\checkmark$ & $\checkmark$ & $\checkmark$ & $\checkmark$ \\
\hline Bentong District Health Office & $\begin{array}{l}\text { Dr. Rosli Ismail } \\
\text { District Medical Officer of Health }\end{array}$ & $\checkmark$ & $\checkmark$ & $\checkmark$ & $\checkmark$ & $\checkmark$ \\
\hline Tampin District Health Office & $\begin{array}{l}\text { Dr. Khalijah Mohd. Yusof } \\
\text { District Medical Officer of Health }\end{array}$ & $\checkmark$ & $\checkmark$ & $\checkmark$ & $\checkmark$ & $\checkmark$ \\
\hline Tampin District Health Office & $\begin{array}{l}\text { Dr. Norsiah Ali } \\
\text { Family Medicine Specialist }\end{array}$ & $\checkmark$ & $\checkmark$ & $\checkmark$ & $\checkmark$ & $\checkmark$ \\
\hline Prisons Department & Mr. Anbalagan s/o Subramaniam & $\checkmark$ & $\checkmark$ & $\checkmark$ & $\checkmark$ & $\checkmark$ \\
\hline $\begin{array}{l}\text { Department of Islamic } \\
\text { Development }\end{array}$ & Marzita Ibrahim & $\checkmark$ & $\checkmark$ & $\checkmark$ & $\checkmark$ & $\checkmark$ \\
\hline National Anti-Drug Agency & Melati Ahmad & $\checkmark$ & $\checkmark$ & $\checkmark$ & $\checkmark$ & $\checkmark$ \\
\hline National Anti-Drug Agency & Wan Norhizan & $\checkmark$ & $\checkmark$ & $\checkmark$ & $\checkmark$ & $\checkmark$ \\
\hline Royal Malaysian Police Dept. & Asp Sam Phan & $\checkmark$ & $\checkmark$ & $\checkmark$ & $\checkmark$ & $\checkmark$ \\
\hline
\end{tabular}


NCPI - Part B [to be administered to civil society organizations, bilateral agencies, and UN organizations]

Note: Discussions were conducted through group work

\begin{tabular}{|l|l|c|c|c|c|}
\hline \multirow{2}{*}{ Organisation } & \multicolumn{1}{c|}{ Names/ Position } & \multicolumn{3}{c|}{ Respondents to Part B } \\
\hline & \multicolumn{1}{c|}{ B. I } & B. II & B. II & B. IV \\
\hline Malaysian AIDS Council & Ms.Roswati, Executive Director & $\checkmark$ & $\checkmark$ & $\checkmark$ & $\checkmark$ \\
\hline Malaysian AIDS Council & $\begin{array}{l}\text { Mr.Parimelazhagan Ellan } \\
\text { Programme Director }\end{array}$ & $\checkmark$ & $\checkmark$ & $\checkmark$ & $\checkmark$ \\
\hline Malaysian AIDS Council & $\begin{array}{l}\text { Tamayanty Kurusamy } \\
\text { Senior Programe Executive }\end{array}$ & $\checkmark$ & $\checkmark$ & $\checkmark$ & $\checkmark$ \\
\hline Malaysian AIDS Council & $\begin{array}{l}\text { Mr. Mohammad Shahrani Mohamad } \\
\text { Tamrin, Senior Executive }\end{array}$ & $\checkmark$ & $\checkmark$ & $\checkmark$ & $\checkmark$ \\
\hline Malaysian AIDS Council & $\begin{array}{l}\text { Ms. Manohara, Programme } \\
\text { Manager }\end{array}$ & $\checkmark$ & $\checkmark$ & $\checkmark$ & $\checkmark$ \\
\hline Malaysian AIDS Council & Mr.Gunasegaran & $\checkmark$ & $\checkmark$ & $\checkmark$ & $\checkmark$ \\
\hline Malaysian AIDS Council & $\begin{array}{l}\text { Ms. Malini Sivapragasam, Executive } \\
\text { (Sex Worker/TG) }\end{array}$ & $\checkmark$ & $\checkmark$ & $\checkmark$ & $\checkmark$ \\
\hline Malaysian AIDS Council & Norlela Mokhtar & $\checkmark$ & $\checkmark$ & $\checkmark$ & $\checkmark$ \\
\hline Malaysian AIDS Council & Ridzuan Kamaruddin & $\checkmark$ & $\checkmark$ & $\checkmark$ & $\checkmark$ \\
\hline Malaysian AIDS Council & $\begin{array}{l}\text { Azhari Said } \\
\text { NSEP Manager }\end{array}$ & $\checkmark$ & $\checkmark$ & $\checkmark$ & $\checkmark$ \\
\hline Malaysian AIDS Council & $\begin{array}{l}\text { Dr. Zaki Arzmi, Manager of } \\
\text { Resource Centre }\end{array}$ & $\checkmark$ & $\checkmark$ & $\checkmark$ & $\checkmark$ \\
\hline PT Ikhlas Drop in Center & Zulkifli Zamri & $\checkmark$ & $\checkmark$ & $\checkmark$ & $\checkmark$ \\
\hline Rumah Solehah PPIM & Mdm. Fadzilah Abd. Hamid & $\checkmark$ & $\checkmark$ & $\checkmark$ & $\checkmark$ \\
\hline $\begin{array}{l}\text { Shelter Home, Batu Arang } \\
\text { Selangor }\end{array}$ & Anthony Gomes & $\checkmark$ & $\checkmark$ & $\checkmark$ & $\checkmark$ \\
\hline
\end{tabular}




\section{National Commitments and Policy Instrument (NCPI) \\ PART A}

[to be administered to government officials]

\section{STRATEGIC PLAN}

1. Has the country developed a national multisectoral strategy to respond to HIV?

(Multi-sectoral strategies should include, but are not limited to, those developed by Ministries such as the ones listed under 1.2)

IF YES, what was the period covered [write in]:

\begin{tabular}{|c|c|}
\hline Yes & No \\
\hline
\end{tabular}

IF YES, briefly describe key developments/modifications between the current national strategy and the prior one.

IF NO or NOT APPLICABLE, briefly explain why.

IF YES, complete questions 1.1 through 1.10; If NO, go to question 2.

\subsection{Which government ministries or agencies have overall responsibility for the development and implementation of the national mu/tisectoral strategy to respond to HIV?}

Name of government ministries or agencies [write in]:

Ministry of Health

\subsection{Which sectors are included in the multi-sectoral strategy with a specific HIV budget} for their activities?

\begin{tabular}{|l|c|c|c|c|}
\hline SECTORS & \multicolumn{3}{l}{ Included in Strategy } & \multicolumn{2}{l|}{ Earmarked Budget } \\
\hline Education & Yes & No & Yes & No \\
\hline Health & Yes & No & Yes & No \\
\hline Labour & Yes & No & Yes & No \\
\hline Military / Police & Yes & No & Yes & No \\
\hline Transportation & Yes & No & Yes & No \\
\hline Women, Family \& Community Development & Yes & No & Yes & No \\
\hline Young People & Yes & No & Yes & No \\
\hline Other [write in]: & \multicolumn{4}{|l|}{} \\
\hline National Service & Yes & No & Yes & No \\
\hline Dept. of Islamic Development & Yes & No & Yes & No \\
\hline National Anti-Drug Agency & Yes & No & Yes & No \\
\hline Dept. of Immigration & Yes & No & Yes & No \\
\hline Ministry of Information & Yes & No & Yes & No \\
\hline Dept. of Social Welfare & Yes & No & Yes & No \\
\hline Department of Prisons & Yes & No & Yes & No \\
\hline Attorney General Chambers & Yes & No & Yes & No \\
\hline Economic Planning Unit & Yes & No & Yes & No \\
\hline Ministry of Higher Education & Yes & No & Yes & No \\
\hline Ministry of Education & Yes & No & Yes & No \\
\hline Ministry of Finance & Yes & No & Yes & No \\
\hline
\end{tabular}


IF NO earmarked budget for some or all of the above sectors, explain what funding is used ensure implementation of their HIV specific activities?

In many instances, when there are no earmarked funds for HIV specific activities, the relevant government agency utilises its own pre-existing internal programme budget/ allocation when needed. This enables for projects to be proposed and implemented through an ad-hoc approach. E.g. the Ministry of Women, Family and Community Development has utilised its own allocation to fund the setting up and running of three DICs for women, PLHIV and transgender persons through a CBO.

\subsection{Does the mu/tisectoral strategy address the following target populations/other vulnerable populations, settings and cross-cutting issues?}

\begin{tabular}{|l|c|c|}
\hline KEY POPULATIONS AND OTHER VULNERABLE POPULATIONS & \multicolumn{1}{|c|}{} \\
\hline Men who have sex with men & Yes & No \\
\hline Migrants/mobile populations & Yes & No \\
\hline Orphans and other vulnerable children & Yes & No \\
\hline People with disabilities & Yes & No \\
\hline People who inject drugs & Yes & No \\
\hline Sex workers & Yes & No \\
\hline Transgendered people & Yes & No \\
\hline Women and girls & Yes & No \\
\hline Young women / young men & Yes & No \\
\hline Other specific vulnerable subpopulations ${ }^{31}$ & Yes & No \\
\hline SETTINGS & & \\
\hline Prisons & Yes & No \\
\hline Schools & Yes & No \\
\hline Workplace & Yes & No \\
\hline CROSS-CUTTING ISSUES & & \multicolumn{2}{|c|}{ No } \\
\hline Addressing stigma and discrimination & Yes & No \\
\hline Gender empowerment and/or gender equality & Yes & No \\
\hline HIV and poverty & Yes & No \\
\hline Human rights protection & Yes & No \\
\hline Involvement of people living with HIV & Yes & No \\
\hline
\end{tabular}

IF NO, explain how key populations were identified? 


\subsection{What are the identified key populations and vulnerable groups for HIV programmes in the country [write in]?}

\section{KEY POPULATIONS}

Injecting drug users

Women

Young people

Children

People Living With HIV

Transgender

Sex workers

Men who have sex with men

Mobile populations (legal \& illegal migrants, displaced persons, refugees \& migrant labourers)

\subsection{Does the multisectoral strategy include an operational plan?}

\begin{tabular}{|l|l|}
\hline Yes & No \\
\hline
\end{tabular}

\subsection{Does the multisectoral strategy or operational plan include:}

\begin{tabular}{|r|l|c|c|c|}
\hline \multicolumn{2}{|l|}{} & & & \\
\hline a) & Formal programme goals? & Yes & No & N/A \\
\hline b) & Clear targets and/or milestones? & Yes & No & N/A \\
\hline c) & Detailed costs for each programmatic area? & Yes & No & N/A \\
\hline d) & $\begin{array}{l}\text { An indication of funding sources to support } \\
\text { programme implementation? }\end{array}$ & Yes & No & N/A \\
\hline e) & A monitoring and evaluation framework? & Yes & No & N/A \\
\hline
\end{tabular}

\subsection{Has the country ensured "full involvement and participation" of civil society ${ }^{32}$ in the development of the multisectoral strategy?

\begin{tabular}{|c|c|c|}
\hline $\begin{array}{c}\text { Active } \\
\text { involvement }\end{array}$ & $\begin{array}{c}\text { Moderate } \\
\text { involvement }\end{array}$ & $\begin{array}{c}\text { No } \\
\text { involvement }\end{array}$ \\
\hline
\end{tabular}

If active involvement, briefly explain how this was organised:

Civil society participation was present at every stage of the development of the National Strategic Plan on HIV/AIDS (2006-2010). Consultations with key community based organisations and individuals were conducted to insure their inputs and concerns were reflected into the final document. Besides the consultation phase of NSP development, key civil society representatives were also involved and participated in the finalisation of the National Action Plan 2010 framework. In addition to that, the role of civil society has been embedded into the planning, implementation, monitoring and assessment of the activities linked to the NSP. At state and district levels, AIDS officers of the Ministry of Health work closely with their civil society counterparts in the planning and implementation of programmes. All proposals submitted for funding consideration under the NSP now require the endorsement of the AIDS officer under whose area of responsibility the proposed programme would be implemented.

IF NO or MODERATE involvement, briefly explain why this was the case :

Not applicable 


\subsection{Has the multi-sectoral strategy been endorsed by most external development} partners (bi-laterals; multi-laterals)?

\begin{tabular}{l|l|l} 
Yes & No & N/A
\end{tabular}

\subsection{Have external development partners aligned and harmonized their HIV-related programmes to the national multi-sectoral strategy?}

\begin{tabular}{|c|c|c|c|}
\hline $\begin{array}{c}\text { Yes, all } \\
\text { partners }\end{array}$ & $\begin{array}{c}\text { Yes, some } \\
\text { partners }\end{array}$ & No & N/A \\
\hline
\end{tabular}

IF SOME PARTNERS or NO, briefly explain for which areas there is no alignment/harmonization and why:

The United Nations Theme Group (UNTG) on HIV/AIDS in Malaysia serves as the primary platform for interaction among United Nations Agencies and other major stakeholders in support of Malaysia's national response. Key agencies, specifically the United Nations Development Programme (UNDP), United Nations Children's Fund (UNICEF), World Health Organisation (WHO), the UN Population Fund (UNFPA), and UNHCR whose offices are present in Malaysia have developed specific intervention programmes to provide financial and technical support to the Government of Malaysia's 5 year plan. UNAIDS provides significant and similar support through the Regional Support Team - Asia Pacific.

A number of bilateral partners (e.g. foreign embassies) provide support to specific civil society projects dealing on issues of prevention as well as care and treatment.

2. Has the country integrated HIV into its general development plans such as in: a) National Development Plans, b) Common Country Assessments / UN Development Assistance Framework, c) Poverty Reduction Strategy, d) sector wide approach?

\begin{tabular}{l|l|l} 
Yes & No & N/A
\end{tabular}

\subsection{IF YES, in which development plans is policy support for HIV and AIDS integrated?}

\begin{tabular}{|l|c|c|c|}
\hline SPECIFIC DEVELOPMENT PLANS & & & \\
\hline $\begin{array}{l}\text { Common Country Assessment/ UN Development } \\
\text { Assistance Framework }\end{array}$ & Yes & No & N/A \\
\hline National Development Plan & Yes & No & N/A \\
\hline Poverty Reduction Strategy & Yes & No & N/A \\
\hline Sector Wide Approach & Yes & No & N/A \\
\hline
\end{tabular}


2.2 IF YES, are the following specific HIV-related areas included in one or more of the development plans?

\begin{tabular}{|l|c|c|c|}
\hline HIV-RELATED AREA INCLUDED IN PLAN(S) & & & \\
\hline HIV impact alleviation & Yes & No & N/A \\
\hline $\begin{array}{l}\text { Reduction of gender inequalities as they relate to HIV } \\
\text { prevention/treatment, care and/or support }\end{array}$ & Yes & No & N/A \\
\hline $\begin{array}{l}\text { Reduction of income inequalities as they relate to HIV } \\
\text { prevention/ treatment, care and /or support }\end{array}$ & Yes & No & N/A \\
\hline Reduction of stigma and discrimination & Yes & No & N/A \\
\hline $\begin{array}{l}\text { Treatment, care and support (including social security or } \\
\text { other schemes) }\end{array}$ & Yes & No & N/A \\
\hline $\begin{array}{l}\text { Women's economic empowerment (e.g. access to credit, } \\
\text { access to land, training) }\end{array}$ & Yes & & \\
\hline
\end{tabular}

3. Has the country evaluated the impact of HIV on its socio-economic development for planning purposes?

\begin{tabular}{|l|l|l|}
\hline Yes & No & N/A \\
\hline
\end{tabular}

3.1 IF YES, on a scale of 0 to 5 (where 0 is "Low" and 5 is "High"), to what extent had the evaluation informed resource allocation decisions?

\begin{tabular}{|c|c|c|c|c|c|}
\hline LOW & & & & & HIGH \\
\hline 0 & 1 & 2 & 3 & 4 & 5 \\
\hline
\end{tabular}

4. Does the country have a strategy for addressing HIV issues among its national uniformed services (such as military, police, peacekeepers, prison staff, etc)?

\begin{tabular}{|l|l|}
\hline Yes & No \\
\hline
\end{tabular}

5. Has the country followed up on commitments made in 2011 Political Declaration on HIV/AIDS? $?^{32}$

\begin{tabular}{|c|c|}
\hline Yes & No \\
\hline
\end{tabular}

5.1 Have the national strategy and national HIV budget been revised accordingly?

\begin{tabular}{|l|l|} 
Yes & No \\
\hline
\end{tabular}

5.2 Are there reliable estimates of current needs and of future needs of the number of adults and children requiring antiretroviral therapy

\begin{tabular}{|c|c|c|}
\hline $\begin{array}{c}\text { Estimates } \\
\text { of current } \\
\text { and future } \\
\text { needs }\end{array}$ & $\begin{array}{c}\text { Estimates } \\
\text { of current } \\
\text { needs only }\end{array}$ & No \\
\hline
\end{tabular}




\subsection{Is HIV programme coverage being monitored?}

\begin{tabular}{|l|l|} 
Yes & No \\
\hline
\end{tabular}

IF YES, is coverage monitored by sex (male, female)?

\begin{tabular}{|l|l|}
\hline Yes & No \\
\hline
\end{tabular}

IF YES, is coverage monitored by population groups?

\begin{tabular}{|l|l|}
\hline Yes & No \\
\hline
\end{tabular}

IF YES, for which population group?

(a) Injecting drug user

(b) Women

(c) Female Sex worker

(d) Young people

(e) Children

(f) People Living With HIV

(g) Transgendered person

Briefly explain how this information is used?

The information concerning coverage is utilised in the determination and prioritisation of resource allocation in support of programme implementation. The decision making as to which programme is supported by Government funding is influenced by the effectiveness and degree of existing and estimated coverage of current interventions. This information is also utilised in influencing and modifying the design of programmes.

Is coverage monitored by geographical area?

IF YES, at which geographical levels (provincial, district, other)?

District level

State/Provincial level

National level

\section{Briefly explain how this information is used?}

The information concerning geographical areas is utilised to determine where services and interventions are most needed in response to clearly defined priorities. Together with coverage data, this information is utilised to make informed decisions concerning the type of programmes needed, for whom and where. The geographical information is particularly of critical use when determining priorities concerning resource allocation for areas such as those in East Malaysia, which are considered hard to reach and remote.

\subsection{Has the country developed a plan to strengthen health systems?}

\begin{tabular}{|l|l|}
\hline Yes & No \\
\hline
\end{tabular}


Please include information as to how this has impacted HIV-related infrastructure, human resources and capacities, and logical systems to deliver medications:

ARV has been decentralized to reach PLHIV at the periphery and now ARV is available at all government health centres which was previously delivered only in hospitals.

Testing and counselling is available in all government health facilities.

The expansion of PMTCT to include all private health facilities

Eligibility criteria for ARV initiation has been shifted from CD4 250 to 350

Counselling HIV services has been strengthen through credential officer trained in counselling.

\section{Overall, on scale of 0 to 10 (where 0 is "Very poor" and 10 is "Excellent"), how would you rate strategy planning efforts in your country's HIV programmes in 2011?}

\begin{tabular}{|c|c|c|c|c|c|c|c|c|c|c|}
\hline $\begin{array}{c}\text { Very } \\
\text { Poor }\end{array}$ & & & & & & & & & & Excellent \\
\hline 0 & 1 & 2 & 3 & 4 & 5 & 6 & 7 & 8 & 9 & 10 \\
\hline
\end{tabular}

Since 2009, what have been key achievements in this area:

The expansion and up scaling of both the Methadone Maintenance Therapy (MMT) and Needle Syringe Exchange Programme (NSEP) was a particularly key achievement in the national HIV programme. In 2008, the MMT intervention broke new ground; particularly as it involved the provision of these services for detainees in incarcerated settings, namely drug rehabilitation centres and prisons. In 2009, ARVs were also made available to prisoners who were confirmed with HIV.

The engagement with Muslim religious leaders together with the Ministry of Women, Family and Community Development, brought about more care and support programmes for infected and affected communities. The past two years have seen dramatic improvements with involvement of non-health sectors which include the setting up of shelters supported by the abovementioned Ministry and the Department of Islamic Development (JAKIM).

\section{What challenges remain in this area:}

Issues of vulnerability resulting in sexual transmission of HIV affecting school going and out-ofschool youth

Issue of stigma and discrimination which hamper access and retention of IDUs in existing harm reduction programmes.

The current economic climate threatens the availability and scale of public funding to support, maintain and sustain the different components of the national AIDS programme.

The continued over dependence on the Ministry of Health to address the issue of HIV and AIDS. Continues to be a challenge to obtain the interest and buy-in of other Ministries. 


\section{POLITICAL SUPPORT AND LEADERSHIP}

Strong political support includes: government and political leaders who regularly speak out about AIDS and demonstrate leadership in different ways: allocation of national budgets to support HIV programmes; and, effective use of government and civil society organizations to support HIV programmes.

1. Do the following high officials speak publicly and favourably about HIV efforts in major domestic forums at least twice a year?
A. Government ministers
B. Other high officials at sub-national level

\begin{tabular}{|c|c|}
\hline Yes & No \\
\hline \multicolumn{2}{|c|}{} \\
\hline Yes & No \\
\hline
\end{tabular}

\subsection{In the last 12 months, have the head government or other high level officials taken action that demonstrated leadership in the response to HIV?}

(for example, promised more resources to rectify identified weaknesses in HIV response, spoke of HIV as human rights issue in a major domestic/international forum, and such activities as visiting an HIV clinic, etc.)

\section{Yes}

Briefly describe actions/examples of instances where the head of government or other high officials have demonstrated leadership:

The government has made commitment to achieve vertical elimination of HIV transmission during the last World AIDS Day celebration which was officiated by Deputy Minister of Health on $10^{\text {th }}$ December 2011.

2. Does the country have an officially recognized national multisectoral AIDS coordination body? (i.e., a National AIDS Council or equivalent)?

\begin{tabular}{|l|l|} 
Yes & No \\
\hline
\end{tabular}

IF NO, briefly explain why not and how HIV programmes are being managed:

Not applicable

2.1 IF YES:

IF YES, does the national multisectoral AIDS coordination body:

Have terms of reference?

Have active government leadership and participation?

\begin{tabular}{l|l} 
Yes & No \\
Yes & No
\end{tabular}

Have an official chair person?

Yes

No

IF YES, what is his/her name and position title? H.E. Dato' Sri LiowTiong Lai (Health Minister)

Have a defined membership?

Yes

No

IF $\boldsymbol{Y E S}$, how many members? 20 members 


\begin{tabular}{|c|c|c|}
\hline Include civil society representatives? & Yes & No \\
\hline IF $\boldsymbol{Y E S}$, how many? & & \\
\hline Include people living with HIV? & Yes & No \\
\hline IF $\boldsymbol{Y E S}$, how many? & & \\
\hline Include private sector? & Yes & No \\
\hline $\begin{array}{l}\text { Strengthen donor coordination to avoid parallel funding and duplication of } \\
\text { effort in programming and reporting? }\end{array}$ & Yes & No \\
\hline
\end{tabular}

\section{Does the country have a mechanism to promote interaction between government, civil society organisations and the private sector for implementing HIV strategies/ programmes?}

\begin{tabular}{|l|l|l|}
\hline Yes & No & N/A \\
\hline
\end{tabular}

IF YES, briefly describe the main achievements:

In realizing the role played by the NGO in responding to HIV/AIDS, the government of Malaysia has formed the Malaysian AIDS Council (MAC) in 1992 as an umbrella body to coordinate activities by several NGOs on HIV/AIDS issues. The Malaysian AIDS Council (MAC) has been able:

To coordinate the activities of NGOs and CBOs working on HIV and AIDS in the country.

To work with the Ministry of Health in contributing towards the development, implementation, monitoring and assessment of HIV related policy.

To highlight the issues and concerns of marginalised communities to policy and decision makers at the highest levels of the Government.

To act as a critical partner in the implementation of the Government's harm reduction programmes.

What challenges remain in this area:

The MAC has an outstretched secretariat which is tasked to do multiple functions across a wide range of programmatic issues (from implementing the harm reduction programme to the monitoring of the entire civil society component of the national AIDS programme under the government grant (between RM 4 million (USD 1.2 million) - RM 14 million (USD 4.1 million)).

No proper assessment has been done to measure the impact and effectiveness of interventions led by the MAC since its formation. Programmes are tied and determined by available grant money. However, a monitoring and evaluation framework has been put in place to begin the process of reporting back on the effectiveness and impact of programmes.

4. What percentage of the national HIV budget was spent on activities implemented by civil society in the past year? 


\section{What kind of support does the National AIDS Commission (or equivalent) provide to civil society organizations for the implementation of HIV-related activities?}

\begin{tabular}{|l|c|c|}
\hline \multicolumn{2}{|l|}{} \\
\hline Capacity building & Yes & No \\
\hline Coordination with other implementing partners & Yes & No \\
\hline Information on priority needs & Yes & No \\
\hline Procurement and distribution of medications and other supplies & Yes & No \\
\hline Technical guidance & Yes & No \\
\hline Other [write in]: & Yes & No \\
\hline
\end{tabular}

Providing financial support to participate in conferences and study visits

Provides yearly financial support (Needle Syringe Exchange Programme (NSEP), government grants to civil society organisations

\section{Has the country reviewed national policies and laws to determine which, if any, are} inconsistent with the National AIDS Control policies?

\begin{tabular}{|l|l|}
\hline Yes & No \\
\hline
\end{tabular}

6.1 IF YES, were policies and laws amended to be consistent with the National AIDS Control policies?

IF YES, name and describe how the policies/laws were amended:

Prevention and Control of Infectious Diseases Act 1988 (ACT 342) was amended in 2007

Name and describe any inconsistencies that remain between any policies/ laws and the National AIDS Control policies:

Condoms are frequently used as evidence during detention or persecution of persons for illegal behaviour, e.g. evidence of sex work, premarital sex or MSM activity. The dissemination, awareness and promotion of condoms are a prominent part of all HIV programmes with MARPs.

Penal Code 377 criminalises anal and oral sex with penalties which include imprisonment, fines and whipping.

Transgender persons are often prosecuted under the 1955 Minor Offences Act which terms crossdressing as a form of indecent behaviour.

7. Overall, on a scale of 0 to 10 (where 0 is "Very Poor" and 10 is "Excellent"), how would you rate the political support for the HIV programme in 2011?

\begin{tabular}{|c|c|c|c|c|c|c|c|c|c|c|}
\hline $\begin{array}{c}\text { Very } \\
\text { Poor }\end{array}$ & & & & & & & & & & Excellent \\
\hline 0 & 1 & 2 & 3 & 4 & 5 & 6 & 7 & 8 & 9 & 10 \\
\hline
\end{tabular}


Since 2009, what have been key achievements in this area:

The Government has provided the highest political public support and coverage for the Harm Reduction programmes (NSEP \& MMT) to overcome popular opposition (which included Muslim religious leaders) due to the controversial nature of the interventions.

What challenges remain in this area:

Occasionally opposition by public figures occur and act as barriers which impede the implementation of HIV prevention programmes with most-at-risk populations.

\section{HUMAN RIGHTS}

\subsection{Does the country have non-discrimination laws or regulations which specify protections for specific key populations and other vulnerable groups? Circle yes if the policy specifies any of the following key populations and vulnerable group:}

\begin{tabular}{|l|c|c|}
\hline KEY POPULATIONS and VULNERABLE GROUPS & Yes & No \\
\hline People living with HIV & Yes & No \\
\hline Men who have sex with men & Yes & No \\
\hline Migrants/ mobile populations Women & Yes & No \\
\hline Orphans and other vulnerable children & Yes & No \\
\hline People with disabilities & Yes & No \\
\hline People who inject drugs & Yes & No \\
\hline Prison inmates & Yes & No \\
\hline Sex workers & Yes & No \\
\hline Transgendered people & Yes & No \\
\hline Women and girls & Yes & No \\
\hline Young women / young men & Yes & No \\
\hline Other specific vulnerable subpopulations [write in]: & & \\
\hline
\end{tabular}

\subsection{Does the country have a general (i.e. not specific to HIV-related discrimination) law on non-discrimination?}

\begin{tabular}{|l|l|}
\hline Yes & No \\
\hline
\end{tabular}

IF YES, to question 1.1 or 1.2 , briefly describe the content of the laws: 
Briefly explain what mechanisms are in place to ensure these law are implemented:

Briefly comment on the degree to which they are currently implemented:

2. Does the country have laws, regulations or policies that present obstacles to effective HIV prevention, treatment, care and support for most-at-risk populations or other vulnerable subpopulations?

\section{Yes}

No

IF YES, for which key populations and vulnerable groups?

People living with HIV

Men who have sex with men

Migrants/ mobile populations Women

Orphans and other vulnerable children

People with disabilities

People who inject drugs

Prison inmates

Sex workers

Transgendered people

Women and girls

Young women / young men

Other specific vulnerable subpopulations [write in]:

Briefly describe the content of these laws, regulations or policies

Briefly comment on how they pose barriers

The possession of injecting drug equipment or drugs such as morphine without a prescription is technically illegal and subject to criminal prosecution. The relevant Government agencies are currently has ongoing continuous dialogues with the different affected bodies in an effort to reconcile these legal impediments to HIV prevention programmes. 


\section{PREVENTION}

1. Does the country have a policy or strategy that promotes information, education and communication (IEC) on HIV to the general population?

IF YES, what key messages are explicitly promoted?

\begin{tabular}{|l|c|c|}
\hline Abstain from injecting drugs & Yes & No \\
\hline Avoid commercial sex & Yes & No \\
\hline Avoid inter-generational sex & Yes & No \\
\hline Be faithful & Yes & No \\
\hline Sexually abstinent & Yes & No \\
\hline Delay sexual debut & Yes & No \\
\hline Engage in safe(r) sex & Yes & No \\
\hline Fight against violence against women & Yes & No \\
\hline Greater acceptance and involvement of people living with HIV & Yes & No \\
\hline Greater involvement of men in reproductive health programmes & Yes & No \\
\hline Know your HIV status & Yes & No \\
\hline Males to get circumcised under medical supervision & Yes & No \\
\hline Prevent mother-to-child transmission of HIV & Yes & No \\
\hline Promote greater equality between men and women & Yes & No \\
\hline Reduce the number of sexual partners & Yes & No \\
\hline Use clean needles and syringes & Yes & No \\
\hline Use condoms consistently & Yes & No \\
\hline Other [write in below]: & Yes & No \\
\hline
\end{tabular}

\subsection{In the last year, did the country implement an activity or programme to promote} accurate reporting on HIV by the media?

\begin{tabular}{l|l} 
Yes & No
\end{tabular}

\section{Does the country have a policy or strategy promoting HIV-related reproductive and} sexual health education for young people?

\begin{tabular}{|l|l|}
\hline Yes & No \\
\hline
\end{tabular}

2.1

\section{Is HIV education part of the curriculum in:}

Primary schools?

Secondary schools?

Teacher training?

\begin{tabular}{|c|c|}
\hline Yes & No \\
\hline Yes & No \\
\hline Yes & No \\
\hline
\end{tabular}


2.2 Does the strategy include age-appropriate, gender-sensitive sexual and reproductive health elements?

$$
\begin{array}{|c|c|}
\hline \text { Yes } & \text { No } \\
\hline
\end{array}
$$

2.3 Does the country have an HIV education strategy for out-of-school young people?

\begin{tabular}{|c|c|}
\hline Yes & No \\
\hline
\end{tabular}

3. Does the country have a policy or strategy to promote information, education and communication and other preventive health interventions for key or other vulnerable subpopulations?

Briefly describe the content of this policy or strategy:

\subsection{IF YES, which subpopulations and what elements of HIV prevention do the policy/strategy address?}

Check which specific populations and elements are included in the policy/strategy

\begin{tabular}{|l|c|c|c|c|c|c|}
\hline & IDU & MSM & $\begin{array}{c}\text { Sex } \\
\text { workers }\end{array}$ & $\begin{array}{c}\text { Client of } \\
\text { sex } \\
\text { workers }\end{array}$ & $\begin{array}{c}\text { Prison } \\
\text { inmates }\end{array}$ & $\begin{array}{c}\text { Other } \\
\text { populations } \\
\text { [trans- } \\
\text { gendered } \\
\text { person] }\end{array}$ \\
\hline Condom promotion & $\checkmark$ & $\checkmark$ & $\checkmark$ & $\checkmark$ & & $\checkmark$ \\
\hline Drug substitution therapy & $\checkmark$ & $\checkmark$ & $\checkmark$ & $\checkmark$ & $\checkmark$ & $\checkmark$ \\
\hline HIV testing and counselling & $\checkmark$ & $\checkmark$ & $\checkmark$ & $\checkmark$ & $\checkmark$ & $\checkmark$ \\
\hline Needle and syringe exchange & $\checkmark$ & $\checkmark$ & $\checkmark$ & $\checkmark$ & & $\checkmark$ \\
\hline $\begin{array}{l}\text { Reproductive health, including sexually } \\
\text { transmitted infections prevention and } \\
\text { treatment }\end{array}$ & $\checkmark$ & $\checkmark$ & $\checkmark$ & & $\checkmark$ & $\checkmark$ \\
\hline Stigma and discrimination reduction & $\checkmark$ & $\checkmark$ & $\checkmark$ & & $\checkmark$ & $\checkmark$ \\
\hline $\begin{array}{l}\text { Targeted information on risk reduction } \\
\text { and HIV education }\end{array}$ & $\checkmark$ & $\checkmark$ & $\checkmark$ & & $\checkmark$ & $\checkmark$ \\
\hline $\begin{array}{l}\text { Vulnerability reduction (e.g. income } \\
\text { generation) }\end{array}$ & N/A & N/A & $\checkmark$ & N/A & N/A & $\checkmark$ \\
\hline
\end{tabular}

3.2 Overall, on a scale of 0 to 10 (where 0 is "Very Poor" and 10 is "Excellent"), how would you rate policy efforts in support of HIV prevention in 2011 ?

\begin{tabular}{|c|c|c|c|c|c|c|c|c|c|c|}
\hline $\begin{array}{c}\text { Very } \\
\text { Poor }\end{array}$ & & & & & & & & & & Excellent \\
\hline 0 & 1 & 2 & 3 & 4 & 5 & 6 & 7 & 8 & 9 & 10 \\
\hline
\end{tabular}


Since 2009, what have been key achievements in this area:

The decision by the Cabinet Committee on AIDS to support the scaling up of the NSEP (Needle and Syringe Exchange Programme)and MMT (Methadone Maintenance Therapy):

MMT to be extended to drug rehabilitation centres, prisons and drug drop-in centres.

NSEP to increase its number of sites and to cater to more clients.

What challenges remain in this area:

The issue of providing comprehensive sexual reproductive health education, including information on HIV for children in school continues to be at an impasse. Though it has been under discussion by various levels of government, implementation of this policy has been erratic due to opposition from various parties on moral and religious grounds

\section{Has the country identified specific needs for HIV prevention programmes?}

\section{Yes}

TF YES, how were these specific needs determined?

Consultation with government (health and non-health sector) and NGOs are conducted during annual planning meetings to ensure that the needs of HIV programmes are identified and outlined for support. The framework which guides the discussion is based on the national strategic plan as well as priorities identified for that particular year.

IF NO, how are HIV prevention programmes being scaled-up?

Not applicable

\subsection{To what extent has HIV prevention been implemented?}

\begin{tabular}{|l|c|c|c|c|c|}
\hline The majority of people in need have access to... & $\begin{array}{c}\text { Strongly } \\
\text { disagree }\end{array}$ & Disagree & Agree & $\begin{array}{c}\text { Strongly } \\
\text { Agree }\end{array}$ & N/A \\
\hline Blood safety & 1 & 2 & 3 & 4 & \\
\hline Condom promotion & 1 & 2 & 3 & 4 & \\
\hline Harm reduction for injecting drug users & 1 & 2 & 3 & 4 & \\
\hline HIV prevention for out-of-school young people & 1 & 2 & 3 & 4 & \\
\hline HIV prevention in the workplace & 1 & 2 & 3 & 4 & \\
\hline HIV testing \& counselling & 1 & 2 & 3 & 4 & \\
\hline IEC on risk reduction & 1 & 2 & 3 & 4 & \\
\hline IEC on stigma and discrimination reduction & 1 & 2 & 3 & 4 & \\
\hline Prevention of mother-to-child transmission of HIV & 1 & 2 & 3 & 4 & \\
\hline Prevention for people living with HIV & 1 & 2 & 3 & 4 & \\
\hline $\begin{array}{l}\text { Reproductive health services including sexually } \\
\text { transmitted infections prevention \& treatment }\end{array}$ & 1 & 2 & 3 & 4 & \\
\hline $\begin{array}{l}\text { Risk reduction for intimate partners of key } \\
\text { populations }\end{array}$ & 1 & 2 & 3 & 4 & \\
\hline
\end{tabular}




\begin{tabular}{|l|l|l|l|l|l|}
\hline Risk reduction for men who have sex with men & 1 & 2 & 3 & 4 & \\
\hline Risk reduction for sex workers & 1 & 2 & 3 & 4 & \\
\hline School-based AIDS education for young people & 1 & 2 & 3 & 4 & \\
\hline Universal precautions in health care settings & 1 & 2 & 3 & 4 & \\
\hline Other: Faith-based interventions for Muslim & 1 & 2 & 3 & 4 & \\
\hline
\end{tabular}

\section{Overall, on a scale of 0 to 10 (where 0 is "Very Poor" and 10 is "Excellent"), how would you rate the implementation of HIV prevention programmes in 2011?}

\begin{tabular}{|c|c|c|c|c|c|c|c|c|c|c|}
\hline $\begin{array}{c}\text { Very } \\
\text { Poor }\end{array}$ & & & & & & & & & & Excellent \\
\hline 0 & 1 & 2 & 3 & 4 & 5 & 6 & 7 & 8 & 9 & 10 \\
\hline
\end{tabular}

\section{TREATMENT, CARE AND SUPPORT}

\section{Has the country identified the essential elements of a comprehensive package of HIV treatment, care and support services?}

\begin{tabular}{|c|c|}
\hline Yes & No \\
\hline
\end{tabular}

IF YES, briefly identify the elements and what has been prioritized

Malaysia already provides and is committed to affordable access to clinical care through the public health system, including free or subsidized access to ART. People Living with HIV (PLHIV) in closed settings and those living outside the major cities are of particularly concern and are the focus of coverage under existing programmes. This is in addition to the services already possible for drug rehabilitation centre internees and prisoners who are living with HIV and are able to have access to HIV related treatment inclusive of CD4 follow-up and monitoring of ART.

Briefly identify how HIV treatment, care and support services are being scaled-up?

Improving eligibility criteria for ARV from CD4 200 to 350

Expanding ARV treatment to involve PLHIV in closed setting

Expansion of PMTCT to include all private health care facilities

Decentralizing ARV from hospital-based to primary care setting

\subsection{To what extent have the following HIV treatment, care and support services been implemented?}

\begin{tabular}{|l|c|c|c|c|c|}
\hline The majority of people in need have access to... & $\begin{array}{c}\text { Strongly } \\
\text { disagree }\end{array}$ & Disagree & Agree & $\begin{array}{c}\text { Strongly } \\
\text { Agree }\end{array}$ & N/A \\
\hline Antiretroviral therapy & 1 & 2 & 3 & 4 & \\
\hline ART for TB patients & 1 & 2 & 3 & 4 & \\
\hline Cotrimoxazole prophylaxis in PLHIV & 1 & 2 & 3 & 4 & \\
\hline
\end{tabular}




\begin{tabular}{|l|c|c|c|c|c|}
\hline Early infant diagnosis & 1 & 2 & 3 & 4 & \\
\hline $\begin{array}{l}\text { HIV care and support in the workplace (including } \\
\text { alternative working arrangements) }\end{array}$ & 1 & 2 & 3 & 4 & \\
\hline HIV testing and counselling for people with TB & 1 & 2 & 3 & 4 & \\
\hline $\begin{array}{l}\text { HIV treatment services in the workplace or } \\
\text { treatment referral systems through the } \\
\text { workplace }\end{array}$ & 1 & 2 & 3 & 4 & \\
\hline Nutritional care & 1 & 2 & 3 & 4 & \\
\hline Paediatric AIDS treatment & 1 & 2 & 3 & 4 & \\
\hline Post-delivery ART provision to women & 1 & 2 & 3 & 4 & \\
\hline $\begin{array}{l}\text { Post-exposure prophylaxis for occupational } \\
\text { exposures to HIV }\end{array}$ & 1 & 2 & 3 & 4 & \\
\hline $\begin{array}{l}\text { Psychosocial support for people living with HIV } \\
\text { and their families }\end{array}$ & 1 & 2 & 3 & 4 & \\
\hline Sexually transmitted infection management & 1 & 2 & 3 & 4 & \\
\hline $\begin{array}{l}\text { TB infection control in HIV treatment and care } \\
\text { facilities }\end{array}$ & 1 & 2 & 3 & 4 & \\
\hline TB preventive therapy for people living with HIV & 1 & 2 & 3 & 4 & \\
\hline TB screening for people living with HIV & 1 & 2 & 3 & 4 & \\
\hline Treatment of common HIV-related infections & 1 & 2 & 3 & 4 & \\
\hline
\end{tabular}

\section{Does the government have a policy or strategy in place to provide social and} economic support to people infected/affected by HIV?

\begin{tabular}{|c|c|}
\hline Yes & No \\
\hline
\end{tabular}

Please clarify which social and economic support is provided:

The Islamic Religious Department has distributed financial aid (Zakat) to PLHIV and their family Welfare Department (under MWFCD) has also extended financial aid to PLHIV and their family

3. Does the country have a policy or strategy for developing/using generic medication or parallel importing of medications for HIV?

\begin{tabular}{l|l|l} 
Yes & No & N/A
\end{tabular}

4. Does the country have access to regional procurement and supply management mechanisms for critical commodities, such as antiretroviral therapy medications, condoms, and substitution medications?

\begin{tabular}{|l|l|}
\hline Yes & No \\
\hline
\end{tabular}

IF YES, for which comodities?

Not applicable 
5. Overall, on a scale of 0 to 10 (where 0 is "Very Poor" and 10 is "Excellent"), how would you rate the efforts in the implementation of HIV treatment, care and support programmes in 2011?

\begin{tabular}{|c|c|c|c|c|c|c|c|c|c|c|}
\hline $\begin{array}{c}\text { Very } \\
\text { Poor }\end{array}$ & & & & & & & & & & Excellent \\
\hline 0 & 1 & 2 & 3 & 4 & 5 & 6 & 7 & 8 & 9 & 10 \\
\hline
\end{tabular}

Since 2009, what have been key achievements in this area:

$1^{\text {st }}$ line ART continues to be provided to treatment eligible HIV patients at no cost while the $2^{\text {nd }}$ line is heavily funded by the Government. The high cost of this provision of treatment currently takes up almost half of the entire national AIDS programme budget.

What challenges remain in this area:

The escalating costs related to management of HIV is translated and shared by both the Government and patient. Though the treatment regime is heavily subsidised by public funds, there is concern that this is unable to continue due to escalating public healthcare costs including cost of drugs and uncertain economic climate. Support services by the NGO often limited in urban areas. Those coming from rural areas are forced to travel at great distance to access these services.

6. Does the country have a policy or strategy to address the additional HIV-related needs of orphans and other vulnerable children?

\begin{tabular}{|c|c|c|}
\hline Yes & No & N/A \\
\hline
\end{tabular}

6.1 IF YES, is there an operational definition for OVC in the country?

\begin{tabular}{|l|l|}
\hline Yes & No \\
\hline
\end{tabular}

6.2 IF YES, does the country have a national action plan specifically for OVC?

\begin{tabular}{|l|l|}
\hline Yes & No \\
\hline
\end{tabular}

6.3 IF YES, does the country have an estimate of OVC being reached by existing interventions?

\begin{tabular}{|l|l|}
\hline Yes & No \\
\hline
\end{tabular}

6.4 IF YES, what percentage of orphans and vulnerable children is being reached? 
7. Overall, on a scale of 0 to 10 (where 0 is "Very Poor" and 10 is "Excellent"), how would you rate the efforts to meet the HIV-related needs of OVC in 2011?

\begin{tabular}{|c|c|c|c|c|c|c|c|c|c|c|}
\hline $\begin{array}{c}\text { Very } \\
\text { Poor }\end{array}$ & & & & & & & & & & Excellent \\
\hline 0 & 1 & 2 & 3 & 4 & 5 & 6 & 7 & 8 & 9 & 10 \\
\hline
\end{tabular}

Since 2009, what have been key achievements in this area:

Not much has changed in this area since the last report. As prioritisation of Government funding has determined that the national AIDS programme would focus its energies on the most-at-risk populations, activities in this area have focused on life skills based education.

What challenges remain in this area:

Though introduction of life skills based education has begun, it remains strictly limited to specific schools. Orphans and vulnerable children are frequently considered under the care and support category. However, very little has been done at the national level. At the level of civil society, a series of initiatives have begun to assist this population through grant programmes to support the cost of schooling, sustenance and others.

\section{MONITORING AND EVALUATION}

\section{Does the country have one national Monitoring and Evaluation (M\&E) plan for HIV?}

\begin{tabular}{l|l|l} 
Yes & In Progress & No
\end{tabular}

Briefly describe any challenges in development or implementation:

1.1 IF YES, years covered [write in]:

$2011-2015$

\subsection{IF YES, have key partners aligned and harmonized their M\&E requirements (including indicators) with the national M\&E plan?}

\begin{tabular}{|c|c|c|c|}
\hline $\begin{array}{c}\text { Yes, all } \\
\text { partners }\end{array}$ & $\begin{array}{c}\text { Yes, some } \\
\text { partners }\end{array}$ & No & N/A \\
\hline
\end{tabular}

Briefly describe what the issues are:

There are still partners that are not able to harmonize their M\&E due to inadequate capacity. 


\section{Does the national Monitoring and Evaluation plan include?}

\begin{tabular}{|c|c|c|}
\hline A data collection strategy & Yes & No \\
\hline \multicolumn{3}{|l|}{ IF $\boldsymbol{Y E S}$, does it address: } \\
\hline Behavioural surveys & Yes & No \\
\hline Evaluation / research studies & Yes & No \\
\hline HIV drug resistance surveillance & Yes & No \\
\hline HIV surveillance & Yes & No \\
\hline Routine programme monitoring & Yes & No \\
\hline A data analysis strategy & Yes & No \\
\hline A data dissemination and use strategy & Yes & No \\
\hline $\begin{array}{l}\text { A well-defined standardized set of indicators that include sex and age } \\
\text { disaggregation (where appropriate) }\end{array}$ & Yes & No \\
\hline Guidelines on tools for data collection & Yes & No \\
\hline
\end{tabular}

\section{Is there a budget for implementation of the M\&E plan?}

\begin{tabular}{|l|l|l|}
\hline Yes & In Progress & No \\
\hline
\end{tabular}

\subsection{IF YES, what percentage of the total HIV programme funding is budgeted for M\&E} activities?

\section{Is there a functional national M\&E unit?}

\begin{tabular}{l|l|l} 
Yes & In Progress & No
\end{tabular}

Briefly describe any obstacle:

Not applicable

\subsection{Where is the national M\&E unit based?}

\begin{tabular}{|l|c|c|}
\hline \multicolumn{3}{|l|}{} \\
\hline In the Ministry of Health? & Yes & No \\
\hline In the National HIV Commission (or equivalent)? & Yes & No \\
\hline Elsewhere [write in]: & Yes & No \\
\hline
\end{tabular}




\subsection{How many and what type of professional staff are working in the national M\&E unit?}

\begin{tabular}{|c|c|c|c|}
\hline POSITION [write in position titles in spaces below] & Fulltime & Part time & Since when? \\
\hline \multicolumn{4}{|l|}{ Permanent Staff [Add as many as needed]: } \\
\hline 1. Public Health Physician & & & 2010 \\
\hline 2. Assistant Environmental Health Officer (Senior) & & & 2010 \\
\hline 3. Assistant Environmental Health Officer & & & 2010 \\
\hline \multirow[t]{2}{*}{ 4. Clerical staffs } & & & 2010 \\
\hline & Fulltime & Part time & Since when? \\
\hline Temporary Staff [Add as many as needed]: & & & \\
\hline
\end{tabular}

\subsection{Are there mechanisms in place to ensure that all key partners submit their M\&E} data/reports to the M\&E Unit for inclusion in the national M\&E system?

\begin{tabular}{l|l} 
Yes & No
\end{tabular}

Briefly describe the data sharing mechanisms:

The M\&E is discussed and disseminated regular quarterly meeting with partners.

What are the major challenges in this area:

Irregularity and discrepancy in data submitted by some partners.

\section{Is there a national M\&E Committee or Working Group that meets regularly to} coordinate M\&E activities?

\begin{tabular}{l|l} 
Yes & No
\end{tabular}

6. Is there a central national database with HIV-related data?

\begin{tabular}{l|l} 
Yes & No
\end{tabular}

IF YES, briefly describe the national database and who manages it:

The national database (National AIDS Registry) is managed by the HIV/STI Section of the Ministry of Health. The database consists of HIV patient related information that include socioeconomic characteristics, transmission mode, status of HIV treatment etc.

6.1 IF YES, does it include information about the content, target populations and geographical coverage of HIV services, as well as their implementing organizations?

Yes, all of the above
Yes, but only some of the above
No. none of the above 
IF YES, but only some of the above, which aspect does it include?

Not applicable

\subsection{Is there a functional Health Information System ${ }^{62}$ ?}

\begin{tabular}{|l|c|c|}
\hline At national level & Yes & No \\
\hline At subnational level & Yes & No \\
\hline $\begin{array}{r}\text { IF } \text { YES, at what level(s)? [write in] } \\
\text { District, State /Provincial and National level }\end{array}$ & & \\
\hline
\end{tabular}

\section{Does the country publish at least once a year an M\&E report on HIV and on, including HIV surveillance data?}

\begin{tabular}{l|l} 
Yes & No
\end{tabular}

\section{How are M\&E data used?}

\begin{tabular}{|l|c|c|}
\hline & & \\
\hline For programme improvement? & Yes & No \\
\hline In developing / revising the national HIV response? & Yes & No \\
\hline For resource allocation? & Yes & No \\
\hline Others [write in]: & & \\
\hline For evaluation of intervention & Yes & No \\
\hline
\end{tabular}

Briefly provide specific examples of how M\&E data are used, and the main challenges if any:

The data from M\&E of the Harm Reduction programmes (NSEP \& MMT) is being used for the scaling up programme. The decision to fund the scaling-up activities was largely determined by the perceived success of the intervention there in reaching to a high number of injecting drug users, higher client return rate and large geographical coverage.

M\&E data was utilised to introduce premarital HIV screening to address the issue of heterosexual transmission. It also enabled the Government to justify its stance in promoting such testing.

The use of M\&E data also allowed for the introduction of a nationwide anonymous HIV testing programme.

The main challenge is to get key affected populations to fully understand the importance of quality data and timely submission of M\&E report/data.

\section{In the last year, was training in M\&E conducted}

\footnotetext{
${ }^{62}$ Such as regularly reporting data from health facilities which are aggregated at district level and sent to national level; data are analysed and used at different levels?
} 


\begin{tabular}{|l|c|c|}
\hline \multicolumn{2}{|l|}{} & \multicolumn{2}{|c|}{ No } \\
\hline At national level? & & \\
\hline $\boldsymbol{I F} \boldsymbol{Y E S}$, what was the number trained: & Yes & No \\
\hline \multicolumn{2}{|l|}{} \\
\hline At subnational level? & & \\
\hline $\boldsymbol{I F} \boldsymbol{Y E S}$, what was the number trained: & Yes & No \\
\hline \multicolumn{2}{|l}{} \\
\hline At service delivery level including civil society? & & \\
\hline IF $\boldsymbol{Y E S}$, what was the number trained:
\end{tabular}

\subsection{Were other M\&E capacity-building activities conducted other than training?}

\begin{tabular}{l|l} 
Yes & No
\end{tabular}

IF YES, describe what type of activities:

Briefings concerning monitoring and evaluation systems and evaluations conducted at the service delivery level, implementation level (states and districts).

10. Overall, on a scale of 0 to 10 (where 0 is "Very Poor" and 10 is "Excellent"), how would you rate the HIV-related monitoring and evaluations (M\&E) in 2011?

\begin{tabular}{|c|c|c|c|c|c|c|c|c|c|c|}
\hline $\begin{array}{c}\text { Very } \\
\text { Poor }\end{array}$ & & & & & & & & & & Excellent \\
\hline 0 & 1 & 2 & 3 & 4 & 5 & 6 & 7 & 8 & 9 & 10 \\
\hline
\end{tabular}

Since 2009, what have been key achievements in this area:

A national M\&E unit has been developed within the Ministry of Health, not only to cater for all programmes indicators but also responsible for estimation and projection of the country's epidemic.

What challenges remain in this area:

There remains a challenge in improving the quantity and quality of technical capacity in both government and civil society bodies. 


\title{
National Commitments and Policy Instrument (NCPI)
}

\author{
PART B
}

[To be administered to representatives from civil society organizations, bilateral agencies, and UN organizations]

\section{CIVIL SOCIETY ${ }^{63}$ INVOLVEMENT}

\section{To what extent (on a scale of 0 to 5 where 0 is "Low" and 5 is "High") has civil society contributed to strengthening the political commitment of top leaders and national strategy/policy formulations?}

\begin{tabular}{|c|c|c|c|c|}
\hline LOW & & & & HIGH \\
\hline 1 & 2 & 3 & 4 & 5 \\
\hline
\end{tabular}

Comments and examples:

Same as 2010 report, CSOs, usually under coordination of the Malaysian AIDS Council, have been able to be engaged in dialogue with key decision makers and political figures such as the Prime Minister, Minister of Health and other Ministers. Political leaders are also often open to attending HIV related functions organized by civil society organizations. End of 2011, now there are 49 partner organizations in Malaysian AIDS Council.

$\mathrm{MOH}$ has change the CD4 medicine eligibility from 250 to 350, following WHO recommendation and HAART is disburse at all major government hospitals and health clinic. Government is giving the firstline medicine for free.

The heads of government bodies (e.g. Department of Islamic Development, Islamic Religious Department of Federal Territory and Selangor, Ministry of Women, Family and Community Development, Human Rights Commission and police) reached through advocacy meetings and workshops. Thus HIV 101 is taught at PULAPOL (Police Training College) and the National Anti-Drug Agency (NADA-AADK) have more friendly approach to PWID (Cure \& Care policy). A key result of this engagement has been the commitment in 2008 by the Ministry of Women, Family and Community Development to support the setting up of 7 shelters for women \& children who are PLHIV and affected by HIV. This was later expanded to 17 shelters in 2011.

The Department of Islamic Development, the Federal Territory and the Selangor Islamic Council have also now committed itself to setting up shelter homes for Muslims living with HIV/AIDS(building completion in 2012 [Selangor] and 2014 [Federal Territory]). Most religious state councils also give financial commitments either involved in psychosocial support projects or monthly financial assistance (RM250-300). The revised Manual HIV and Islam in 2011 (with $\mathrm{MOH}$ and MAC) have created more enabling environment and more understanding by religious clerics. Mukhayyam (camping) with KAPs was also conducted to bring KAPs out of risking behavior and give training/employment opportunities.

Community Welfare Department gives financial assistance (RM300) every month to eligible single parents. And in 2011, the Employers Providers Fund allows PLHIV to withdraw their funds if they need it for AIDS related sickness.

${ }^{63}$ Civil society includes among others: networks and organizations of people living with HIV, women, young people, key affected groups (including men who have sex with men, transgendered people, sex workers, people who inject drugs, migrants, refugees/displaced populations, prisoners), faith-based organizations ; AIDS service organizations; community-based organizations; workers organizations, human rights organizations; etc. Note: The private sector is considered separately. 
2. To what extent (on a scale of 0 to 5 where 0 is "Low" and 5 is "High") have civil society representatives been involved in the planning and budgeting process for the National Strategic Plan on HIV or for the most current activity plan (e.g. attending planning meetings and reviewing drafts)?

\begin{tabular}{|c|c|c|c|c|}
\hline LOW & & & HIGH \\
\hline 1 & 2 & 3 & 4 & 5 \\
\hline
\end{tabular}

\section{Comments and examples:}

Through coordination of the Malaysian AIDS Council (MAC) and working with the Ministry of Health, civil society representatives have been extensively involved in the planning and budgeting process for NSP 2011-2016. To assist in this engagement, MAC has introduced the "cluster" concept to improve upon civil society ownership and participation on key issues as well as functioning as a form of community consultation.

Within each cluster, community representatives are expected to contribute towards the identification of priorities as well as monitoring of activities and interventions. The list of attendee is in the NSP pg. 13-14.

3. To what extent (on a scale of 0 to 5 where 0 is "Low" and 5 is "High") are the services provided by civil society in areas of HIV prevention, treatment, care and support included in:

\section{a. The national HIV strategy?}

\begin{tabular}{|c|c|c|c|c|}
\hline LOW & & & & HIGH \\
\hline 1 & 2 & 3 & 4 & 5 \\
\hline
\end{tabular}

\section{b. The national HIV budget?}

\begin{tabular}{|c|c|c|c|c|}
\hline LOW & & & & HIGH \\
\hline 1 & 2 & 3 & 4 & 5 \\
\hline
\end{tabular}

\section{c. The national HIV reports?}

\begin{tabular}{|c|c|c|c|c|}
\hline LOW & & & & HIGH \\
\hline 1 & 2 & 3 & 4 & 5 \\
\hline
\end{tabular}

Comments and examples:

The National Strategic Plan on HIV/AIDS 2011- 2015 clearly indicates that HIV prevention, particularly amongst most-at-risk populations, is dependent on the programmes and services of civil society organizations. Civil society is consistently consulted by the Ministry of Health in the process of writing national AIDS reports. The National Task Force of NSP is created where CSOs have elected representative to attend the quarterly meeting. Task Force on Harm Reduction also has CSOs representatives. 
4. To what extent (on a scale of 0 to 5 where 0 is "Low" and 5 is "High") is civil society included in the monitoring and evaluation (M\&E) of the HIV response?

a. Developing the national M\&E plan?

\begin{tabular}{|c|c|c|c|c|}
\hline LOW & & & & HIGH \\
\hline 1 & 2 & 3 & 4 & 5 \\
\hline
\end{tabular}

b. Participating in the national M\&E committee/working group responsible for coordination of M\&E activities?

\begin{tabular}{|c|c|c|c|c|}
\hline LOW & & & & HIGH \\
\hline 1 & 2 & 3 & 4 & 5 \\
\hline
\end{tabular}

\section{c. Participate in using data for decision-making?}

\begin{tabular}{|c|c|c|c|c|}
\hline LOW & & & & HIGH \\
\hline 1 & 2 & 3 & 4 & 5 \\
\hline
\end{tabular}

\section{Comments and examples:}

Though there was no prior consultation with any non-governmental HIV organisation including the Malaysian AIDS Council (MAC) in developing the preliminary M\&E framework, the latter and its partner organisations have been included in later discussions concerning the monitoring of progress in responding to the HIV epidemic. They have also been able to contribute in presentation of national data.MAC has an M\&E capacity which was fully established in 2007 and migrated online in 2009. It currently oversees data reported from all projects and programmes of all civil society organisations receiving the Government grant. This monitoring capacity contributes substantially to the national understanding of socio-behavioural data gathered through programmes and interventions with MARPs. M\&E Working Group is part of the National Task Force agenda and all data is being use for proposals.

5. To what extent (on a scale of 0 to 5 where 0 is "Low" and 5 is "High") is the civil society sector representation in HIV efforts inclusive of diverse organizations (e.g. organisations and networks of people living with HIV, of sex workers and faithbased organizations)?

\begin{tabular}{|c|c|c|c|c|}
\hline LOW & & & & HIGH \\
\hline 1 & 2 & 3 & 4 & 5 \\
\hline
\end{tabular}

Comments and examples:

MAC comprises of :

Organisation of people living with HIV ( MyPlus)

Women's organizations

Youth organizations

Faith-based organizations

Lawyers collective council

Community-based organizations

Organizations working with most-at-risk populations (MARP) (including MSM, SW, IDU, migrants)

Associations of medical professionals 
Humanitarian organisations

Yet, MAC or HIV effort is not conducted by Indigenious People organisations, but MAC have done a project with government department handling indeginious population in 2010 and 2011.

6. To what extent (on a scale of 0 to 5 where 0 is "Low" and 5 is "High") is civil society able to access:

a. Adequate financial support to implement its HIV activities?

\begin{tabular}{|c|c|c|c|c|}
\hline LOW & & & & HIGH \\
\hline 1 & 2 & 3 & 4 & 5 \\
\hline
\end{tabular}

b. Adequate technical support to implement its HIV activities?

\begin{tabular}{|c|c|c|c|c|}
\hline LOW & & & & HIGH \\
\hline 1 & 2 & 3 & 4 & 5 \\
\hline
\end{tabular}

Comments and examples:

In 2010 and 2011, Government funding received at same amount as to the previous year. The funding was still considered inadequate to implement upscaling of existing programmes. NGOs receives limited funding from private sector as there is still stigma in funding HIV Prevention projects. The status of Malaysia as Upper-Middle income country have made Malaysia not eligible to some of the funds from international.

A number of NGOs including the Malaysian AIDS Council and PT Foundation were able to access technical support from partners from international non-government organisations such as the International Planned Parenthood Federation (for monitoring and evaluation related work), and Open Society Institute (OSI) (for the harm reduction initiative) and from agencies such as the World Bank (research).

MAC also receives:

Technical Support by Alliance - HLE, GFATM training

Technical Support by WHO - Outreach Manual

Technical Support by TSF - GFATM Training, Consultants

Technical Support by GMS - GFATM Process, Manuals, Support

MAC also has graduated from receiving to giving knowledge sharing and technical support to other international organizations. 


\section{What percentage of the following HIV programmes/services is estimated to be provided by civil society?}

\begin{tabular}{|l|l|l|l|l|}
\hline & & & & \\
\hline Prevention for key-populations & & & & \\
\hline People living with HIV & $<25 \%$ & $25-50 \%$ & $51-75 \%$ & $>75 \%$ \\
\hline Men who have sex with men & $<25 \%$ & $25-50 \%$ & $51-75 \%$ & $>75 \%$ \\
\hline People who inject drugs & $<25 \%$ & $25-50 \%$ & $51-75 \%$ & $>75 \%$ \\
\hline Sex workers & $<25 \%$ & $25-50 \%$ & $51-75 \%$ & $>75 \%$ \\
\hline Transgendered people & $<25 \%$ & $25-50 \%$ & $51-75 \%$ & $>75 \%$ \\
\hline & & & & \\
\hline Testing and Counseling & $<25 \%$ & $25-50 \%$ & $51-75 \%$ & $>75 \%$ \\
\hline Reduction of Stigma and Discrimination & $<25 \%$ & $25-50 \%$ & $51-75 \%$ & $>75 \%$ \\
\hline Clinical services(ART/OI)* & $<25 \%$ & $25-50 \%$ & $51-75 \%$ & $>75 \%$ \\
\hline Home-based care & $<25 \%$ & $25-50 \%$ & $51-75 \%$ & $>75 \%$ \\
\hline Programmes for OVC** & $<25 \%$ & $25-50 \%$ & $51-75 \%$ & $>75 \%$ \\
\hline
\end{tabular}

*ART=Antiretroviral Therapy; OI=Opportunistic infections; **OVC=Orphans and other vulnerable children

\section{Overall, on a scale of 0 to 10 (where 0 is "Very Poor" and 10 is "Excellent"), how would you rate the efforts to increase civil society participation in 2011?}

\begin{tabular}{|c|c|c|c|c|c|c|c|c|c|c|}
\hline Very Poor & \multicolumn{9}{|c|}{ Excellent } \\
\hline 0 & 1 & 2 & 3 & 4 & 5 & 6 & 7 & 8 & 9 & 10 \\
\hline
\end{tabular}

Since 2009, what have been key achievements in this area:

Establishment of the Country Coordinating Mechanism (CCM) which features civil society representation of most-risk populations in a body chaired by the Deputy Minister of Health.

Establishment of the "cluster" concept with the Malaysian AIDS Council in 2008 where NGOs are firmly represented, coordinated, is involved in programming and is able to partake in strategic discussions at the national level. The clusters are expected to take ownership of their individual issues (e.g. sex worker cluster works on all issues affecting sex workers including advocacy).

Engagement of CSOs in NSP, Task Force on Women \& Girls, development has resulted in funding prioritisation of programmes for most-at-risk populations as compared to before.

Inter-governmental agencies (JAKIM, other state Islamic Council, KPWKM, PDRM) and involvement in state Stakeholders meeting.

Dagang-Halal, MARA - employment/training opportunities to KAP.

Working relationship with International Organizations.

Strengthen Corporate Response to HIV (Standard Chartered Malaysia, Chevron, MAC Cosmetics, L'Oreal, Johnson's \& Johnson's, Shell Malaysia, World Vision, Body Shop, YTL, Media Prima) funding direct/indirect, policy 
What challenges remain in this area:

Most CBOs require more capacity building in key technical areas as well as project management skills. The uncertain environment created as a result of unsustainable funding subjected to yearly Government approval has resulted in de-motivating and discouraging potential and current community leaders from continuing on. There is a concern that skilled and experienced civil society personnel are unable to be retained adequately to ensure quality participation and involvement in activities and initiated. CBOs also have difficulties in getting corporate funding.

There is a need for more active commitment in task force movement and guidelines haven't change under JKM Hospice Policy. As there is a high active participation by high ranking officers, but there is still lack of involvement in grass-root setting (PDRM, Local Council).There is also overlapping of services by CSOs in few areas and we still need further discussion on bridging the gap from NSEP CSO projects to government clinics.

\section{POLITICAL SUPPORT AND LEADERSHIP}

\section{Has the Government, through political and financial support, involved people living with HIV, key populations and/or other vulnerable sub-populations in governmental HIV-policy design and programme implementation?}

\section{Yes} No

\section{IF YES, describe some examples of when and how this has happened:}

In NSP development workshops and Task Force Working Group

CCM, Task Force Meeting

EPF withdrawal allowed for AIDS related, after much advocacy by CSO

Local authorities involve local CSO in local task force meeting

Human Resource Ministry get involvement of CSO in reviewing the HIV at Work Place policy

\section{HUMAN RIGHTS}

\subsection{Does the country have non-discrimination laws or regulations which specify protections for specific key populations and other vulnerable subpopulations? Circle yes if the policy specifies any of the following key populations:}

\begin{tabular}{|l|c|c|}
\hline KEY POPULATIONS and VULNERABLE SUBPOPULATIONS & & No \\
\hline People living with HIV & Yes & No \\
\hline Men who have sex with men & Yes & No \\
\hline Migrants/mobile populations & Yes & No \\
\hline Orphans and other vulnerable children & Yes & No \\
\hline People with disabilities & Yes & No \\
\hline People who inject drugs & Yes & No \\
\hline Prison inmates & Yes & No \\
\hline Sex workers & Yes & No \\
\hline Transgendered people & Yes & \multicolumn{2}{|c|}{} \\
\hline
\end{tabular}




\begin{tabular}{|l|c|c|}
\hline Women and girls & Yes & No \\
\hline Young women/ young men & Yes & No \\
\hline Other specific vulnerable subpopulations [write in]: & Yes & No \\
\hline \multicolumn{2}{|l}{} \\
\hline
\end{tabular}

\title{
1.2 Does the country have a general (i.e., not specific to HIV-related discrimination) law on non-discrimination?
}

\begin{tabular}{l|l} 
Yes & No
\end{tabular}

\author{
IF YES, to Question 1.1 or 1.2 , briefly describe the contents of these laws:
}

For PLHIV, there is an only guideline on burial services.

Children Act 2001 on OVC, People with Disabilities Act, Prison Act and Regulation, Section on Rehabilitation and Treatment for prisoner, Women and Girls Act, and CEDAW on Women and Girls.

For young women, men and the general public, Article 8 (2) of the Federal Constitution states "that there should be no discrimination against citizens on the ground only of religion, race, descent, gender or place of birth in any law or in the appointment to any office or employment under a public authority or in the administration of any law relating to the acquisition, holding or disposition of property or the establishing or carrying on of any trade, business, profession, vocation or employment." Therefore there is the possibility of obtaining a legal remedy to instances where such discrimination has occured.

Briefly explain what mechanisms are in place to ensure that these laws are implemented:

There are a number of governmental and civil society mechanisms in place which allow for redress of laws, issues and complaints:

The individual relevant Ministries have their individual public complaints mechanisms which allow members of the public to lodge complaints and to seek redress.

The civil society mechanisms which exist include seeking redress through the entities such as the Malaysian Medical Association, Bar Council, and Human Rights Commission for Malaysia, which will ensure the implementation of the law via different ministries. Specific NGOs which advocate issues are also used to seek support and to further advocate in behalf of the individual.

Briefly comment on the degree to which they are currently implemented:

Moderate, as working relationship between ministries and CSOs mechanisms do sometimes have different in opinions, views and directions as Malaysia have strict beliefs and values, e.g. religion. 


\section{Does the country have laws, regulations or policies that present obstacles ${ }^{64}$ to effective HIV prevention, treatment, care and support for key populations and other vulnerable subpopulations?}

\begin{tabular}{l|r} 
Yes & No
\end{tabular}

\subsection{IF YES, for which subpopulations?}

\begin{tabular}{|l|c|c|}
\hline KEY POPULATIONS and VULNERABLE SUBPOPULATIONS & & \\
\hline People living with HIV & Yes & No \\
\hline Men who have sex with men & Yes & No \\
\hline Migrants/mobile populations & Yes & No \\
\hline Orphans and other vulnerable children & Yes & No \\
\hline People with disabilities & Yes & No \\
\hline People who inject drugs & Yes & No \\
\hline Prison inmates & Yes & No \\
\hline Sex workers & Yes & No \\
\hline Transgendered people & Yes & No \\
\hline Women and girls & Yes & No \\
\hline Young women/young men & Yes & No \\
\hline Other specific vulnerable subpopulations ${ }^{65}[$ write in]: & Yes & No \\
\hline
\end{tabular}

Briefly describe the content of these laws, regulations or policies:

Penal Code 377A \& B - the introduction of the penis into the anus or mouth of the other person is said to commit carnal intercourse against the order of nature. Maximum penalty 20 years imprisonment and liable to fine and whipping.

Section 21 of the Minor Offences Act 1955 - Transgender persons could be charged with indecent behaviour, if they are found to be cross-dressing. The term 'indecent behaviour' has not been defined in the Act, and therefore, it is up to the discretion of the police to determine what constitutes 'indecent' behavior.

Drug Dependant Act (Treatment \& Rehabilitation) 1983 - Any police officer is able to detain a person under suspicion of being a drug user for not more than 24 hours for administration of a urine drug test.

Dangerous Drugs Act 1952 - self administration of drugs is punishable with a fine and/or imprisonment

Dangerous Drugs Act 1952 - it remains illegal to carry injection equipment without a medical prescription and possession of needles is punishable with imprisonment

\footnotetext{
${ }^{64}$ These are not necessarily HIV-specific policies or laws. They include policies, laws, or regulations which may deter people from or make it difficult for them to access prevention, treatment, care and support services. Examples cited in country reports in the past have include: "laws that criminalize same sex relationships"," laws that criminalize possession of condoms or drug paraphernalia";"loitering laws"; "laws that preclude importation of generic medicines"; "policies that preclude distribution or possession of condoms in prisons";"policies that preclude on-citizens from accessing ART"; "criminalization of HIV transmission and exposure", "inheritance laws/rights for women", "laws that prohibit provision of sexual and reproductive health information and services to young people", etc

${ }^{65}$ Other specific vulnerable populations other than above, may be defined as having been locally identified as being at higher risk of HIV infection (e.g.(in alphabetical order) bisexual people, clients of sex workers, indigenous people, internally displaced people, prisoners, and refugees)
} 
Briefly comment on how they pose barriers:

Fear of persecution and discrimination makes it difficult to reach out to MSM and transgender persons. Religious bodies and laws enforcement agencies less likely to cooperate as MSM \& TG sexual behaviour is considered unacceptable by society.

Although there is no existing law or policy against individuals carrying condoms, women in particular are subject to accusations of soliciting for sex or being branded a sex worker. This could result in overnight detention or harassment by law enforcement officers. Such evidentiary use of the condom, discourages sex workers from using them as well as brothels from providing them on the premises. This also applies in a similar fashion to MSM where spas and massage centres refuse to supply condoms for fear of legal action being taken on them resulting in the loss of their operating licence and depriving them of business.

Current laws stipulate for compulsory drug treatment and provide for punishment of drug users with canning and imprisonment should the person relapse after discharge from government run drug rehabilitation centres (DRC). Civil society groups believe that treatment for drug addiction should be an option and not compulsory under the law.

Clients of the Needle Syringe Exchange Programme (NSEP) become 'easy targets' for law enforcement officers. As the latter continues to have the authority to detain persons suspected to be drug users, this could discourage effective utilisation of the programme by the IDU community as they could be arrested while being in the vicinity of the NSEP centre.

The carrying of syringes and needles, outside of healthcare settings, is still technically illegal despite the existence of a government Harm Reduction programme. This results in complications and contradictory messages whereupon a government programme is encouraging the exchange and use of clean needles and syringes while law enforcement bodies are told that the usage of drugs and the carrying of drug paraphernalia are barred under the law. However, due to the NSEP, the active enforcement of this legislation was reportedly relaxed.

The existence of laws which are in direct contradiction with the activities of the Government initiated NSEP continue to send contradictory signals to law enforcement bodies and judiciary. This could present itself as a significant obstacle in successfully ensuring the sustainability and continued existence of the programme.

Laws and regulations which especially govern and restrict communication of HIV awareness and prevention messages are of particular concern. The use of particular text and explicit graphics (such as putting on a condom on a penis) in such messages could be considered and subject to legal prosecution for the use of pornography under legislation which governs the print media.

Though the NSP under Strategy 1 recognises the existence and vulnerability of the MSM population, their sexual behaviour is subject to prosecution under existing legislation (Penal Code 377 on the issue of sodomy).

Mandatory testing of foreign workers continue to conducted, screening for HIV and other infectious diseases such as Hepatitis B \& C as well as tuberculosis. Despite being recognised as a vulnerable population under Strategy 5 of the NSP, there is no pre and post test counselling. In most cases, the individual has no knowledge of their medical tests and are only told whether they are medically fit to work and be employed in Malaysia. Failing such screening tests result in deportation of the individual. 
3. Does the country have a policy, law or regulation to reduce violence against women, including for example, victims of sexual assault or women living with HIV?

\section{Yes}

No

Briefly describe the content of the policy, law or regulation and the populations included:

Domestic Violence Act 1994

Women and Girls Act

National Policy on Women

National Policy on Youth

Penal Code 377 (Rape, Carnal Intercourse)

Code of Practice to prevent and eliminate sexual harassment at workplace 1999

CEDAW - Convention Elimination Discrimination against Women, Malaysia is one of signatory country and has been used in a recent court case.

\section{Is the promotion and protection of human rights explicitly mentioned in any HIV policy or strategy?}

\begin{tabular}{|l|l|}
\hline Yes & No \\
\hline
\end{tabular}

IF YES, briefly describe how human rights are mentioned in this HIV policy or strategy:

There is no policy or strategy explicitly mentioned Human Rights promotion and protection, but the guiding principle of National Strategic Plan on HIV/AIDS 2006-2010 and 2011-2015 clearly indicates that People Living With HIV have the same right to health care and community support as other members of society. They have the right to participate in any socio-economic activity, without prejudice and discrimination.

\section{Is there a mechanism to record, document and address cases of discrimination experienced by people living with HIV, key populations and other vulnerable populations?}

\section{Yes} No

IF YES, briefly describe this mechanisms:

Legal Aid Centre under the Bar Council records and documents all discrimination cases.

Public Complaint under different ministries

Various civil society organisations (CSOs) as well as entities such as the Bar Council and Legal Aid Centre are active in the recording and documentation of such cases. However to ensure that cases are brought to a higher level to address the issue, it is very often dependent on the PLHIV or persons affected by the discrimination to proceed.

However, the reality is that if a person who is living with HIV suffers discrimination as a result of stigma, it is often considered hard to prove. Documentation continues to be a problem as people 
who suffer such discrimination are reluctant to proceed further due to the risk of exposure of one's status. Practical problems abound with regards to addressing HIV related acts of discrimination.

Advocacy is done through reports lodged to relevant ministries, the use of the media and engagement with the legal system. Relevant ministries such as the Ministry of Human Resource have in-built mechanisms (e.g. Code of Practice on HIV/AIDS in the Workplace) for redress by PLHIV within the context of the working environment.

6. Does the country have a policy or strategy of free services for the following? Indicate if these services are provided free-of-charge to all people, to some people or not at all (circle "yes" or "no" as applicable).

\begin{tabular}{|l|c|c|c|c|c|c|}
\hline & $\begin{array}{c}\text { Provided free of } \\
\text { charge to all } \\
\text { people in the } \\
\text { country }\end{array}$ & \multicolumn{2}{|c|}{$\begin{array}{c}\text { Provided free of charge } \\
\text { to some people in the } \\
\text { country }\end{array}$} & $\begin{array}{c}\text { Provided, but only at a } \\
\text { cost }\end{array}$ \\
\hline Antiretroviral treatment & Yes & No & Yes & No & Yes & No \\
\hline HIV prevention services & Yes & No & Yes & No & Yes & No \\
\hline $\begin{array}{l}\text { HIV-related care and } \\
\text { support interventions }\end{array}$ & Yes & No & Yes & No & Yes & No \\
\hline
\end{tabular}

If applicable, which populations have been identified as priority, and for which services?

Basically, prevention services are free-of-charge to all people. First-line medications are free but mainly for Malaysian and Permanent Residence at all government health care providers (HCP) and CSO and at a cost for UNHCR (Refugees, Asylum Seekers). Private HCP and GPs also do provide these services but only at a cost.

\section{Does the country have a policy or strategy to ensure equal access for women and men to HIV prevention, treatment, care and support?}

\begin{tabular}{|l|l|}
\hline Yes & No \\
\hline
\end{tabular}

\subsection{In particular, does the country have a policy or strategy to ensure access to HIV prevention, treatment, care and support for women outside the context of pregnancy and childbirth?}

\begin{tabular}{|l|l|}
\hline Yes & No \\
\hline
\end{tabular}

8. Does the country have a policy or strategy to ensure equal access for key populations and/or other vulnerable sub-populations to HIV prevention, treatment, care and support?

\footnotetext{
${ }^{66}$ Such as blood safety, condom promotion, harm reduction for people who inject drugs, HIV prevention for out-of-school young people, HIV prevention in the workplace, HIV testing and counseling, IEC on risk reduction, IEC on stigma and discrimination reduction, prevention of mother- to-child transmission of HIV, prevention for people living with HIV, reproductive health services including sexually transmitted infections prevention and treatment, risk reduction for intimate partners of key populations, risk reduction for men who have sex with men, risk reduction for sex workers, school-based HIV education for young people, universal precautions in health care settings.
} 
IF YES, briefly describe the content of this policy/strategy and the populations included:

Under Strategy 1 of the National Strategic Plan on HIV/AIDS 2006-2010 (NSP), the Government is committed to ensure equal access to treatment, care and other support services, guaranteed confidentiality, and access to voluntary counselling and testing.Under Strategy 1 of the National Strategic Plan on HIV/AIDS 2011-2015, the goverment is committed to improve the quality and coverage of prevention programmes among most at risk and vulnerable populations. And this also stated in Strategy 2, 3 and 4.All key populations will receive support based on Health Rights under the MOH HIV Prevention programs, Shelter Home Policy of Ministry of Women, Social and Community Development and MAC's HIV Prevention programs.

\subsection{IF YES, does this policy/strategy include different types of approaches to ensure equal access for different key populations and/or other vulnerable sub- populations?}

\begin{tabular}{|l|l|}
\hline Yes & No \\
\hline
\end{tabular}

IF YES, briefly explain the different types of approaches to ensure equal access for different populations:

HIV Screening for all

For PWID - addressing drug addition and HIV prevention through harm reductionutilising the Needle Syringe Exchange Programme (NSEP) and Methadone MaintenanceTherapy (MMT).

For SW/TS/MSM - HIV prevention and intervention through VCT, telephone counselling,outreach programmes, condom awareness, SRH/STI and community drop-in centres

For youth with high risk behaviour - focusing on prevention through education andawareness programmes to facilitate behavioural change (e.g. life skill basededucation, sexual reproductive health)

Indigenous population - awareness through seminars and talks conducted as part ofoutreach programmes to rural and remote locations. E.g. Baram Project.

For PLHIV - Treatment, care and support through shelter and hospital peer supportprogrammes

For prison inmates - are given access to ART and Methadone Maintenance Therapytreatment and referrals for counselling.

For internees at drug rehabilitation centres (Pusat Serenti) - the provision of referralservices and access to treatment.

Community based organizations remain the dominant actor in the provision of HIVservices to the undocumented population (e.g. refugees, migrant workers, undocumented migrants).

\section{Does the country have a policy or law prohibiting HIV screening for general employment purposes (recruitment, assignment/relocation, appointment, promotion and termination)?}

\begin{tabular}{|l|l|}
\hline Yes & No \\
\hline
\end{tabular}

IF $\boldsymbol{Y E S}$, briefly describe the content of the policy or law:

Not applicable 
10. Does the country have the following human rights monitoring and enforcement mechanisms?

a. Existence of independent national institutions for the promotion and protection of human rights, including human rights commissions, law reform commissions, watchdogs, and ombudspersons which consider HIV-related issues within their work

\begin{tabular}{|l|l|} 
Yes & No \\
\hline
\end{tabular}

b. Performance indicators or benchmarks for compliance with human rights standards in the context of HIV efforts

\begin{tabular}{|c|c|}
\hline Yes & No \\
\hline
\end{tabular}

IF YES on any of the above questions, describe some examples:

Human Rights Commission of Malaysia (SUHAKAM) is able to adopt HIV and AIDS issues for redress. SUHAKAM was established by Parliament under the Human Rights Commission of Malaysia Act 1999, Act 597. Their main function is to inquire into complaints regarding violation of human rights including HIV-related issues.

Bar Council - The Legal Aid facility is able to consider HIV cases as part of its portfolio. These Issues are linked to discrimination and denial of specific rights.

11. In the last 2 years, have there been the following training and/or capacity-building activities:

a. Programmes to educate, raise awareness among people living with HIV and key populations concerning their rights (in the context of $\mathrm{HIV}^{67}$ ?

\begin{tabular}{l|l} 
Yes & No
\end{tabular}

b. Programmes for members of the judiciary and law enforcement ${ }^{68}$ on HIV and human rights issues that may come up in the context of their work?

\begin{tabular}{|c|c|}
\hline Yes & No \\
\hline
\end{tabular}

12 Are the following legal support services available in the country?

a. Legal aid systems for HIV case work

\begin{tabular}{|c|c|}
\hline Yes & No \\
\hline
\end{tabular}

b. Private sector law firms or university-based centres to provide free or reducedcost legal services to people living with HIV

\begin{tabular}{|l|l|}
\hline Yes & No \\
\hline
\end{tabular}

\footnotetext{
${ }^{67}$ Including, for example, Know-your-rights campaigns-campaigns that empower those affected by HIV to know their rights and the laws in context of the epidemic (see UNAIDS Guidance Note: Addressing HIV-related law at National Level, Working Paper, 30 April 2008)

${ }^{68}$ Including, for example, judges, magistrates, prosecutors, police, human rights commissioners and employment tribunal/ labour court judges or commissioners
} 


\section{Are there programmes in place to reduce HIV-related stigma and discrimination?}

\begin{tabular}{|l|c|c|}
\cline { 2 - 3 } \multicolumn{1}{c|}{} & Yes & No \\
\hline IF $\boldsymbol{Y} E \boldsymbol{S}$, what types of programmes? & & No \\
\hline Programmes for health care workers & Yes & No \\
\hline Programmes for the media & Yes & No \\
\hline Programmesi n the workplace & Yes & No \\
\hline Other [write in]: Islamic Religious Leaders, Law Enforcement Agencies & Yes &
\end{tabular}

14. Overall, on a scale of 0 to 10 (where 0 is "Very Poor" and 10 is "Excellent"), how would you rate the policies, laws and regulations in place to promote and protect human rights in relation to HIV in 2011?

\begin{tabular}{|c|c|c|c|c|c|c|c|c|c|c|}
\hline $\begin{array}{l}\text { Very } \\
\text { Poor }\end{array}$ & & & & & & & & & & $\begin{array}{l}\text { Excel } \\
\text { lent }\end{array}$ \\
\hline 0 & 1 & 2 & 3 & 4 & 5 & 6 & 7 & 8 & 9 & 10 \\
\hline
\end{tabular}

Since2009, what have been key achievements in this area:

Continuous engagement with religious bodies, particularly with Muslim religious authorities, has resulted in changes to their perception and attitude towards marginalized groups such as female sex workers and transgender persons.

A revised Malaysian 'Manual HIV and Islam' with Islamic Development Department, MOH and MAC, with series of implementation workshop to religious leaders.

MOH follows WHO recommendation on CD4 eligibility for treatment from 250 to 350 .

Shelter for PLHIV under JAKIM and State Islamic Council

Involvement of public figures on reducing stigma and discrimination

What challenges remain in this area:

Need to review existing labour legislation to address the issue of stigma \& discrimination of PLHIV at workplace. This would strengthen implementation and adherence to the existing Code of Practice on Prevention and Management of HIV/AIDS at the Workplace, which was initiated by the Ministry of Human Resource.

The abovementioned Code of Practice, though already in existence for several years, needs to be further promoted and encouraged for adoption by the private sector.

Need to identify and recommend review of laws and regulations which may have an impact on effective implementation of the Needle Syringe Exchange Programme (e.g. Dangerous Drugs Act 1952 which criminalises the use and possession of syringes \& needles without a medical prescription.

Although there has been improved involvement and acceptance from Department of Islamic Development (JAKIM), the state religious authorities need to be better engaged on HIV related issues.

There is a continual need to sensitize and involve all stakeholders who work directly or have direct contact with MARPs such as the local government authorities, prisons department, religious authorities, law enforcement bodies (e.g. police), National Anti Drug Agency (NADA) and immigration department. 


\section{Overall, on a scale of 0 to 10 (where 0 is "Very Poor" and 10 is "Excellent"), how would you rate the effort to implement human rights related policies, laws and regulations in 2011?}

\begin{tabular}{|c|c|c|c|c|c|c|c|c|c|c|}
\hline Very Poor & \multicolumn{9}{|c|}{ Excellent } \\
\hline 0 & 1 & 2 & 3 & 4 & 5 & 6 & 7 & 8 & 9 & 10 \\
\hline
\end{tabular}

Since2009, what have been key achievements in this area:

EPF, for AIDS Related but not for PLHIV (for medication)

Continuous efforts by the Department of Islamic Development (JAKIM) and Islamic Council from few states.

What challenges remain in this area:

HIV at Work Place policy is not implemented by all

No insurance coverage for PLHIV

For Social Security Organisation Protection Scheme or SOCSO, PLHIV who are not able to work cannot apply for SOCSO coverage

On death certificates, the cause of death is documented as 'AIDS'.

\section{PREVENTION}

\section{Has the country identified the specific needs for HIV prevention programmes?}

\section{Yes} $\mathrm{No}$

IF YES, how were these specific needs determined?

Same as in 2010 report, specific needs were determined through extensive consultation, discussions and meetings between the different NGOs and CBOs working on HIV issues and their counterparts at the Ministry of Health, Ministry of Women, Family and Community Development, Department of Islamic Development, HIV research groups (e.g. Centre of Excellence for Research in AIDS) and multilateral agencies such as those from the United Nations.

IF NO, how are HIV prevention programmes being scaled-up?

Not applicable 


\subsection{To what extent has HIV prevention been implemented?}

\begin{tabular}{|c|c|c|c|c|c|}
\hline \multirow[b]{2}{*}{ HIV prevention component } & \multicolumn{5}{|c|}{ The majority of people in need have access to... } \\
\hline & $\begin{array}{l}\text { Strongly } \\
\text { disagree }\end{array}$ & Disagree & Agree & $\begin{array}{c}\text { Strongly } \\
\text { agree }\end{array}$ & $\mathrm{N} / \mathrm{A}$ \\
\hline Bloods safety & 1 & 2 & 3 & 4 & \\
\hline Condom promotion & 1 & 2 & 3 & 4 & \\
\hline $\begin{array}{l}\text { Harm reduction for people who inject } \\
\text { drugs }\end{array}$ & 1 & 2 & 3 & 4 & \\
\hline $\begin{array}{l}\text { HIV prevention for out-of-school young } \\
\text { people }\end{array}$ & 1 & 2 & 3 & 4 & \\
\hline HIV prevention in the workplace & 1 & 2 & 3 & 4 & \\
\hline HIV testing and counseling & 1 & 2 & 3 & 4 & \\
\hline $\mathrm{IEC}^{69}$ on risk reduction & 1 & 2 & 3 & 4 & \\
\hline $\begin{array}{l}\text { IEC on stigma and discrimination } \\
\text { reduction }\end{array}$ & 1 & 2 & 3 & 4 & \\
\hline $\begin{array}{l}\text { Prevention of mother-to-child } \\
\text { transmission of HIV }\end{array}$ & 1 & 2 & 3 & 4 & \\
\hline $\begin{array}{l}\text { Prevention for people living with } \\
\text { HIV }\end{array}$ & 1 & 2 & 3 & 4 & \\
\hline $\begin{array}{l}\text { Reproductive health services including } \\
\text { sexually transmitted infections prevention } \\
\text { and treatment }\end{array}$ & 1 & 2 & 3 & 4 & \\
\hline $\begin{array}{l}\text { Risk reduction for intimate partners of key } \\
\text { populations }\end{array}$ & 1 & 2 & 3 & 4 & \\
\hline $\begin{array}{l}\text { Risk reduction for men who have sex } \\
\text { with men }\end{array}$ & 1 & 2 & 3 & 4 & \\
\hline Risk reduction for sex workers & 1 & 2 & 3 & 4 & \\
\hline $\begin{array}{l}\text { School-based HIV education for young } \\
\text { people }\end{array}$ & 1 & 2 & 3 & 4 & \\
\hline $\begin{array}{l}\text { Universal precautions in healthcare } \\
\text { settings }\end{array}$ & 1 & 2 & 3 & 4 & \\
\hline Other $[$ write in]: & 1 & 2 & 3 & 4 & \\
\hline
\end{tabular}

${ }^{69} \mathrm{IEC}=$ information, education, communication 
2. Overall, on a scale of 0 to 10 (where 0 is "Very Poor" and 10 is "Excellent"), how would you rate the efforts in the implementation of HIV prevention programmes in 2011?

\begin{tabular}{|c|c|c|c|c|c|c|c|c|c|c|}
\hline Very Poor & \multicolumn{9}{|c|}{ Excellent } \\
\hline 0 & 1 & 2 & 3 & 4 & 5 & 6 & 7 & 8 & 9 & 10 \\
\hline
\end{tabular}

Since2009, what have been key achievements in this area:

HIV prevention to all key populations under CSO

MSM receives international funding for MSM Poz, MSM Borneo and ISEAN-Hivos Program

Malaysia successfully receiving GFATM R10 for expanding SW, TG and NSEP Program

Scale-up of CSO on NSEP Program under $\mathrm{MOH}$ funding

Reduce of HIV Infection

What challenges remain in this area:

Young People still not focused, as they are more at risk - they are sexually active age.

No HIV Prevention or Sexual Education at school level.

Not all key stakeholders involve in national response

Women \& Girls Task Force is not active

Rural area not reached

\section{TREATMENT, CARE AND SUPPORT}

\section{Has the country identified the essential elements of a comprehensive package of HIV treatment, care and support services?}

IF $\boldsymbol{Y E S}$, Briefly identify the elements and what has been prioritized:

My Plus established and created in for Care and Support of PLHIV Network

Paramedic/Para-counselors trained in HIV Post-Basic training

Financial assistance for children till 18 years old

HAART given free to all first line, partial funded for second line (may apply medicine assistance scheme at MAF)

HAART and MMT provision available in incarcerated settings

Briefly identify how HIV treatment, care and support services are being scaled-up?

Manual for Shelter Home

Children Care Standard under UNICEF Fund

SOP for Hospital Peer Support Program (and there was discussion on changing the service to PLHIV

Peer Support Program 


\subsection{To what extent have the following HIV treatment, care and support services been implemented?}

\begin{tabular}{|c|c|c|c|c|c|}
\hline \multirow[b]{2}{*}{ HIV treatment, care and support service } & \multicolumn{5}{|c|}{ The majority of people in need have access to... } \\
\hline & $\begin{array}{l}\text { Strongly } \\
\text { disagree }\end{array}$ & Disagree & Agree & $\begin{array}{l}\text { Strongly } \\
\text { agree }\end{array}$ & $\mathrm{N} / \mathrm{A}$ \\
\hline Anti retroviral therapy & 1 & 2 & 3 & 4 & \\
\hline ART for TB patients & 1 & 2 & 3 & 4 & \\
\hline $\begin{array}{l}\text { Cotrimoxazole prophylaxisin people living } \\
\text { with HIV }\end{array}$ & 1 & 2 & 3 & 4 & \\
\hline Early infant diagnosis & 1 & 2 & 3 & 4 & \\
\hline $\begin{array}{l}\text { HIV care and support in the workplace } \\
\text { (including alternative working arrangements) }\end{array}$ & 1 & 2 & 3 & 4 & \\
\hline HIV testing and counseling for people with TB & 1 & 2 & 3 & 4 & \\
\hline $\begin{array}{l}\text { HIV treatment services in the workplace or } \\
\text { treatment referral systems through } \\
\text { the workplace }\end{array}$ & 1 & 2 & 3 & 4 & \\
\hline Nutritional care & 1 & 2 & 3 & 4 & \\
\hline Pediatric AIDS treatment & 1 & 2 & 3 & 4 & \\
\hline Post-delivery ART provision to women & 1 & 2 & 3 & 4 & \\
\hline $\begin{array}{l}\text { Post-exposure prophylaxis for } \\
\text { non-occupational exposure (e.g. sexual } \\
\text { assault) }\end{array}$ & 1 & 2 & 3 & 4 & \\
\hline $\begin{array}{l}\text { Post-exposure prophylaxis for } \\
\text { occupational exposures to HIV }\end{array}$ & 1 & 2 & 3 & 4 & \\
\hline $\begin{array}{l}\text { Psychosocial support for people living with HIV } \\
\text { and their families }\end{array}$ & 1 & 2 & 3 & 4 & \\
\hline $\begin{array}{l}\text { Sexually transmitted infection } \\
\text { management }\end{array}$ & 1 & 2 & 3 & 4 & \\
\hline $\begin{array}{l}\text { TB infection control in HIV treatment and } \\
\text { care facilities }\end{array}$ & 1 & 2 & 3 & 4 & \\
\hline $\begin{array}{l}\text { TB preventive therapy for people living with } \\
\text { HIV }\end{array}$ & 1 & 2 & 3 & 4 & \\
\hline TB screening for people living with HIV & 1 & 2 & 3 & 4 & \\
\hline $\begin{array}{l}\text { Treatment of common HIV-related } \\
\text { infections }\end{array}$ & 1 & 2 & 3 & 4 & \\
\hline Other [write in]: & 1 & 2 & 3 & 4 & \\
\hline
\end{tabular}


1.2 Overall, on a scale of 0 to 10 (where 0 is "Very Poor" and 10 is "Excellent"), how would you rate the efforts in the implementation of HIV treatment, care and support programmes in 2011?

\begin{tabular}{|c|c|c|c|c|c|c|c|c|c|c|}
\hline Very Poor & \multicolumn{1}{|c|}{ Excellent } \\
\hline 0 & 1 & 2 & 3 & 4 & 5 & 6 & 7 & 8 & 9 & 10 \\
\hline
\end{tabular}

Since2009, what have been key achievements in this area:

Coverage of treatments are free to all Malaysian at all government hospitals

Half-way home supports morally for PLHIV

Religious Council and JAKIM plan to establish PLHIV Shelter Home

Quality of life for PLHIV Children improved (UNICEF Project)

HAART and MMT at incarcerated setting

What challenges remain in this area:

Shortage of half-way house / case worker / social worker

No home-based care program

Psychosocial support

JKM (government shelter homes) not receiving PLHIV

Self-stigma by PLHIV in accessing treatment

Behavior Modification

2. Does the country have a policy or strategy to address the additional HIVrelated needs of orphans and other vulnerable children?

\begin{tabular}{|l|l|}
\hline Yes & No \\
\hline
\end{tabular}

2.1 IF YES, is there an operational definition for orphans and vulnerable children in the country?

\begin{tabular}{|l|l|}
\hline Yes & No \\
\hline
\end{tabular}

2.2 IF YES, does the country have a national action plan specifically for orphans and vulnerable children?

\begin{tabular}{|l|l|}
\hline Yes & No \\
\hline
\end{tabular}

2.3 IF YES, does the country have an estimate of orphans and vulnerable children being reached by existing interventions?

\begin{tabular}{|l|l|}
\hline Yes & No \\
\hline
\end{tabular}

2.4 IF YES, what percentage of orphans and vulnerable children is being reached? 
3. Overall, on a scale of 0 to 10 (where 0 is "Very Poor" and 10 is "Excellent"), how would you rate the efforts to meet the HIV-related needs of orphans and other vulnerable children in 2011?

\begin{tabular}{|c|c|c|c|c|c|c|c|c|c|c|}
\hline Very Poor & \multicolumn{10}{|c|}{ Excellent } \\
\hline 0 & 1 & 2 & 3 & 4 & 5 & 6 & 7 & 8 & 9 & 10 \\
\hline
\end{tabular}

Since2009, what have been key achievements in this area:

UNICEF Programme - Standardization of Minimum Care Standard, Develop Conducive Environment in Shelter Setting, Element of Safety, Play Therapy, Child Rights.

L'Oreal and M.A.C Cosmetics Fund the current running program.

World Vision funds shelter.

What challenges remain in this area:

After 18 years old, no exit plan for these children.

Political commitments on the PLHIV Children Health Right.

SOP on Home-based care for PLHIV Children.

Sensitization of children learning centre on universal precautions. 
$\begin{array}{ll}\text { Country } & \text { : Malaysia } \\ \text { Name of local currency } & : \text { MYR (RM) } \\ \text { Currency expressed in } & : \text { RM }\end{array}$
Average exchange rate for the year (local currency to
AIDS SPENDING CATEGORIES

\section{TOTAL}

\section{PREVENTION}

1.01 Communication for social and behavioural change

1.03 Voluntary counseling and testing (VCT)

1.04 Risk-reduction for vulnerable and accessible populations

1.05. Prevention - Youth in school

1.06 Prevention - Youth out-of-school

1.07 Prevention of HIV transmission aimed at people living with HIV

1.08 Prevention programmes for sex workers and their clients

1.09 Programmes for men who have sex with men

1.10 Harm-reduction programmes for injecting drug users

1.11 Prevention programmes in the workplace

1.12 Condom social marketing

1.13 Public and commercial sector male condom provision

1.14 Public and commercial sector female condom provision

1.15 Microbicides

1.16 Prevention, diagnosis and treatment of sexually transmitted infections (STI)

1.17 Prevention of mother-to-child transmission

1.18 Male Circumcision

1.19 Blood safety

1.20 Safe medical injections

1.21 Universal precautions

1.22 Post-exposure prophylaxis

1.98 Prevention activities not disaggregated by intervention

1.99 Prevention activities not elsewhere classified

\section{CARE AND TREATMENT}

2.01 Outpatient care

2.01.01 Provider- initiated testing and counseling

2.01.02 Opportunistic infection (OI) outpatient prophylaxis and treatment

2.01.03 Antiretroviral therapy

2.01.04 Nutritional support associated to ARV therap

2.01.05 Specific HIV-related laboratory monitoring

2.01.06 Dental programmes for PLHIV

2.01.07 Psychological treatment and support services

2.01.08 Outpatient palliative care

2.01.09 Home-based care

2.01.10 Traditional medicine and informal care and treatment services

2.01.98 Outpatient care services not disaggregated by intervention

2.01.99 Outpatient Care services not elsewhere classified
TOTAL

$96,474,291.01$

$25,515,620.50 \quad 25.05$

$1,074,977.00$

$392,584.00$

$144,000.00$
$147,459.00$

$147,459.00$
$767,964.00$

$767,964.00$
$577,804.00$

$577,804.00$
$362,020.00$

$362,020.00$

$1,259,488.00$

$541,110.00$
$14,766,685.60$

14,766,685.60

$35,000.00$

$118,453.00$

$118,200.00$
0.00

0.00
$3,000.00$

$3,000.00$
$303,840.00$

$3,227,179.50$

0.00
$200,000.00$

$20,000.00$

$20,000.00$
$125,736.40$
$10,000.00$

$10,000.00$

$1,115,380.00$

$1,115,380.00$
$250,740.00$

\begin{tabular}{r|r|}
\hline $50,769,038.01$ & 52.62
\end{tabular}

$50,769,038.01$
$54,335,118.01$

\begin{tabular}{r|}
$54,335,118.01$ \\
\hline $40,000.00$ \\
\hline $153,460.00$
\end{tabular}

$153,460.00$
$7543,102.00$

\begin{tabular}{r|r}
$35,843,102.00$ & 70.6
\end{tabular}

$243,000.00$

$8,190,365.00$

0.00
$248,196.00$

0.00

0.00
$21,590.00$

0.00
$73,239.01$

$3,784,239.01$
$: 3.02$

\begin{tabular}{|c|c|c|c|c|c|c|c|}
\hline \multicolumn{4}{|c|}{ Public Sources } & \multicolumn{4}{|c|}{ International Sources } \\
\hline \multirow{2}{*}{ Public Sub-Total } & \multirow{2}{*}{$\begin{array}{l}\text { Central / } \\
\text { National }\end{array}$} & \multirow{2}{*}{$\begin{array}{c}\text { Sub- } \\
\text { National }\end{array}$} & \multirow{2}{*}{$\begin{array}{l}\text { All Other } \\
\text { Public }\end{array}$} & \multirow{2}{*}{$\begin{array}{l}\text { International } \\
\text { Sub-Total }\end{array}$} & \multirow{2}{*}{ Bilat. } & \multicolumn{2}{|c|}{ Multilateral } \\
\hline & & & & & & UN Agencies & Global Fund \\
\hline $94,777,413.39$ & $94,777,413.39$ & 0.00 & 0.00 & $1,696,877.62$ & 0.00 & $1,696,877.62$ & 0.00 \\
\hline $25,059,872.50$ & $25,059,872.50$ & 0.00 & 0.00 & $455,748.00$ & 0.00 & $455,748.00$ & 0.00 \\
\hline $1,059,977.00$ & $1,059,977.00$ & 0.00 & 0.00 & $15,000.00$ & 0.00 & $15,000.00$ & 0.00 \\
\hline $392,584.00$ & $392,584.00$ & 0.00 & 0.00 & 0.00 & 0.00 & 0.00 & 0.00 \\
\hline $144,000.00$ & $144,000.00$ & 0.00 & 0.00 & 0.00 & 0.00 & 0.00 & 0.00 \\
\hline $10,000.00$ & $10,000.00$ & 0.00 & 0.00 & $137,459.00$ & 0.00 & $137,459.00$ & 0.00 \\
\hline $767,964.00$ & $767,964.00$ & 0.00 & 0.00 & 0.00 & 0.00 & 0.00 & 0.00 \\
\hline $473,171.00$ & $473,171.00$ & 0.00 & 0.00 & $104,633.00$ & 0.00 & $104,633.00$ & 0.00 \\
\hline $362,020.00$ & $362,020.00$ & 0.00 & 0.00 & 0.00 & 0.00 & 0.00 & 0.00 \\
\hline $1,060,832.00$ & $1,060,832.00$ & 0.00 & 0.00 & $198,656.00$ & 0.00 & $198,656.00$ & 0.00 \\
\hline $541,110.00$ & $541,110.00$ & 0.00 & 0.00 & 0.00 & 0.00 & 0.00 & 0.00 \\
\hline $14,766,685.60$ & $14,766,685.60$ & 0.00 & 0.00 & 0.00 & 0.00 & 0.00 & 0.00 \\
\hline $35,000.00$ & $35,000.00$ & 0.00 & 0.00 & 0.00 & 0.00 & 0.00 & 0.00 \\
\hline $118,453.00$ & $118,453.00$ & 0.00 & 0.00 & 0.00 & 0.00 & 0.00 & 0.00 \\
\hline $72,200.00$ & $72,200.00$ & 0.00 & 0.00 & 0.00 & 0.00 & 0.00 & 0.00 \\
\hline 0.00 & 0.00 & 0.00 & 0.00 & 0.00 & 0.00 & 0.00 & 0.00 \\
\hline $3,000.00$ & $3,000.00$ & 0.00 & 0.00 & 0.00 & 0.00 & 0.00 & 0.00 \\
\hline $303,840.00$ & $303,840.00$ & 0.00 & 0.00 & 0.00 & 0.00 & 0.00 & 0.00 \\
\hline $3,227,179.50$ & $3,227,179.50$ & 0.00 & 0.00 & 0.00 & 0.00 & 0.00 & 0.00 \\
\hline 0.00 & 0.00 & 0.00 & 0.00 & 0.00 & 0.00 & 0.00 & 0.00 \\
\hline $200,000.00$ & $200,000.00$ & 0.00 & 0.00 & 0.00 & 0.00 & 0.00 & 0.00 \\
\hline $20,000.00$ & $20,000.00$ & 0.00 & 0.00 & 0.00 & 0.00 & 0.00 & 0.00 \\
\hline $125,736.40$ & $125,736.40$ & 0.00 & 0.00 & 0.00 & 0.00 & 0.00 & 0.00 \\
\hline $10,000.00$ & $10,000.00$ & 0.00 & 0.00 & 0.00 & 0.00 & 0.00 & 0.00 \\
\hline $1,115,380.00$ & $1,115,380.00$ & 0.00 & 0.00 & 0.00 & 0.00 & 0.00 & 0.00 \\
\hline $250,740.00$ & $250,740.00$ & 0.00 & 0.00 & 0.00 & 0.00 & 0.00 & 0.00 \\
\hline $50,769,038.01$ & $50,769,038.01$ & 0.00 & 0.00 & 0.00 & 0.00 & 0.00 & 0.00 \\
\hline $54,335,118.01$ & $48,955,952.01$ & 0.00 & 0.00 & 0.00 & 0.00 & 0.00 & 0.00 \\
\hline $40,000.00$ & $40,000.00$ & 0.00 & 0.00 & 0.00 & 0.00 & 0.00 & 0.00 \\
\hline $153,460.00$ & $153,460.00$ & 0.00 & 0.00 & 0.00 & 0.00 & 0.00 & 0.00 \\
\hline $35,843,102.00$ & $35,843,102.00$ & 0.00 & 0.00 & 0.00 & 0.00 & 0.00 & 0.00 \\
\hline $243,000.00$ & $243,000.00$ & 0.00 & 0.00 & 0.00 & 0.00 & 0.00 & 0.00 \\
\hline $8,190,365.00$ & $8,190,365.00$ & 0.00 & 0.00 & 0.00 & 0.00 & 0.00 & 0.00 \\
\hline 0.00 & 0.00 & 0.00 & 0.00 & 0.00 & 0.00 & 0.00 & 0.00 \\
\hline $248,196.00$ & $248,196.00$ & 0.00 & 0.00 & 0.00 & 0.00 & 0.00 & 0.00 \\
\hline 0.00 & 0.00 & 0.00 & 0.00 & 0.00 & 0.00 & 0.00 & 0.00 \\
\hline $21,590.00$ & $21,590.00$ & 0.00 & 0.00 & 0.00 & 0.00 & 0.00 & 0.00 \\
\hline 0.00 & 0.00 & 0.00 & 0.00 & 0.00 & 0.00 & 0.00 & 0.00 \\
\hline $3,784,239.01$ & $3,784,239.01$ & 0.00 & 0.00 & 0.00 & 0.00 & 0.00 & 0.00 \\
\hline $432,000.00$ & $432,000.00$ & 0.00 & 0.00 & 0.00 & 0.00 & 0.00 & 0.00 \\
\hline
\end{tabular}




\begin{tabular}{|c|c|c|c|c|c|c|c|c|c|c|}
\hline \multirow{3}{*}{ AIDS SPENDING CATEGORIES } & \multirow{3}{*}{ TOTAL } & \multirow{3}{*}{$\%$} & \multicolumn{4}{|c|}{ Public Sources } & \multicolumn{4}{|c|}{ International Sources } \\
\hline & & & \multirow[b]{2}{*}{ Public Sub-Total } & \multirow{2}{*}{$\begin{array}{l}\text { Central / } \\
\text { National } \\
\end{array}$} & \multirow{2}{*}{$\begin{array}{c}\text { Sub- } \\
\text { National }\end{array}$} & \multirow{2}{*}{$\begin{array}{l}\text { All Other } \\
\text { Public }\end{array}$} & \multirow{2}{*}{$\begin{array}{l}\text { International } \\
\text { Sub-Total }\end{array}$} & \multirow{2}{*}{ Bilat. } & \multicolumn{2}{|c|}{ Multilateral } \\
\hline & & & & & & & & & UN Agencies & Global Fund \\
\hline 2.02 In-patient care & $1,813,086.00$ & & $1,813,086.00$ & $1,813,086.00$ & 0.00 & 0.00 & 0.00 & 0.00 & 0.00 & 0.00 \\
\hline 2.02.01 Inpatient treatment of opportunistic infections (OI) & $1,813,086.00$ & & $1,813,086.00$ & $1,813,086.00$ & 0.00 & 0.00 & 0.00 & 0.00 & 0.00 & 0.00 \\
\hline 2.02 .02 Inpatient palliative care & 0.00 & & 0.00 & 0.00 & 0.00 & 0.00 & 0.00 & 0.00 & 0.00 & 0.00 \\
\hline 2.02.98 Inpatient care services not disaggregated by intervention & 0.00 & & 0.00 & 0.00 & 0.00 & 0.00 & 0.00 & 0.00 & 0.00 & 0.00 \\
\hline 2.02 .99 In-patient services not elsewhere classified & 0.00 & & 0.00 & 0.00 & 0.00 & 0.00 & 0.00 & 0.00 & 0.00 & 0.00 \\
\hline 2.03 Patient transport and emergency rescue & 0.00 & & 0.00 & 0.00 & 0.00 & 0.00 & 0.00 & 0.00 & 0.00 & 0.00 \\
\hline 2.98 Care and treatment services not disaggregated by intervention & 0.00 & & 0.00 & 0.00 & 0.00 & 0.00 & 0.00 & 0.00 & 0.00 & 0.00 \\
\hline 2.99 Care and treatment services not-elsewhere classified & 0.00 & & 0.00 & 0.00 & 0.00 & 0.00 & 0.00 & 0.00 & 0.00 & 0.00 \\
\hline 3. ORPHANS AND VULNERABLE CHILDREN (OVC) & $1,889,466.00$ & 1.86 & $1,752,994.00$ & $1,752,994.00$ & 0.00 & 0.00 & $136,472.00$ & 0.00 & $136,472.00$ & 0.00 \\
\hline 3.01 OVC Education & 0.00 & & 0.00 & 0.00 & 0.00 & 0.00 & 0.00 & 0.00 & 0.00 & 0.00 \\
\hline 3.02 OVC Basic health care & 0.00 & & 0.00 & 0.00 & 0.00 & 0.00 & 0.00 & 0.00 & 0.00 & 0.00 \\
\hline 3.03 OVC Family/home support & 0.00 & & 0.00 & 0.00 & 0.00 & 0.00 & 0.00 & 0.00 & 0.00 & 0.00 \\
\hline 3.04 OVC Community support & 0.00 & & 0.00 & 0.00 & 0.00 & 0.00 & 0.00 & 0.00 & 0.00 & 0.00 \\
\hline 3.05 OVC Social services and Administrative costs & 0.00 & & 0.00 & 0.00 & 0.00 & 0.00 & 0.00 & 0.00 & 0.00 & 0.00 \\
\hline 3.06 OVC Institutional Care & $1,889,466.00$ & & $1,752,994.00$ & $1,752,994.00$ & 0.00 & 0.00 & $136,472.00$ & 0.00 & $136,472.00$ & 0.00 \\
\hline 3.98 OVC services not disaggregated by intervention & 0.00 & & 0.00 & 0.00 & 0.00 & 0.00 & 0.00 & 0.00 & 0.00 & 0.00 \\
\hline 3.99 OVC services not-elsewhere classified & 0.00 & & 0.00 & 0.00 & 0.00 & 0.00 & 0.00 & 0.00 & 0.00 & 0.00 \\
\hline 4. PROGRAM MANAGEMENT AND ADMIN. STRENGTHENING & $13,508,525.56$ & 13.26 & $13,320,563.88$ & $13,320,563.88$ & 0.00 & 0.00 & $187,961.68$ & 0.00 & $187,961.68$ & 0.00 \\
\hline 4.01 Planning, coordination and programme management & $1,518,936.68$ & & $1,341,711.00$ & $1,341,711.00$ & 0.00 & 0.00 & $177,225.68$ & 0.00 & $177,225.68$ & 0.00 \\
\hline 4.02 Admin. \& transaction costs associated with managing and disbursing funds & $332,506.00$ & & $332,506.00$ & $332,506.00$ & 0.00 & 0.00 & 0.00 & 0.00 & 0.00 & 0.00 \\
\hline 4.03 Monitoring and evaluation & $364,620.00$ & & $364,620.00$ & $364,620.00$ & 0.00 & 0.00 & 0.00 & 0.00 & 0.00 & 0.00 \\
\hline 4.04 Operations research & $20,736.00$ & & $10,000.00$ & $10,000.00$ & 0.00 & 0.00 & $10,736.00$ & 0.00 & $10,736.00$ & 0.00 \\
\hline 4.05 Serological-surveillance (Serosurveillance) & $210,000.00$ & & $210,000.00$ & $210,000.00$ & 0.00 & 0.00 & 0.00 & 0.00 & 0.00 & 0.00 \\
\hline 4.06 HIV drug-resistance surveillance & 0.00 & & 0.00 & 0.00 & 0.00 & 0.00 & 0.00 & 0.00 & 0.00 & 0.00 \\
\hline 4.07 Drug supply systems & $5,000.00$ & & $5,000.00$ & $5,000.00$ & 0.00 & 0.00 & 0.00 & 0.00 & 0.00 & 0.00 \\
\hline 4.08 Information technology & $112,858.00$ & & $112,858.00$ & $112,858.00$ & 0.00 & 0.00 & 0.00 & 0.00 & 0.00 & 0.00 \\
\hline 4.09 Patient tracking & $70,000.00$ & & $70,000.00$ & $70,000.00$ & 0.00 & 0.00 & 0.00 & 0.00 & 0.00 & 0.00 \\
\hline 4.10 Upgrading and construction of infrastructure & $277,160.00$ & & $277,160.00$ & $277,160.00$ & 0.00 & 0.00 & 0.00 & 0.00 & 0.00 & 0.00 \\
\hline 4.11 Mandatory HIV testing (not VCT) & $170,000.00$ & & $170,000.00$ & $170,000.00$ & 0.00 & 0.00 & 0.00 & 0.00 & 0.00 & 0.00 \\
\hline 4.98 Program Management \& Admin. Strengthening not disaggregated by type & $10,139,091.88$ & & $10,139,091.88$ & $10,139,091.88$ & 0.00 & 0.00 & 0.00 & 0.00 & 0.00 & 0.00 \\
\hline 4.99 Program Management \& Admin. Strengthening not-elsewhere classified & $287,617.00$ & & $287,617.00$ & $287,617.00$ & 0.00 & 0.00 & 0.00 & 0.00 & 0.00 & 0.00 \\
\hline 5. INCENTTIVES FOR HUMAN RESOURCES & $1,898,813.74$ & 1.86 & $1,869,945.00$ & $1,869,945.00$ & 0.00 & 0.00 & $28,868.74$ & 0.00 & $28,868.74$ & 0.00 \\
\hline 5.01 Monetary incentives for human resources & $15,840.00$ & & $15,840.00$ & $15,840.00$ & 0.00 & 0.00 & 0.00 & 0.00 & 0.00 & 0.00 \\
\hline 5.02 Formative education to build-up an HIV workforce & $94,400.00$ & & $94,400.00$ & $94,400.00$ & 0.00 & 0.00 & 0.00 & 0.00 & 0.00 & 0.00 \\
\hline 5.03 Training & $1,156,473.74$ & & $1,127,605.00$ & $1,127,605.00$ & 0.00 & 0.00 & $28,868.74$ & 0.00 & $28,868.74$ & 0.00 \\
\hline 5.98 Incentives for Human Resources not specified by kind & $632,100.00$ & & $632,100.00$ & $632,100.00$ & 0.00 & 0.00 & 0.00 & 0.00 & 0.00 & 0.00 \\
\hline 5.99 Incentives for Human Resources not elsewhere classified & 0.00 & & 0.00 & 0.00 & 0.00 & 0.00 & 0.00 & 0.00 & 0.00 & 0.00 \\
\hline 6. SOC. PROTECTION \& SOC. SERVICES EXCLUD. OVC & $2,000,000.00$ & 1.96 & $2,000,000.00$ & $2,000,000.00$ & 0.00 & 0.00 & 0.00 & 0.00 & 0.00 & 0.00 \\
\hline 6.01 Social protection through monetary benefits & 0.00 & & 0.00 & 0.00 & 0.00 & 0.00 & 0.00 & 0.00 & 0.00 & 0.00 \\
\hline 6.02 Social protection through in-kind benefits & 0.00 & & 0.00 & 0.00 & 0.00 & 0.00 & 0.00 & 0.00 & 0.00 & 0.00 \\
\hline 6.03 Social protection through provision of social services & $2,000,000.00$ & & $2,000,000.00$ & $2,000,000.00$ & 0.00 & 0.00 & 0.00 & 0.00 & 0.00 & 0.00 \\
\hline 6.04 HIV-specific income generation projects & 0.00 & & 0.00 & 0.00 & 0.00 & 0.00 & 0.00 & 0.00 & 0.00 & 0.00 \\
\hline 6.98 Social protection services and social services not disaggregated by type & 0.00 & & 0.00 & 0.00 & 0.00 & 0.00 & 0.00 & 0.00 & 0.00 & 0.00 \\
\hline 6.99 Social protection services and social services not elsewhere classified & 0.00 & & 0.00 & 0.00 & 0.00 & 0.00 & 0.00 & 0.00 & 0.00 & 0.00 \\
\hline
\end{tabular}


[GLOBAL AIDS RESPONSE PROGRESS REPORT 2012]

\begin{tabular}{|c|c|c|c|c|c|c|c|c|c|c|}
\hline \multirow{3}{*}{ AIDS SPENDING CATEGORIES } & \multirow{3}{*}{ TOTAL } & \multirow{3}{*}{$\%$} & \multicolumn{4}{|c|}{ Public Sources } & \multicolumn{4}{|c|}{ International Sources } \\
\hline & & & \multirow{2}{*}{ Public Sub-Total } & \multirow{2}{*}{$\begin{array}{l}\text { Central / } \\
\text { National }\end{array}$} & \multirow{2}{*}{$\begin{array}{c}\text { Sub- } \\
\text { National }\end{array}$} & \multirow{2}{*}{$\begin{array}{l}\text { All Other } \\
\text { Public }\end{array}$} & \multirow{2}{*}{$\begin{array}{c}\text { International } \\
\text { Sub-Total }\end{array}$} & \multirow{2}{*}{ Bilat. } & \multicolumn{2}{|c|}{ Multilateral } \\
\hline & & & & & & & & & UN Agencies & Global Fund \\
\hline 7. ENABLING ENVIRONMENT & $887,827.20$ & 0.87 & 0.00 & 0.00 & 0.00 & 0.00 & $887,827.20$ & 0.00 & $887,827.20$ & 0.00 \\
\hline 7.01 Advocacy & $20,000.00$ & & 0.00 & 0.00 & 0.00 & 0.00 & $20,000.00$ & 0.00 & $20,000.00$ & 0.00 \\
\hline 7.02 Human rights programmes & 0.00 & & 0.00 & 0.00 & 0.00 & 0.00 & 0.00 & 0.00 & 0.00 & 0.00 \\
\hline 7.03 AIDS-specific institutional development & 0.00 & & 0.00 & 0.00 & 0.00 & 0.00 & 0.00 & 0.00 & 0.00 & 0.00 \\
\hline 7.04 AIDS-specific programmes focused on women & 0.00 & & 0.00 & 0.00 & 0.00 & 0.00 & 0.00 & 0.00 & 0.00 & 0.00 \\
\hline 7.05 Programmes to reduce Gender Based Violence & $150,075.88$ & & 0.00 & 0.00 & 0.00 & 0.00 & $150,075.88$ & 0.00 & $150,075.88$ & 0.00 \\
\hline 7.98 Enabling Environment and Community Development not disaggregated by type & $717,751.32$ & & 0.00 & 0.00 & 0.00 & 0.00 & $717,751.32$ & 0.00 & $717,751.32$ & 0.00 \\
\hline 7.99 Enabling Environment and Community Development not elsewhere classified & 0.00 & & 0.00 & 0.00 & 0.00 & 0.00 & 0.00 & 0.00 & 0.00 & 0.00 \\
\hline 8. RESEARCH & $5,000.00$ & 0.00 & $5,000.00$ & $5,000.00$ & 0.00 & 0.00 & 0.00 & 0.00 & 0.00 & 0.00 \\
\hline 8.01 Biomedical research & 0.00 & & 0.00 & 0.00 & 0.00 & 0.00 & 0.00 & 0.00 & 0.00 & 0.00 \\
\hline 8.02 Clinical research & 0.00 & & 0.00 & 0.00 & 0.00 & 0.00 & 0.00 & 0.00 & 0.00 & 0.00 \\
\hline 8.03 Epidemiological research & $5,000.00$ & & 5000.00 & 5000.00 & 0.00 & 0.00 & 0.00 & 0.00 & 0.00 & 0.00 \\
\hline 8.04 Social science research & 0.00 & & 0.00 & 0.00 & 0.00 & 0.00 & 0.00 & 0.00 & 0.00 & 0.00 \\
\hline 8.05 Vaccine-related research & 0.00 & & 0.00 & 0.00 & 0.00 & 0.00 & 0.00 & 0.00 & 0.00 & 0.00 \\
\hline 8.98 Research not disaggregated by type & 0.00 & & 0.00 & 0.00 & 0.00 & 0.00 & 0.00 & 0.00 & 0.00 & 0.00 \\
\hline 8.99 Research not elsewhere classified & 0.00 & & 0.00 & 0.00 & 0.00 & 0.00 & 0.00 & 0.00 & 0.00 & 0.00 \\
\hline
\end{tabular}


Country

Name of local currency

: Malaysia

MYR (RM)

Currency expressed in

Year : 2011

Average exchange rate for the year (local currency to USD) : $\quad 3.02$

\begin{tabular}{|c|c|c|c|c|c|c|}
\hline \multirow[b]{2}{*}{ TOTAL } & \multirow[b]{2}{*}{$\%$} & \multicolumn{4}{|c|}{ Public Sources } & \multirow[b]{2}{*}{$\begin{array}{l}\text { International } \\
\text { Sub-Total }\end{array}$} \\
\hline & & Public Sub-Total & $\begin{array}{l}\text { Central/ } \\
\text { National }\end{array}$ & $\begin{array}{c}\text { Sub- } \\
\text { National }\end{array}$ & $\begin{array}{l}\text { All Other } \\
\text { Public }\end{array}$ & \\
\hline $120,420,418.36$ & & $110,737,815.32$ & $110,238,843.32$ & $256,546.00$ & $242,426.00$ & $7,670,211.04$ \\
\hline $29,841,733.80$ & 24.78 & $22,730,055.40$ & $22,682,787.40$ & $42,268.00$ & $5,000.00$ & $7,057,493.40$ \\
\hline $1,222,798.00$ & & $1,222,798.00$ & $1,213,030.00$ & $9,768.00$ & 0.00 & 0.00 \\
\hline $680,418.00$ & & $672,518.00$ & $640,018.00$ & $32,500.00$ & 0.00 & 0.00 \\
\hline $122,000.00$ & & $122,000.00$ & $122,000.00$ & 0.00 & 0.00 & 0.00 \\
\hline $90,674.00$ & & $79,354.00$ & $79,354.00$ & 0.00 & 0.00 & $11,320.00$ \\
\hline $717,354.00$ & & $717,354.00$ & $717,354.00$ & 0.00 & 0.00 & 0.00 \\
\hline $439,012.94$ & & $249,105.00$ & $249,105.00$ & 0.00 & 0.00 & $165,637.94$ \\
\hline $347,790.00$ & & $330,000.00$ & $330,000.00$ & 0.00 & 0.00 & 0.00 \\
\hline $3,991,842.70$ & & $481,893.00$ & $481,893.00$ & 0.00 & 0.00 & $3,509,949.70$ \\
\hline $493,925.00$ & & $489,700.00$ & $489,700.00$ & 0.00 & 0.00 & 0.00 \\
\hline $17,427,504.76$ & 58.40 & $14,056,919.00$ & $14,051,919.00$ & 0.00 & $5,000.00$ & $3,370,585.76$ \\
\hline $35,000.00$ & & $35,000.00$ & $35,000.00$ & 0.00 & 0.00 & 0.00 \\
\hline $285,946.00$ & & $285,946.00$ & $285,946.00$ & 0.00 & 0.00 & 0.00 \\
\hline $119,900.00$ & & $119,900.00$ & $119,900.00$ & 0.00 & 0.00 & 0.00 \\
\hline 0.00 & & 0.00 & 0.00 & 0.00 & 0.00 & 0.00 \\
\hline 0.00 & & 0.00 & 0.00 & 0.00 & 0.00 & 0.00 \\
\hline $184,392.00$ & & $184,392.00$ & $184,392.00$ & 0.00 & 0.00 & 0.00 \\
\hline $2,609,998.40$ & & $2,609,998.40$ & $2,609,998.40$ & 0.00 & 0.00 & 0.00 \\
\hline & & 0.00 & 0.00 & 0.00 & 0.00 & 0.00 \\
\hline $200,000.00$ & & $200,000.00$ & $200,000.00$ & 0.00 & & 0.00 \\
\hline $20,000.00$ & & $20,000.00$ & $20,000.00$ & 0.00 & 0.00 & 0.00 \\
\hline $63,428.00$ & & $63,428.00$ & $63,428.00$ & 0.00 & 0.00 & 0.00 \\
\hline $10,000.00$ & & $10,000.00$ & $10,000.00$ & 0.00 & 0.00 & 0.00 \\
\hline $779,750.00$ & & $779,750.00$ & $779,750.00$ & 0.00 & 0.00 & 0.00 \\
\hline 0.00 & & 0.00 & 0.00 & 0.00 & 0.00 & 0.00 \\
\hline $65,356,231.48$ & 54.27 & $64,962,703.48$ & $64,725,277.48$ & 0.00 & $237,426.00$ & 0.00 \\
\hline $59,324,034.00$ & & $58,930,506.00$ & $58,693,080.00$ & 0.00 & $237,426.00$ & 0.00 \\
\hline $40,000.00$ & & $40,000.00$ & & 0.00 & 0.00 & 0.00 \\
\hline $191,220.00$ & & $191,220.00$ & $191,220.00$ & 0.00 & 0.00 & 0.00 \\
\hline $47,923,388.00$ & 73.33 & $47,653,860.00$ & $47,653,860.00$ & 0.00 & 0.00 & 0.00 \\
\hline $253,000.00$ & & $253,000.00$ & $253,000.00$ & 0.00 & 0.00 & 0.00 \\
\hline $10,113,000.00$ & & $10,113,000.00$ & $10,113,000.00$ & 0.00 & 0.00 & 0.00 \\
\hline & & 0.00 & 0.00 & 0.00 & & 0.00 \\
\hline $361,426.00$ & & $237,426.00$ & 0.00 & 0.00 & $237,426.00$ & 0.00 \\
\hline 0.00 & & 0.00 & 0.00 & 0.00 & 0.00 & 0.00 \\
\hline $10,000.00$ & & $10,000.00$ & $10,000.00$ & 0.00 & 0.00 & 0.00 \\
\hline 0.00 & & 0.00 & 0.00 & 0.00 & 0.00 & 0.00 \\
\hline 0.00 & & 0.00 & 0.00 & 0.00 & 0.00 & 0.00 \\
\hline & & & & 0.00 & 0.00 & 0.00 \\
\hline
\end{tabular}

International Resources

\begin{tabular}{|c|c|c|c|c|c|}
\hline \multirow{2}{*}{ Bilat. } & \multicolumn{2}{|c|}{ Multilaterals } & \multicolumn{3}{|c|}{ Private Sources } \\
\cline { 2 - 3 } & $\begin{array}{c}\text { UN } \\
\text { Agencies }\end{array}$ & Globale Sub- & $\begin{array}{c}\text { Hound } \\
\text { Total } \\
\text { funds }\end{array}$ & $\begin{array}{c}\text { All Other } \\
\text { Private }\end{array}$ \\
\hline
\end{tabular}

TOTAL

1. PREVENTION

1.01 Communication for social and behavioural change

1.02 Community mobilization

1.03 Voluntary counseling and testing $(\mathrm{VCT})$
1.04 Risk-reduction for vulnerable and accessible populations

1.05. Prevention - Youth in school

1.06 Prevention - Youth out-of-school

1.07 Prevention of HIV transmission aimed at people living with
1.08 Prevention programmes for sex workers and their clients

1.09 Programmes for men who have sex with men

1.10 Harm-reduction programmes for injecting drug users

1.11 Prevention programmes in the workplace

1.13 Public and commercial sector male condom provision

1.14 Public and commercial sector female condom provision

1.15 Microbicides

1.17 Prevention of mother-to-child transmission

1.18 Male circumcision

1.19 Blood safety

1.21 Universal precautions

2. CARE AND TREATMENT

2.01 Outpatient care

2.01.01 Provider- initiated testing and counseling

2.01.02 Opportunistic infection

2.01.04 Nutritional support associated to ARV therapy

2.01.05 Specific HIV-related laboratory

2.01.06 Dental programmes for PLHIV

2.01.09 Home-based care

2.01.10 Traditional medicine and informal care and treatment services

\begin{tabular}{|l|}
\hline 2.01.98 Outpatient care services not disaggregated by interve \\
\hline 2.01.99 Outpatient Care services not elsewhere classified \\
\hline
\end{tabular}

432.000 .00

\begin{tabular}{|c|c|c|c|c|c|}
\hline & Agencies & Global Fund & lotal & funas & Private \\
\hline 0.00 & 929,039.52 & $6,741,171.52$ & $2,012,392.00$ & $1,115,097.00$ & $897,295.00$ \\
\hline 0.00 & $316,321.88$ & $6,741,171.52$ & $54,185.00$ & 0.00 & $54,185.00$ \\
\hline & 0.00 & 0.00 & 0.00 & 0.00 & 0.00 \\
\hline & 0.00 & 0.00 & $7,900.00$ & 0.00 & $7,900.00$ \\
\hline & 0.00 & 0.00 & 0.00 & 0.00 & 0.00 \\
\hline & $11,320.00$ & 0.00 & 0.00 & 0.00 & 0.00 \\
\hline & 0.00 & 0.00 & 0.00 & 0.00 & 0.00 \\
\hline & $165,637.94$ & 0.00 & $24,270.00$ & 0.00 & $24,270.00$ \\
\hline & 0.00 & 0.00 & $17,790.00$ & 0.00 & $17,790.00$ \\
\hline & $\begin{array}{l}139,363.94 \\
\end{array}$ & $3,370,585.76$ & 0.00 & 0.00 & 0.00 \\
\hline & 0.00 & 0.00 & $4,225.00$ & 0.00 & $4,225.00$ \\
\hline & 0.00 & $3,370,585.76$ & 0.00 & 0.00 & 0.00 \\
\hline & 0.00 & 0.00 & 0.00 & 0.00 & 0.00 \\
\hline & 0.00 & 0.00 & 0.00 & 0.00 & 0.00 \\
\hline & 0.00 & 0.00 & 0.00 & 0.00 & 0.00 \\
\hline & 0.00 & 0.00 & 0.00 & 0.00 & 0.00 \\
\hline & 0.00 & 0.00 & 0.00 & 0.00 & 0.00 \\
\hline & 0.00 & 0.00 & 0.00 & 0.00 & 0.00 \\
\hline & 0.00 & 0.00 & 0.00 & 0.00 & 0.00 \\
\hline & 0.00 & 0.00 & 0.00 & 0.00 & 0.00 \\
\hline & 0.00 & 0.00 & 0.00 & 0.00 & 0.00 \\
\hline & 0.00 & 0.00 & 0.00 & 0.00 & 0.00 \\
\hline & 0.00 & 0.00 & 0.00 & 0.00 & 0.00 \\
\hline & 0.00 & 0.00 & 0.00 & 0.00 & 0.00 \\
\hline & 0.00 & 0.00 & 0.00 & 0.00 & 0.00 \\
\hline & 0.00 & 0.00 & 0.00 & 0.00 & 0.00 \\
\hline 0.00 & 0.00 & 0.00 & $393,528.00$ & $269,528.00$ & $124,000.00$ \\
\hline 0.00 & 0.00 & 0.00 & $393,528.00$ & $269,528.00$ & $124,000.00$ \\
\hline & 0.00 & 0.00 & 0.00 & 0.00 & 0.00 \\
\hline & 0.00 & 0.00 & 0.00 & 0.00 & 0.00 \\
\hline & 0.00 & 0.00 & $269,528.00$ & $269,528.00$ & 0.00 \\
\hline & 0.00 & 0.00 & 0.00 & 0.00 & 0.00 \\
\hline & 0.00 & 0.00 & 0.00 & 0.00 & 0.00 \\
\hline & 0.00 & 0.00 & 0.00 & 0.00 & 0.00 \\
\hline & 0.00 & 0.00 & $124,000.00$ & 0.00 & $124,000.00$ \\
\hline & 0.00 & 0.00 & 0.00 & 0.00 & 0.00 \\
\hline & 0.00 & 0.00 & 0.00 & 0.00 & 0.00 \\
\hline & 0.00 & 0.00 & 0.00 & 0.00 & 0.00 \\
\hline & 0.00 & 0.00 & 0.00 & 0.00 & 0.00 \\
\hline & 0.00 & 0.00 & 0.00 & 0.00 & 0.00 \\
\hline
\end{tabular}




\begin{tabular}{|c|c|c|c|c|c|c|c|c|c|c|c|c|c|}
\hline \multirow{3}{*}{$\begin{array}{l}\text { AIDS SPENDING CATEGORIES } \\
2.02 \text { In-patient care }\end{array}$} & \multirow{3}{*}{$\begin{array}{l}\text { TOTAL } \\
2,048,788.00\end{array}$} & \multirow{3}{*}{$\%$} & \multicolumn{4}{|c|}{ Public Sources } & \multicolumn{4}{|c|}{ International Resources } & \multicolumn{3}{|c|}{ Private Sources } \\
\hline & & & \multirow{2}{*}{\begin{tabular}{|r} 
Public Sub-Total \\
$2,048,788.00$
\end{tabular}} & \multirow{2}{*}{ 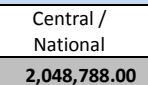 } & \multirow{2}{*}{$\begin{array}{c}\begin{array}{c}\text { Sub- } \\
\text { National }\end{array} \\
\mathbf{0 . 0 0}\end{array}$} & \multirow{2}{*}{$\begin{array}{l}\begin{array}{c}\text { All Other } \\
\text { Public }\end{array} \\
0.00\end{array}$} & \multirow{2}{*}{$\begin{array}{c}\begin{array}{c}\text { International } \\
\text { Sub-Total }\end{array} \\
0.00\end{array}$} & \multirow{2}{*}{$\begin{array}{r}\text { Bilat. } \\
0.00\end{array}$} & \multicolumn{2}{|c|}{ Multilaterals } & \multirow{2}{*}{$\begin{array}{c}\begin{array}{c}\text { Private Sub- } \\
\text { Total }\end{array} \\
0.00\end{array}$} & \multirow{2}{*}{$\begin{array}{c}\begin{array}{c}\text { Household } \\
\text { funds }\end{array} \\
0.00\end{array}$} & \multirow{2}{*}{$\begin{array}{l}\begin{array}{c}\text { All Other } \\
\text { Private }\end{array} \\
0.00\end{array}$} \\
\hline & & & & & & & & & 0.00 & 0.00 & & & \\
\hline 2.02.01 Inpatient treatment of opportunistic infections (OI) & $2,048,788.00$ & & $2,048,788.00$ & $2,048,788.00$ & 0.00 & 0.00 & 0.00 & & 0.00 & 0.00 & 0.00 & 0.00 & 0.00 \\
\hline 2.02 .02 Inpatient palliative care & 0.00 & & 0.00 & 0.00 & 0.00 & 0.00 & 0.00 & & 0.00 & 0.00 & 0.00 & 0.00 & 0.00 \\
\hline 2.02 .98 Inpatient care services not disaggregated by intervention & 0.00 & & 0.00 & 0.00 & 0.00 & 0.00 & 0.00 & & 0.00 & 0.00 & 0.00 & 0.00 & 0.00 \\
\hline 2.02.99 In-patient services not elsewhere classified & 0.00 & & 0.00 & 0.00 & 0.00 & 0.00 & 0.00 & & 0.00 & 0.00 & 0.00 & 0.00 & 0.00 \\
\hline 2.03 Patient transport and emergency rescue & 0.00 & & 0.00 & 0.00 & 0.00 & 0.00 & 0.00 & & 0.00 & 0.00 & 0.00 & 0.00 & 0.00 \\
\hline 2.98 Care and tratment services not disaggregated by intervention & $3,983,409.48$ & & $3,983,409.48$ & $3,983,409.48$ & 0.00 & 0.00 & 0.00 & & 0.00 & 0.00 & 0.00 & 0.00 & 0.00 \\
\hline 2.99 Care and treatment services not-elsewhere classified & 0.00 & & 0.00 & 0.00 & 0.00 & 0.00 & 0.00 & & 0.00 & 0.00 & 0.00 & 0.00 & 0.00 \\
\hline 3. ORPHANS AND VULNERABLE CHILDREN (OVC) & $2,388,460.00$ & 1.98 & $2,003,342.00$ & $2,003,342.00$ & 0.00 & 0.00 & $137,462.00$ & 0.00 & $137,462.00$ & 0.00 & $247,656.00$ & 0.00 & $247,656.00$ \\
\hline 3.01 OVC Education & $7,000.00$ & & $7,000.00$ & $7,000.00$ & 0.00 & 0.00 & 0.00 & & 0.00 & 0.00 & 0.00 & 0.00 & 0.00 \\
\hline 3.02 OVC Basic health care & 0.00 & & 0.00 & 0.00 & 0.00 & 0.00 & 0.00 & & 0.00 & 0.00 & 0.00 & 0.00 & 0.00 \\
\hline 3.03 OVC Family/home support & 0.00 & & 0.00 & 0.00 & 0.00 & 0.00 & 0.00 & & 0.00 & 0.00 & 0.00 & 0.00 & 0.00 \\
\hline 3.04 OVC Community support & 0.00 & & 0.00 & 0.00 & 0.00 & 0.00 & 0.00 & & 0.00 & 0.00 & 0.00 & 0.00 & 0.00 \\
\hline 3.05 OVC Social services and Administrative costs & 0.00 & & 0.00 & 0.00 & 0.00 & 0.00 & 0.00 & & 0.00 & 0.00 & 0.00 & 0.00 & 0.00 \\
\hline 3.06 OVC Institutional Care & $2,381,460.00$ & & $1,996,342.00$ & $1,996,342.00$ & 0.00 & 0.00 & $137,462.00$ & & $137,462.00$ & 0.00 & $247,656.00$ & 0.00 & $247,656.00$ \\
\hline 3.98 OVC services not disaggregated by intervention & 0.00 & & 0.00 & 0.00 & 0.00 & 0.00 & 0.00 & & 0.00 & 0.00 & 0.00 & 0.00 & 0.00 \\
\hline 3.99 OVC services not-elsewhere classified & 0.00 & & 0.00 & 0.00 & 0.00 & 0.00 & 0.00 & & 0.00 & 0.00 & 0.00 & 0.00 & 0.00 \\
\hline 4. PROGRAM MANAGEMENT AND ADMINISTRATION STRENGTHENING & $14,386,954.72$ & 11.95 & $13,486,408.44$ & $13,465,408.44$ & $21,000.00$ & 0.00 & 3,364.28 & 0.00 & 3,364.28 & 0.00 & $897,182.00$ & $845,569.00$ & $51,613.00$ \\
\hline 4.01 Planning, coordination and programme management & $1,419,883.28$ & & $1,416,519.00$ & $1,416,519.00$ & 0.00 & 0.00 & $3,364.28$ & & $3,364.28$ & 0.00 & 0.00 & 0.00 & 0.00 \\
\hline 4.02 Admin. \& transaction costs associated with managing and disbursing funds & $1,244,784.00$ & & $399,215.00$ & $378,215.00$ & $21,000.00$ & 0.00 & 0.00 & & 0.00 & 0.00 & $845,569.00$ & $845,569.00$ & 0.00 \\
\hline 4.03 Monitoring and evaluation & $450,914.00$ & & $450,914.00$ & $450,914.00$ & 0.00 & 0.00 & 0.00 & & 0.00 & 0.00 & 0.00 & 0.00 & 0.00 \\
\hline 4.04 Operations research & $61,613.00$ & & $10,000.00$ & $10,000.00$ & 0.00 & 0.00 & 0.00 & & 0.00 & 0.00 & $51,613.00$ & 0.00 & $51,613.00$ \\
\hline 4.05 Serological-surveillance (Serosurveillance) & $210,000.00$ & & $210,000.00$ & $210,000.00$ & 0.00 & 0.00 & 0.00 & & 0.00 & 0.00 & 0.00 & 0.00 & 0.00 \\
\hline 4.06 HIV drug-resistance surveillance & 0.00 & & 0.00 & 0.00 & 0.00 & 0.00 & 0.00 & & 0.00 & 0.00 & 0.00 & 0.00 & 0.00 \\
\hline 4.07 Drug supply systems & $5,000.00$ & & $5,000.00$ & $5,000.00$ & 0.00 & 0.00 & 0.00 & & 0.00 & 0.00 & 0.00 & 0.00 & 0.00 \\
\hline 4.08 Information technology & $133,870.00$ & & $133,870.00$ & $133,870.00$ & 0.00 & 0.00 & 0.00 & & 0.00 & 0.00 & 0.00 & 0.00 & 0.00 \\
\hline 4.09 Patient tracking & $70,000.00$ & & $70,000.00$ & $70,000.00$ & 0.00 & 0.00 & 0.00 & & 0.00 & 0.00 & 0.00 & 0.00 & 0.00 \\
\hline 4.10 Upgrading and construction of infrastructure & $190,000.00$ & & $190,000.00$ & $190,000.00$ & 0.00 & 0.00 & 0.00 & & 0.00 & 0.00 & 0.00 & 0.00 & 0.00 \\
\hline 4.11 Mandatory HIV testing (not VCT) & $170,000.00$ & & $170,000.00$ & $170,000.00$ & 0.00 & 0.00 & 0.00 & & 0.00 & 0.00 & 0.00 & 0.00 & 0.00 \\
\hline 4.98 Program Management \& Admin. Strengthening not disaggregated by type & $10,164,718.44$ & & $10,164,718.44$ & $10,164,718.44$ & 0.00 & 0.00 & 0.00 & & 0.00 & 0.00 & 0.00 & 0.00 & 0.00 \\
\hline 4.99 Program Management \& Admin. Strengthening not-elsewhere classified & $266,172.00$ & & $266,172.00$ & $266,172.00$ & 0.00 & 0.00 & 0.00 & & 0.00 & 0.00 & 0.00 & 0.00 & 0.00 \\
\hline 5. INCENTIVES FOR HUMAN RESOURCES & $1,483,721.00$ & 1.23 & $1,452,721.00$ & $1,452,721.00$ & 0.00 & 0.00 & $31,000.00$ & 0.00 & $31,000.00$ & 0.00 & 0.00 & 0.00 & 0.00 \\
\hline 5.01 Monetary incentives for human resources & $14,600.00$ & & $14,600.00$ & $14,600.00$ & 0.00 & 0.00 & 0.00 & & 0.00 & 0.00 & 0.00 & 0.00 & 0.00 \\
\hline 5.02 Formative education to build-up an HIV workforce & $102,000.00$ & & $102,000.00$ & $102,000.00$ & 0.00 & 0.00 & 0.00 & & 0.00 & 0.00 & 0.00 & 0.00 & 0.00 \\
\hline 5.03 Training & $824,121.00$ & & $793,121.00$ & $793,121.00$ & 0.00 & 0.00 & $31,000.00$ & & $31,000.00$ & 0.00 & 0.00 & 0.00 & 0.00 \\
\hline 5.98 Incentives for Human Resources not specified by kind & $438,000.00$ & & $438,000.00$ & $438,000.00$ & 0.00 & 0.00 & 0.00 & & 0.00 & 0.00 & 0.00 & 0.00 & 0.00 \\
\hline 5.99 Incentives for Human Resources not elsewhere classified & $105,000.00$ & & $105,000.00$ & $105,000.00$ & 0.00 & 0.00 & 0.00 & & 0.00 & 0.00 & 0.00 & 0.00 & 0.00 \\
\hline $\begin{array}{l}\text { 6. SOCIAL PROTECTION AND SOCIAL SERVICES EXCLUDING ORPHANS } \\
\text { AND VULNERABLE CHILDREN }\end{array}$ & $2,362,000.00$ & 1.96 & $2,000,000.00$ & $2,000,000.00$ & 0.00 & 0.00 & 0.00 & 0.00 & 0.00 & 0.00 & $362,000.00$ & 0.00 & $362,000.00$ \\
\hline 6.01 Social protection through monetary benefits & $350,000.00$ & & 0.00 & 0.00 & 0.00 & 0.00 & 0.00 & & 0.00 & 0.00 & $350,000.00$ & 0.00 & $350,000.00$ \\
\hline 6.02 Social protection through in-kind benefits & 0.00 & & 0.00 & 0.00 & 0.00 & 0.00 & 0.00 & & 0.00 & 0.00 & 0.00 & 0.00 & 0.00 \\
\hline 6.03 Social protection through provision of social services & $2,000,000.00$ & & $2,000,000.00$ & $2,000,000.00$ & 0.00 & 0.00 & 0.00 & & 0.00 & 0.00 & 0.00 & 0.00 & 0.00 \\
\hline 6.04 HIV-specific income generation projects & $2,000,0.00$ & & $2,000,0.00$ & 0.00 & 0.00 & 0.00 & 0.00 & & 0.00 & 0.00 & 0.00 & 0.00 & 0.00 \\
\hline 6.98 Social protection services and social services not disaggregated by type & 0.00 & & 0.00 & 0.00 & 0.00 & 0.00 & 0.00 & & 0.00 & 0.00 & 0.00 & 0.00 & 0.00 \\
\hline 6.99 Social protection services and social services not elsewhere classified & $12,000.00$ & & 0.00 & 0.00 & 0.00 & 0.00 & 0.00 & & 0.00 & 0.00 & $12,000.00$ & 0.00 & $12,000.00$ \\
\hline
\end{tabular}


AIDS SPENDING CATEGORIES

\section{ENABLING ENVIRONMENT}

\begin{tabular}{l}
7.01 Advocacy \\
\hline 7.02 ans \\
\hline
\end{tabular}

7.02 Human rights programmes

7.03 AIDS-specific institutional development

7.04 AlDS-specific programmes focused on women

7.05 Programmes to reduce Gender Based Violence

7.99 Enabling Environment and Community Development not elsewhere classified 8. RESEARCH

8.01 Biomedical researc

8.02 Clinical research

8.03 Epidemiological research

\begin{tabular}{l}
8.04 Social science research \\
\hline 8.05 Vaccine-related research \\
\hline
\end{tabular}

8.05 Vaccine-related research
8.98 Research not disaggregated by type

8.99 Research not elsewhere classified

\section{TOTAL}

4,596,317.36

$434,686.32$ $436,000.00$
$3,833,591.00$ $3,833,591.00$
0.00

0.00
$174,818.74$

$117,221.30$

0.00

$5,000.00$

0.00

0.00

$5,000.00$

\begin{tabular}{r|}
\hline 0.00 \\
0.00 \\
\hline
\end{tabular}

0.00
0.00

0.00

\begin{tabular}{|c|c|c|c|c|c|c|c|c|c|c|}
\hline \multicolumn{4}{|c|}{ Public Sources } & \multicolumn{4}{|c|}{ International Resources } & \multicolumn{3}{|c|}{ Private Sources } \\
\hline Public Sub-Total & $\begin{array}{l}\text { Central/ } \\
\text { National }\end{array}$ & $\begin{array}{c}\text { Sub- } \\
\text { National }\end{array}$ & $\begin{array}{l}\text { All Other } \\
\text { Public }\end{array}$ & $\begin{array}{l}\text { International } \\
\text { Sub-Total }\end{array}$ & Bilat. & & & $\begin{array}{l}\text { Private Sub- } \\
\text { Total }\end{array}$ & $\begin{array}{l}\text { Household } \\
\text { funds }\end{array}$ & $\begin{array}{l}\text { All Other } \\
\text { Private }\end{array}$ \\
\hline $4,097,585.00$ & $3,904,307.00$ & $193,278.00$ & 0.00 & $440,891.36$ & 0.00 & $440,891.36$ & 0.00 & $57,841.00$ & 0.00 & $57,841.00$ \\
\hline $227,994.00$ & $34,716.00$ & $193,278.00$ & 0.00 & $148,851.32$ & & $148,851.32$ & 0.00 & $57,841.00$ & 0.00 & $57,841.00$ \\
\hline $36,000.00$ & $36,000.00$ & 0.00 & 0.00 & 0.00 & & 0.00 & 0.00 & 0.00 & 0.00 & 0.00 \\
\hline $3,833,591.00$ & $3,833,591.00$ & 0.00 & 0.00 & 0.00 & & 0.00 & 0.00 & 0.00 & 0.00 & 0.00 \\
\hline 0.00 & 0.00 & 0.00 & 0.00 & 0.00 & & 0.00 & 0.00 & 0.00 & 0.00 & 0.00 \\
\hline 0.00 & 0.00 & 0.00 & 0.00 & $174,818.74$ & & $174,818.74$ & 0.00 & 0.00 & 0.00 & 0.00 \\
\hline 0.00 & 0.00 & 0.00 & 0.00 & $117,221.30$ & & $117,221.30$ & 0.00 & 0.00 & 0.00 & 0.00 \\
\hline 0.00 & 0.00 & 0.00 & 0.00 & 0.00 & & 0.00 & 0.00 & 0.00 & 0.00 & 0.00 \\
\hline $5,000.00$ & $5,000.00$ & 0.00 & 0.00 & 0.00 & 0.00 & 0.00 & 0.00 & 0.00 & 0.00 & 0.00 \\
\hline 0.00 & 0.00 & 0.00 & 0.00 & 0.00 & & 0.00 & 0.00 & 0.00 & 0.00 & 0.00 \\
\hline 0.00 & 0.00 & 0.00 & 0.00 & 0.00 & & 0.00 & 0.00 & 0.00 & 0.00 & 0.00 \\
\hline $5,000.00$ & $5,000.00$ & 0.00 & 0.00 & 0.00 & & 0.00 & 0.00 & 0.00 & 0.00 & 0.00 \\
\hline 0.00 & 0.00 & 0.00 & 0.00 & 0.00 & & 0.00 & 0.00 & 0.00 & 0.00 & 0.00 \\
\hline 0.00 & 0.00 & 0.00 & 0.00 & 0.00 & & 0.00 & 0.00 & 0.00 & 0.00 & 0.00 \\
\hline 0.00 & 0.00 & 0.00 & 0.00 & 0.00 & & 0.00 & 0.00 & 0.00 & 0.00 & 0.00 \\
\hline 0.00 & 0.00 & 0.00 & 0.00 & 0.00 & & 0.00 & 0.00 & 0.00 & 0.00 & 0.00 \\
\hline
\end{tabular}


ANNEX 4: DISTRIBUTION OF HIV/AIDS/DEATH BY YEAR, MALAYSIA 1986 - 2011

\begin{tabular}{|c|c|c|c|c|c|c|c|c|c|c|c|c|c|c|c|}
\hline \multirow{3}{*}{ Year } & \multicolumn{5}{|c|}{ No of HIV Cases } & \multicolumn{5}{|c|}{ No of AIDS Cases } & \multicolumn{5}{|c|}{ No. of Deaths } \\
\hline & \multicolumn{2}{|c|}{ MALE } & \multicolumn{2}{|c|}{ FEMALE } & \multirow{2}{*}{ TOTAL } & \multicolumn{2}{|c|}{ MALE } & \multicolumn{2}{|c|}{ FEMALE } & \multirow{2}{*}{ TOTAL } & \multicolumn{2}{|c|}{ MALE } & \multicolumn{2}{|c|}{ FEMALE } & \multirow{2}{*}{ TOTAL } \\
\hline & NO & $\%$ & NO & $\%$ & & NO & $\%$ & NO & $\%$ & & NO & $\%$ & NO & $\%$ & \\
\hline 1986 & 3 & 100 & 0 & 0 & 3 & 1 & 100 & 0 & 0 & 1 & 1 & 100 & 0 & 0 & 1 \\
\hline 1987 & 2 & 100 & 0 & 0 & 2 & 0 & 100 & 0 & 0 & 0 & 0 & 100 & 0 & 0 & 0 \\
\hline 1988 & 7 & 77.8 & 2 & 22.2 & 9 & 2 & 100 & 0 & 0 & 2 & 2 & 100 & 0 & 0 & 2 \\
\hline 1989 & 197 & 98.5 & 3 & 1.5 & 200 & 2 & 100 & 0 & 0 & 2 & 1 & 100 & 0 & 0 & 1 \\
\hline 1990 & 769 & 98.8 & 9 & 1.2 & 778 & 18 & 100 & 0 & 0 & 18 & 10 & 100 & 0 & 0 & 10 \\
\hline 1991 & 1741 & 97.0 & 53 & 3.0 & 1794 & 58 & 96.7 & 2 & 3.3 & 60 & 10 & 52.6 & 9 & 47.4 & 19 \\
\hline 1992 & 2443 & 97.3 & 69 & 2.7 & 2512 & 70 & 95.9 & 3 & 4.1 & 73 & 44 & 95.7 & 2 & 4.3 & 46 \\
\hline 1993 & 2441 & 97.4 & 66 & 2.6 & 2507 & 64 & 90.1 & 7 & 9.9 & 71 & 50 & 90.9 & 5 & 9.1 & 55 \\
\hline 1994 & 3289 & 96.9 & 104 & 3.1 & 3393 & 98 & 93.3 & 7 & 6.7 & 105 & 74 & 92.5 & 6 & 7.5 & 80 \\
\hline 1995 & 4037 & 96.2 & 161 & 3.8 & 4198 & 218 & 93.6 & 15 & 6.4 & 233 & 150 & 90.9 & 15 & 9.1 & 165 \\
\hline 1996 & 4406 & 95.8 & 191 & 4.2 & 4597 & 327 & 94.2 & 20 & 5.8 & 347 & 259 & 95.6 & 12 & 4.4 & 271 \\
\hline 1997 & 3727 & 95.0 & 197 & 5.0 & 3924 & 538 & 94.7 & 30 & 5.3 & 568 & 449 & 94.9 & 24 & 5.1 & 473 \\
\hline 1998 & 4327 & 93.6 & 297 & 6.4 & 4624 & 818 & 93.5 & 57 & 6.5 & 875 & 655 & 95.1 & 34 & 4.9 & 689 \\
\hline 1999 & 4312 & 91.9 & 380 & 8.1 & 4692 & 1114 & 92.8 & 86 & 7.2 & 1200 & 824 & 94.3 & 50 & 5.7 & 874 \\
\hline 2000 & 4626 & 90.6 & 481 & 9.4 & 5107 & 1071 & 91.7 & 97 & 8.3 & 1168 & 825 & 93.5 & 57 & 6.5 & 882 \\
\hline 2001 & 5472 & 92.2 & 466 & 7.8 & 5938 & 1188 & 91.2 & 114 & 8.8 & 1302 & 975 & 92.3 & 81 & 7.7 & 1056 \\
\hline 2002 & 6349 & 91.0 & 629 & 9.0 & 6978 & 1068 & 89.5 & 125 & 10.5 & 1193 & 976 & 92.8 & 76 & 7.2 & 1052 \\
\hline 2003 & 6083 & 90.0 & 673 & 10.0 & 6756 & 939 & 87.3 & 137 & 12.7 & 1076 & 786 & 90.4 & 83 & 9.6 & 869 \\
\hline 2004 & 5731 & 89.2 & 696 & 10.8 & 6427 & 1002 & 87.3 & 146 & 12.7 & 1148 & 954 & 89.3 & 114 & 10.7 & 1068 \\
\hline 2005 & 5383 & 88.0 & 737 & 12.0 & 6120 & 1044 & 85.5 & 177 & 14.5 & 1221 & 1087 & 89.6 & 144 & 10.4 & 1231 \\
\hline 2006 & 4955 & 85.0 & 875 & 15.0 & 5830 & 1620 & 87.9 & 222 & 12.1 & 1842 & 1167 & 91.8 & 154 & 8.2 & 1321 \\
\hline 2007 & 3804 & 83.6 & 745 & 16.4 & 4549 & 937 & 82.9 & 193 & 17.1 & 1130 & 1227 & 89.3 & 147 & 10.7 & 1374 \\
\hline 2008 & 2988 & 80.9 & 704 & 19.1 & 3692 & 795 & 84.5 & 146 & 15.5 & 941 & 929 & 88.5 & 121 & 11.5 & 1050 \\
\hline 2009 & 2527 & 82.0 & 553 & 18.0 & 3080 & 621 & 83.8 & 120 & 16.2 & 741 & 710 & 88.2 & 95 & 11.8 & 805 \\
\hline 2010 & 2984 & 81.7 & 668 & 18.3 & 3652 & 868 & 83.9 & 167 & 16.1 & 1035 & 782 & 86.5 & 122 & 13.5 & 904 \\
\hline 2011 & 2744 & 78.9 & 735 & 21.1 & 3479 & 1131 & 84.8 & 203 & 15.2 & 1334 & 596 & 86.6 & 92 & 13.4 & 688 \\
\hline TOTAL & 85347 & 90.0 & 9494 & 10.0 & 94841 & 15612 & 88.3 & 2074 & 11.7 & 17686 & 13543 & 90.4 & 1443 & 9.6 & 14986 \\
\hline
\end{tabular}

